\title{
INGRID KOWATSCH
}

Acurácia diagnóstica da ecocardiografia sob estresse associada ao estudo da perfusão miocárdica com contraste na avaliação da isquemia miocárdica: estudo comparativo entre adenosina e dobutamina.

Tese apresentada à Faculdade de Medicina da Universidade de São Paulo para obtenção do título de Doutor em Ciências

Área de Concentração: Cardiologia

Orientador: Prof. Dr. Wilson Mathias Júnior

SÃo PAULO 


\section{FICHA CATALOGRÁFICA}

Preparada pela Biblioteca da

Faculdade de Medicina da Universidade de São Paulo

Creprodução autorizada pelo autor

\section{Kowatsch, Ingrid}

Acurácia diagnóstica da ecocardiografia sob estresse associada ao estudo da perfusão miocárdica com contraste na avaliação da isquemia miocárdica : estudo comparativo entre adenosina e dobutamina / Ingrid Kowatsch. -- São Paulo, 2005.

Tese(doutorado)--Faculdade de Medicina da Universidade de São Paulo. Departamento de Cardio-Pneumologia.

Area de concentração: Cardiologia.

Orientador: Wilson Mathias Junior

Descritores: 1.CORONARIOPATIA/diagnóstico 2.ISQUEMIA MIOCÁRDICA/ diagnóstico 3.ECOCARDIOGRAFIA/métodos 4.ADENOSINA/uso diagnóstico 5.DOBUTAMINA/uso diagnóstico 6.SENSIBILIDADE E ESPECIFICIDADE

USP/FM/SBD-135/05 
Dedicatória 
Aos meus pais, Franz e Olinda, pelo amor incondicional, incentivo e exemplo de integridade.

Ao meu irmão Franz, pela grande amizade, compreensão e companheirismo. 


\section{Agradecimentos}


Ao Prof. Dr. Wilson Mathias Júnior (Diretor do Serviço de Ecocardiografia do Instituto do Coração - Hospital das Clínicas da Faculdade de Medicina da Universidade de São Paulo), pela confiança e incentivo e por compartilhar seus conhecimentos e entusiasmo, com muita dedicação, compreensão e amizade.

À Dra. Jeane Mike Tsutsui, pela ajuda na elaboração dessa tese e, principalmente, pela amizade e companheirismo constantes.

Ao Dr. Altamiro F.F.Osório e à Dra. Maria Luciana Z. Hannouche Trindade, pelo companheirismo e apoio durante todo o caminho da pós-graduação.

Às Dras. Juliana C. Frizera e Viviane Tiemi Hota, pela amizade e ajuda na coleta dos dados.

Às auxiliares de enfermagem, Claudete H.S. Rocha, Elaine Cristina Rodrigues, Ivaneide O.N. Farias e à enfermeira Cristina Akiko Shirahige, pela amizade em todos momentos e pelo empenho na realização dos exames ecocardiográficos.

Ao Prof. Dr. Luiz Antônio Machado César (Diretor da Unidade de Cardiopatia Coronária Crônica do Instituto do Coração - Hospital das Clínicas da Faculdade de Medicina da Universidade de São Paulo), pela seleção dos pacientes que participaram dessa tese.

Ao Prof. Dr. Eulógio Emílio Martinez Filho (Diretor da Unidade de Hemodinâmica do Instituto do Coração - Hospital das Clínicas da Faculdade de Medicina da Universidade de São Paulo), ao Dr. Gilberto A. Marchiori, ao Dr. Pedro Lemos e à Patrícia Gomes, pela análise e quantificação das lesões coronarianas.

Ao Prof. Dr. Paulo Jorge Moffa (Médico chefe do Setor de Eletrocardiologia do Instituto do Coração - Hospital das Clínicas da Faculdade de Medicina da Universidade de São Paulo) e ao Dr. Augusto Hiroshi Ushida, pela análise dos traçados eletrocardiográficos. 
À Neusa Rodrigues Dini, Juliana Lattari Sobrinho e Eva Malheiros G. de Oliveira, pelo suporte e compreensão durante toda a pós-graduação.

À Telma Cristina Bastos de Souza pelo grande incentivo nos momentos finais dessa tese.

Aos médicos assistentes, pós-graduandos e estagiários do Serviço de Ecocardiografia do Instituto do Coração - Hospital das Clínicas da Faculdade de Medicina da Universidade de São Paulo, pela amizade, incentivo e companheirismo diário.

A todos pacientes que participaram desse estudo, pelo grande sentimento altruísta e ao desenvolvimento da ciência.

Ao Funcor e à Fapesp, pelo apoio financeiro. 
Sumário 
página

Lista de abreviaturas .................................................... xii

Lista de símbolos ................................................................... xiii

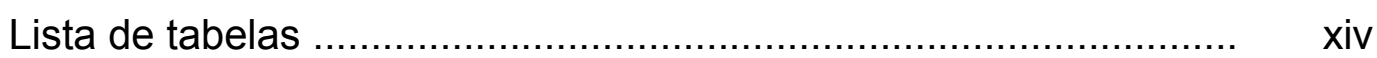

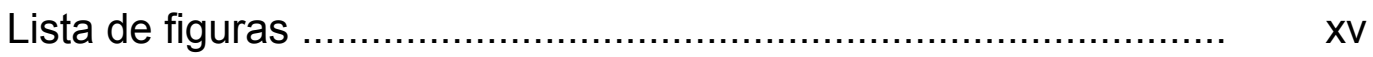

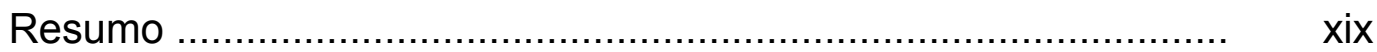

Summary ............................................................... xxii

INTRODUÇÃO ........................................................... 1

Métodos não-invasivos para a detecção e avaliação da doença arterial coronariana .......................................................... 3

Eletrocardiografia ............................................... 3

Ergometria ........................................................... 3

Cintilografia miocárdica ............................................ 4

Tomografia computadorizada ultra-rápida de múltiplos

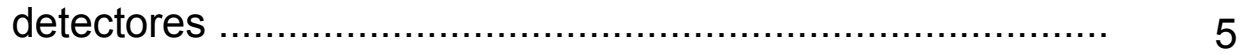

Ressonância magnética ............................................ 6

Ecocardiografia em repouso ...................................... 8

Ecocardiografia sob estresse pelo esforço físico ................ 8

Ecocardiografia sob estresse farmacológico ..................... 9

Ecocardiografia com contrastes miocárdicos ..................... 14

Acurácia da análise qualitativa da ecocardiografia com contraste miocárdico para a detecção de doença arterial coronariana.

Quantificação do fluxo miocárdico pela ecocardiografia com perfusão miocárdica em tempo real

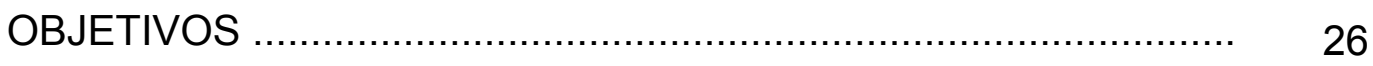

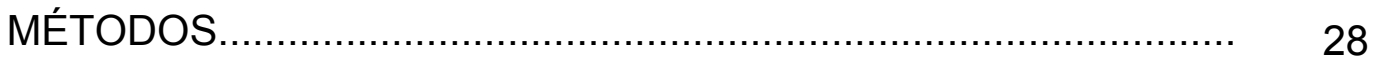

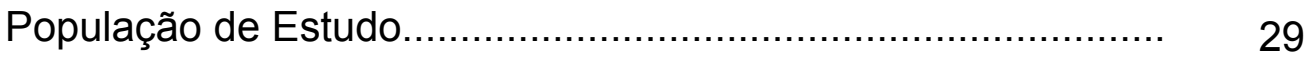

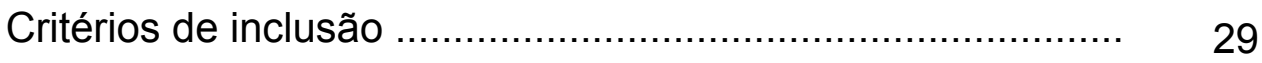

Critérios de exclusão ................................................ 30

Protocolo de estudo ......................................................... 31

Ecocardiografia com perfusão miocárdica em tempo real .... 31

Protocolo de estresse pela adenosina ............................. 33 
Protocolo de estresse pela dobutamina

Análise eletrocardiográfica durante a ecocardiografia sob estresse

Determinação qualitativa da motilidade e perfusão miocárdicas

Determinação quantitativa da perfusão miocárdica

Exeqüibilidade e acurácia diagnóstica da EPMTR

Variabilidade intra e interobservador

Angiografia coronariana

Análise estatística

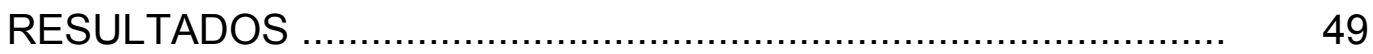

Angiografia Coronariana Quantitativa ................................ 51

Eletrocardiografia ....................................................... 52

EPMTR sob Estresse pela Dobutamina e pela Adenosina ....... 53

Dados hemodinâmicos ................................................. 54

Exeqüibilidade ...................................................... 56

Acurácia diagnóstica da análise qualitativa ...................... 57

Análise Quantitativa do Fluxo Sangüíneo Miocárdico ......... 58

Parâmetros diagnósticos para detecção de DAC ..................... 62

Comparação da acurácia diagnóstica entre as variáveis obtidas durante a EPMTR, sob estresse pela dobutamina e pela adenosina

Valor adicional da EPMTR para detecção de DAC

Acurácia diagnóstica da EPMTR para detecção de doença uniarterial e multiarterial

Exeqüibilidade da EPMTR

Avaliação quantitativa do eletrocardiograma e qualitativa da motilidade e da perfusão miocárdica

Avaliação quantitativa da perfusão miocárdica

Limitações deste estudo

Aplicações clínicas 
Listas

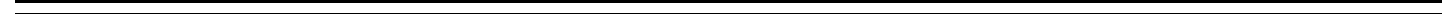




\section{Abreviaturas}

$\begin{array}{ll}\text { ACQ } & \text { angiografia coronariana quantitativa } \\ \text { ADA } & \text { artéria coronária descendente anterior } \\ \text { CD } & \text { artéria coronária direita } \\ \text { CX } & \text { artéria coronária circunflexa } \\ \text { DAC } & \text { doença arterial coronariana } \\ \text { ECG } & \text { eletrocardiograma em 12 derivações } \\ \text { EPMTR } & \text { ecocardiografia com perfusão miocárdica em tempo real } \\ \text { FC } & \text { freqüência cardiaca } \\ \text { NS } & \text { não significativo } \\ \text { PAD } & \text { pressão arterial diastólica } \\ \text { PAS } & \text { pressão arterial sistólica } \\ \text { PESDA } & \text { perfluorocarbon-exposed sonicated dextrose and } \\ \text { RPECT } & \text { receiver operator characteristic } \\ & \text { albumin } \\ \text { RMC } & \text { ressonância magnética cardiovascular } \\ \text { ROC } & \text { rensia miocárdica tomográfica por emissão de } \\ & \end{array}$




\section{Símbolos}

\begin{tabular}{|c|c|}
\hline$\%$ & porcentagem \\
\hline$\mu \mathrm{g} / \mathrm{kg} / \mathrm{min}$ & microgramas por quilograma por minuto \\
\hline$<$ & menor que \\
\hline$=$ & igual a \\
\hline$>$ & maior que \\
\hline \pm & mais ou menos \\
\hline A & volume de sangue miocárdico \\
\hline$A \times ß$ & fluxo sanguíneo miocárdico \\
\hline$ß$ & velocidade do fluxo sanguíneo miocárdico \\
\hline bpm & batimentos por minuto \\
\hline $\mathrm{Hz}$ & hertz \\
\hline $\mathrm{kHz}$ & quilohertz \\
\hline $\mathrm{mg}$ & miligrama \\
\hline $\mathrm{MHz}$ & megahertz \\
\hline $\mathrm{ml}$ & mililitro \\
\hline $\mathrm{ml} / \mathrm{kg}$ & mililitros por quilograma \\
\hline $\mathrm{mm}$ & milímetro \\
\hline $\mathrm{mmHg}$ & milímetros de mercúrio \\
\hline $\mathrm{ms}$ & milisegundo \\
\hline
\end{tabular}




\section{Tabelas}

página

Tabela 1 Características clínicas dos pacientes submetidos à ecocardiografia com perfusão miocárdica em tempo real, sob estresse pela dobutamina e pela adenosina

Tabela 2 Parâmetros diagnósticos da avaliação eletrocardiográfica durante a ecocardiografia com perfusão miocárdica em tempo real, sob estresse pela dobutamina e pela adenosina, para detecção global de lesão obstrutiva $>50 \%$

Tabela 3 Dados hemodinâmicos dos pacientes submetidos à ecocardiografia com perfusão miocárdica em tempo real, sob estresse pela dobutamina e pela adenosina

Tabela 4 Efeitos adversos observados durante a ecocardiografia com perfusão miocárdica em tempo real, sob estresse pela dobutamina e pela adenosina

Tabela 5 Parâmetros diagnósticos da motilidade miocárdica obtidos pela ecocardiografia com perfusão miocárdica em tempo real, sob estresse pela dobutamina e pela adenosina, para detecção global de lesão obstrutiva $>50 \%$

Tabela 6 Parâmetros diagnósticos da avaliação qualitativa da perfusão miocárdica na ecocardiografia com perfusão miocárdica em tempo real, sob estresse pela dobutamina e pela adenosina para detecção global de lesão obstrutiva $>50 \%$

Tabela 7 Parâmetros de medidas quantitativas obtidas pela ecocardiografia com perfusão miocárdica em tempo real, sob estresse pela dobutamina, nos territórios arteriais com e sem lesão angiograficamente significativa

Tabela 8 Parâmetros de medidas quantitativas obtidas pela ecocardiografia com perfusão miocárdica em tempo real, sob estresse pela adenosina, nos territórios arteriais com lesão $>50 \%$ e sem lesão significativa

Tabela 9 Parâmetros diagnósticos da ecocardiografia com perfusão miocárdica em tempo real, sob estresse pela dobutamina e pela adenosina, para detecção de pacientes com e sem lesão angiograficamente significativa 


\section{Figuras}

página

Figura 1 llustração do modelo de avaliação da perfusão miocárdica proposto por Wei e colaboradores. Com infusão contínua de contraste, ocorre saturação do miocárdio pelas microbolhas (quadro E). A aplicação de pulsos ultrasônicos de alta energia (flash) permite a destruição das microbolhas no miocárdio (quadro $A$ ) e o subseqüente repreenchimento (quadros $\mathrm{B}$ a $\mathrm{E}$ )

Figura 2 Demonstração do repreenchimento miocárdico pelas microbolhas nos batimentos posteriores a um flash e método de cálculo do fluxo miocárdico regional pela ecocardiografia com perfusão miocárdica em tempo real ....

Figura 3 Protocolo de estudo de ecocardiografia com perfusão miocárdica em tempo real (EPMTR), sob estresse pela adenosina. As imagens nos planos apical quatro câmaras (4C), três câmaras (3C) e duas câmaras (2C) eram adquiridas no estado basal e durante a infusão de adenosina, com monitorização da freqüência cardíaca, pressão arterial sistêmica, eletrocardiograma e oximetria de pulso

Figura 4 Protocolo de estudo de ecocardiografia com perfusão miocárdica em tempo real (EPMTR), sob estresse pela dobutamina. As imagens nos planos apicais quatro câmaras (4C), três câmaras (3C) e duas câmaras (2C) eram adquiridas no estado basal e no pico do estresse pela dobutamina quando se atingia no mínimo $85 \%$ da freqüência cardíaca máxima predita para a idade (FCMP) ou na presença de sinais ecocardiográficos de isquemia ....

Figura 5 Divisão do ventrículo esquerdo em 17 segmentos nos planos apical quatro, três e duas câmaras, segundo as recomendações do Joint Committee on American Heart Association. $\mathrm{ADA}=$ artéria coronária descendente anterior; $\mathrm{CD}=$ artéria coronária direita; $\mathrm{CX}=$ artéria coronária circunflexa

Figura 6 Imagem do plano apical de quatro câmaras, obtido pela ecocardiografia com perfusão miocárdica em tempo real, mostrando a colocação de regiões de interesse (RI) nos diferentes segmentos miocárdicos 
Figura 7 Reserva de velocidade de fluxo (ß) nos territórios arteriais com lesão $>50 \%$ e sem lesão significativa obtidos pela ecocardiografia com perfusão miocárdica em tempo real, sob estresse pela dobutamina

Figura 8 Reserva de velocidade de fluxo (ß) nos territórios arteriais com lesão $>50 \%$ e sem lesão significativa obtidos pela ecocardiografia com perfusão miocárdica em tempo real, sob estresse pela adenosina

Figura 9 Curva ROC realizada para a determinação do melhor valor de corte da reserva da velocidade de fluxo miocárdico $(\beta)$ e reserva do fluxo miocárdico $(A x \beta)$ para a presença de DAC, utilizando-se a ecocardiografia com perfusão miocárdica em tempo real, sob estresse pela dobutamina

Figura 10 Curva ROC realizada para determinação do melhor valor de corte da reserva da velocidade de fluxo miocárdico $(\beta)$ e reserva do fluxo miocárdico $(\operatorname{Ax} \beta)$ para a presença de DAC, utilizando-se a ecocardiografia com perfusão miocárdica em tempo real, sob estresse pela adenosina ..

Figura 11 Comparação dos parâmetros diagnósticos de sensibilidade, especificidade e acurácia da ecocardiografia com perfusão miocárdica em tempo real, sob estresse pela dobutamina e pela adenosina, para detecção de pacientes com lesão angiograficamente significativa

Figura 12 Parâmetros diagnósticos de sensibilidade, especificidade e acurácia para detecção de pacientes com lesão angiograficamente significativa, baseados nas análises do eletrocardiograma em 12 derivações (ECG), motilidade segmentar, perfusão qualitativa e perfusão quantitativa, obtidas pela ecocardiografia com perfusão miocárdica em tempo real, sob estresse pela dobutamina

Figura 13 Parâmetros diagnósticos de sensibilidade, especificidade e acurácia para deteç̧ão de doença arterial coronariana, baseados nas análises do eletrocardiograma em 12 derivações (ECG), motilidade segmentar, perfusão qualitativa e perfusão quantitativa, obtidas pela ecocardiografia com perfusão miocárdica em tempo real, sob estresse pela adenosina 
Figura 14 No painel superior, apresentam-se, como exemplos imagens em plano apical de quatro câmaras obtidas pela ecocardiografia com perfusão miocárdica em tempo real, mostrando perfusão miocárdica normal no estado basal (imagem à esquerda), nítido defeito de perfusão miocárdica na região apical durante o estresse pela adenosina (imagem do meio, setas) e discinesia apical com defeito de perfusão em toda a região apical e parede lateral do ventrículo esquerdo (imagem à direita, setas), com estudo pela dobutamina. $\mathrm{O}$ eletrocardiograma foi negativo para isquemia miocárdica durante o estresse pela adenosina e pela dobutamina (painel inferior)

Figura 15 Curvas de quantificação acústica obtidas a partir das imagens do paciente da Figura 14, na região basal do septo com perfusão miocárdica normal (azul) e na região apical com defeito de perfusão miocárdica (vermelho) no estado basal (painel superior), durante o estresse pela adenosina (painel inferior à esquerda) e durante o estresse pela dobutamina (painel inferior à direita) ..........

Figura 16 Angiografia coronariana do paciente das figuras 14 e 15, demonstrando lesão significativa (suboclusiva) na artéria coronária descendente anterior (setas)

Figura 17 Valor adicional dos diferentes parâmetros obtidos pela ecocardiografia com perfusão miocárdica em tempo real, sob estresse pela dobutamina. ECG = eletrocardiograma em 12 derivações

Figura 18 Valor adicional dos diferentes parâmetros obtidos pela ecocardiografia com perfusão miocárdica em tempo real, sob estresse pela adenosina. ECG = eletrocardiograma de 12 derivações

Figura 19 Sensibilidade do eletrocardiograma em 12 derivações (ECG), motilidade segmentar, perfusão qualitativa e perfusão quantitativa, obtidas pela ecocardiografia com perfusão miocárdica em tempo real sob, estresse pela dobutamina, para detecção de doença coronariana uniarterial

Figura 20 Sensibilidade do eletrocardiograma em 12 derivações (ECG), motilidade segmentar, perfusão qualitativa e perfusão quantitativa, obtidas pela ecocardiografia com perfusão miocárdica em tempo real, sob estresse pela adenosina, para detecção de doença coronariana uniarterial 
Figura 21 Sensibilidade do eletrocardiograma em 12 derivações (ECG), motilidade segmentar, perfusão qualitativa e perfusão quantitativa, obtidas pela ecocardiografia com perfusão miocárdica em tempo real sob, estresse pela dobutamina, para detecção de doença coronariana multiarterial .

Figura 22 Sensibilidade do eletrocardiograma em 12 derivações (ECG), motilidade segmentar, perfusão qualitativa e perfusão quantitativa, obtidas pela ecocardiografia com perfusão miocárdica em tempo real, sob estresse pela adenosina, para detecção de doença coronariana multiarterial . 
Resumo 
Kowatsch I. Acurácia diagnóstica da ecocardiografia sob estresse associada ao estudo da perfusão miocárdica com contraste na avaliação da isquemia miocárdica. Estudo comparativo entre adenosina e dobutamina [Tese]. São Paulo: Faculdade de Medicina, Universidade de São Paulo; 2005. 103p.

A ecocardiografia com perfusão miocárdica em tempo real (EPMTR) permite a quantificação do fluxo sangüíneo miocárdico e, quando realizada durante o estresse, da reserva de fluxo miocárdico (reserva Axß). Essa técnica tem potencial para ser uma importante ferramenta para o diagnóstico nãoinvasivo da doença arterial coronariana (DAC). Apesar do conhecimento atual das alterações fisiológicas que ocorrem com 0 uso de agentes vasodilatadores ou catecolaminas na circulação coronariana, não há dados na literatura comparando diretamente o valor da EPMTR, sob estresse pela dobutamina e pela adenosina, para a deteç̧ão de DAC em humanos. Os objetivos deste estudo foram: avaliar, em um mesmo grupo de pacientes, a exeqüibilidade e a acurácia da EPMTR, sob estresse pela dobutamina e pela adenosina, para a detecção de estenose arterial coronariana angiograficamente significativa e determinar o valor adicional da análise quantitativa da perfusão miocárdica sobre o eletrocardiograma de 12 derivações, da motilidade segmentar e da análise qualitativa da perfusão miocárdica obtidas durante o estresse pela dobutamina e pela adenosina. Estudamos 54 pacientes (média etária de $60 \pm 9$ anos, 33 homens) com suspeita clínica de DAC e indicação de angiografia coronariana. Todos os pacientes foram submetidos à EPMTR sob estresse pela adenosina na dose de $140 \mu \mathrm{g} / \mathrm{kg} / \mathrm{min}$ por seis minutos e, após um intervalo de três a cinco horas, à EPMTR sob estresse pela dobutamina-atropina. O contraste ecocardiográfico utilizado foi o PESDA (Perfluorocarbon-Exposed Sonicated Dextrose and Albumin), administrado por via intravenosa periférica de forma contínua. Para ambas as EPMTR sob estresse pela dobutamina e pela adenosina, foram feitas análises do eletrocardiograma em 12 derivações (ECG), da motilidade segmentar e análise qualitativa e quantitativa da perfusão miocárdica. A quantificação da velocidade do fluxo miocárdico (ß) e do fluxo sangüíneo miocárdico $(A \times ß)$ foi realizada por meio da utilização do programa computacional QLab 3.0 (Philips Medical Systems, Bothell, WA, USA). Todos os pacientes foram submetidos à angiografia coronariana quantitativa (ACQ) em um intervalo de até 30 dias da EPMTR. Foi considerada DAC a presença de lesão coronariana $>50 \%$ do diâmetro luminal. Dos 54 pacientes estudados, $25(46 \%)$ apresentaram lesão coronariana $>50 \%$ e 29 (54\%) não apresentaram lesão coronariana significativa. A exeqüibilidade da quantificação da reserva $A \times ß$ foi semelhante para a EPMTR sob estresse pela adenosina e pela dobutamina (91\% versus $90 \%$ dos territórios arteriais; $p=n s)$. A variabilidade da quantificação interobservador para os parâmetros de reserva $B$ e $A x ß$ foi de $6,8 \%(r=0,98)$ e $5,5 \%(r=0,97)$, respectivamente. A variabilidade intraobservador para os mesmos parâmetros foi de $2,1 \%(r=0,99)$ e $7,4 \%(r=$ 0,95 ), respectivamente. A análise quantitativa da perfusão miocárdica, obtida 
pela EPMTR sob estresse pela dobutamina, apresentou sensibilidade de $84 \%$, especificidade de $76 \%$ e acurácia de $80 \%$ para a detecção de DAC, enquanto que a EPMTR sob estresse pela adenosina apresentou sensibilidade de $88 \%$, especificidade de $72 \%$ e acurácia de $80 \%$. O valor incremental das modalidades estudadas para o diagnóstico de DAC foi analisado em modelo que incluiu o ECG, ECG e motilidade segmentar, ECG e motilidade segmentar e perfusão qualitativa e, por último, ECG e motilidade segmentar e perfusão qualitativa e quantitava, tanto para a EPMTR sob estresse pela dobutamina como pela adenosina ( $\chi^{2}$ de 4,9 versus 20,1 versus 23,7 versus 38,4 ) e ( $\chi^{2}$ de 9,9 versus 20,1 versus 26,7 versus 59,4 ), respectivamente. Concluímos que a avaliação quantitativa da EPMTR apresenta boa exequibilidade. A EPMTR sob estresse pela dobutamina e a pela adenosina apresentam acurácias diagnósticas similares para a detecção de lesão angiograficamente significativa. A análise quantitativa da perfusão miocárdica apresenta valor diagnóstico adicional aos outros parâmetros obtidos durante o estresse pela dobutamina e adenosina.

Palavras-chave: coronariopatia; isquemia miocárdica; ecocardiografia; adenosina; dobutamina; sensibilidade e especificidade 
Kowatsch I. Diagnostic accuracy of quantitative real time myocardial contrast echocardiography for the detection of myocardial ischemia. A comparative study between adenosine and dobutamine [thesis]. São Paulo: "Faculdade de Medicina, Universidade de São Paulo"; 2005. 103p.

Real time myocardial contrast echocardiography (RTMCE) has allowed for the quantification of myocardial blood flow reserve (MBFR). This technique is a valuable tool for the noninvasive detection of coronary artery disease (CAD). Both adenosine and dobutamine are currently used stressor agents during RTMCE. Although it has already been shown the effects of these drugs on the coronary physiology, no study has directly compared both agents during RTMCE. The aims of this study were to determine the feasibility and diagnostic accuracy of adenosine versus dobutamine stress RTMCE for the detection of angiographically significant CAD. In addition, we sought to determine the additional value of quantitative RTMCE over the electrocardiogram, wall motion, and qualitative analysis of myocardial

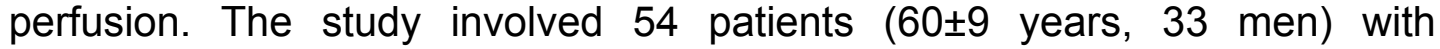
suspected CAD. Patients underwent RTMCE at rest and during continuous infusion of $140 \mu \mathrm{g} / \mathrm{kg} / \mathrm{min}$ of adenosine for six minutes, and dobutamine stress. The contrast agent used in the study was PESDA (PerfluorocarbonExposed Sonicated Dextrose and Albumin) administered in continuous intravenous infusion. Quantification of plateau of acoustic intensity $(A)$ and microbubble velocity $(\beta)$ was performed off line using a specific software (QLab 3.0, Philips Medical Systems, Bothell, WA, USA). Myocardial blood flow was determined as $\operatorname{Ax} \beta$. Quantitative coronary angiography was performed in all patients within 30 days of RTMCE, and CAD was defined as $>50 \%$ luminal diameter coronary stenosis. There were $25(46 \%)$ patients with CAD and $29(54 \%)$ patients without obstructive lesion. The feasibility of quantitative MBFR was the same for adenosine and dobutamine stress RTMCE (91\% versus $90 \%$ in all arterial territories; $p=n s)$. The intraobserver variabilities for the measurements of $\beta$ and $A x ß$ reserve were $2.1 \%(r=0.99)$ and $7.4 \%(r=0.95)$, respectively. The interobserver variabilities for the same parameters were $6.8 \%(r=0.98)$ and $5.5 \%(r=0.97)$, respectively. The sensitivity, specificity and diagnostic accuracy of $\beta$ reserve obtained during dobutamine stress RTMCE for detecting CAD were $84 \%, 76 \%$, and $80 \%$, respectively, and during adenosine stress RTMCE they were $88 \%, 72 \%$ and $80 \%$. The incremental value for the diagnosis of CAD was analyzed in a model that included the EKG, EKG and wall motion, EKG and wall motion and qualitative perfusion analysis and finally, EKG and wall motion and qualitative and quantitative perfusion analysis, for dobutamine and adenosine RTMCE $\left(\chi^{2}=4,9\right.$ versus 20,1 versus 23,7 versus s 38,4$)$ and $\left(\chi^{2}=9,9\right.$ versus $20,1$ versus 26,7 versus 59,4$)$, respectively. In conclusion, quantitative RTMCE is a feasible technique in patients with suspected CAD. Dobutamine and adenosine stress RTMCE had similar diagnostic accuracy for the detection of angiographically significant lesion. Quantitative analysis of 
myocardial perfusion had incremental diagnostic value over the other parameters obtained during both dobutamine and adenosine stress RTMCE.

Key-words: coronary artery disease; myocardial ischemia; echocardiography; adenosine; dobutamine; sensitivity and specificity 


\section{Introdução}


No Brasil, a doença arterial coronariana (DAC) apresenta incidência crescente e foi responsável por 165.626 óbitos em 2000 e 170.948 óbitos em 2002, correspondendo a $18 \%$ do total de óbitos ${ }^{1}$. Foi responsável, ainda, por aproximadamente 11,6 milhões de internações hospitalares no ano de 2003, com um gasto total de $R \$ 385$ milhões para o Sistema Único de Saúde ${ }^{1}$. Nos Estados Unidos da América do Norte, é responsável por um em cada cinco óbitos, sendo que um número expressivo deles está relacionado com indivíduos jovens e cerca de $60 \%$ deles ocorrem de forma súbita, na primeira hora após o início dos sintomas ${ }^{2}$.

Além da alta mortalidade, essa patologia resulta em alto índice de morbidade por insuficiência cardíaca, ocasionando um número significativo de internações hospitalares e longas filas de transplante cardíaco.

A solução para essa problemática certamente implica em medidas drásticas de prevenção envolvendo mudanças culturais e ação de saúde pública. No entanto, enquanto as medidas de longo prazo não se tornam efetivas, o diagnóstico precoce ainda é a melhor estratégia para se prevenir várias das complicações dessa patologia. 
Métodos não-invasivos para a detecção e avaliação da doença arterial coronariana

\section{Eletrocardiografia}

A detecção de DAC pela eletrocardiografia baseia-se na presença de ondas Q e alterações no segmento ST e da onda T. Em 1918, Bousfield descreveu, pela primeira vez, a presença de alterações do segmento ST do eletrocardiograma em pacientes com crise de angina ${ }^{3}$. No entanto, aproximadamente $50 \%$ dos pacientes com angina estável têm eletrocardiograma normal, o qual pode estar alterado em pacientes com hipertrofia ventricular esquerda, disfunção ventricular e uso de digitálicos. Portanto, a eletrocardiografia apresenta baixa sensibilidade e especificidade para o diagnóstico de DAC crônica.

\section{Ergometria}

Muitos trabalhos consolidaram o valor diagnóstico da ergometria para detecção não-invasiva de DAC na prática clínica, especialmente após o desenvolvimento de sistemas computadorizados ${ }^{4,5,6}$.

Stuart e colaboradores, em 1980, realizaram um estudo multicêntrico sobre a segurança desse método na prática clínica. O estudo envolveu 1.375 centros, com um total de 518.448 testes em pacientes que foram 
submetidos à ergometria para pesquisa de DAC, observando uma mortalidade e morbidade menor que $0,01 \%$ e $0,05 \%$, respectivamente ${ }^{7}$.

Gibbons e colaboradores, em uma metanálise que envolveu 24.000 pacientes, verificaram uma sensibilidade de 45 a $50 \%$ e especificidade de 85 a $90 \%$ para o diagnóstico de DAC pela ergometria ${ }^{8}$. A despeito do avanço tecnológico nessa área e apesar de ser considerada uma técnica fisiológica e segura, a ergometria não é precisa em várias situações, como, por exemplo, na presença de bloqueios de ramo e em pacientes com alterações prévias do segmento ST ao eletrocardiograma. Por outro lado, dependendo da população estudada, aproximadamente $21 \%$ dos pacientes podem não ser capazes de se exercitar; outros $21 \%$ o fazem de forma ineficaz, e $24 \%$ têm traçados que não são interpretáveis de modo adequado por apresentarem alterações eletrocardiográficas em repouso ou durante o exercício, impossibilitando sua análise ${ }^{9}$. As limitações mencionadas apontam para a necessidade da associação de métodos por imagem ao eletrocardiograma para a avaliação mais precisa dos sinais de isquemia miocárdica em uma população significativa de pacientes.

\section{Cintilografia miocárdica}

Abreu e colaboradores avaliaram a segurança da cintilografia pela adenosina em 600 pacientes, observando bloqueio atrioventricular transitório 
de primeiro e segundo graus em $9,6 \%$ dos pacientes e nenhuma ocorrência de infarto agudo do miocárdio ou óbito ${ }^{10}$.

Em uma metanálise com 651 pacientes em dez instituições, a cintilografia miocárdica pelo dipiridamol apresentou uma sensibilidade de $88 \%$, especificidade de $67 \%$ e acurácia diagnóstica de $81 \%$ em pacientes com suspeita clínica de DAC ${ }^{11}$. Geleijnse e colaboradores, em 1997, avaliaram a cintilografia miocárdica pela dobutamina em 318 pacientes, constatando uma sensibilidade, especificidade e acurácia diagnóstica de $81 \%, 71 \%$ e $78 \%$, respectivamente ${ }^{12}$.

Atualmente a cintilografia de perfusão miocárdica possui alta acurácia diagnóstica para a detecção de isquemia miocárdica. No entanto, o método apresenta limitações em pacientes com hipertrofia ventricular esquerda 9,13 com bloqueio do ramo esquerdo ${ }^{14}$. Além disso, o alto custo torna seu uso limitado a um pequeno grupo de pacientes ${ }^{10}$.

\section{Tomografia computadorizada ultra-rápida de múltiplos detectores}

A tomografia computadorizada ultra-rápida é uma técnica com alta resolução espacial $(0,5 \mathrm{~mm})$, com menor tempo de obtenção dos cortes tomográficos, com resolução temporal de aproximadamente 200 ms e possui sincronização eletrocardiográfica levando a uma diminuição de artefatos nas imagens capturadas e, dessa forma, permite a análise da anatomia coronariana. Becker e colaboradores estudaram 187 segmentos 
coronarianos e demonstraram uma sensibilidade de $81 \%$, especificidade de $90 \%$, valor preditivo negativo de $90 \%$ e uma concordância moderada com a angiografia coronariana para o diagnóstico de DAC $(\text { kappa }=0,58)^{15}$. Kopp e colaboradores obtiveram, em 112 pacientes, uma sensibilidade, especificidade e valor preditivo negativo de $86 \%, 96 \%$ e $98 \%$ para o diagnóstico de DAC, respectivamente ${ }^{16}$.

Essa técnica apresenta um futuro promissor; porém, atualmente, necessita de estudos clínicos mais amplos e de prognóstico que permitam definir sua indicação clínica. Apresenta limitações, como artefatos nas imagens, devido à mobilidade cardíaca e respiratória, calcificação coronária e presença de arritmias que diminuem a qualidade da imagem.

\section{Ressonância magnética}

A ressonância magnética cardiovascular (RMC) possui capacidade de avaliar as estruturas cardíacas de forma tridimensional e permite a avaliação da motilidade miocárdica em repouso e sob estresse farmacológico. Adicionalmente, é possível, com este método, avaliar a perfusão miocárdica por meio da utilização de contraste paramagnético (Gadolínio). Lee e colaboradores, estudando um modelo animal, compararam o fluxo sangüíneo miocárdico obtido pela RMC com o fluxo quantificado pelo uso de microesferas e com o SPECT, demonstrando que a RMC pode identificar a redução do fluxo miocárdico na presença de lesão coronariana e apresenta 
uma sensibilidade maior que a do SPECT ${ }^{17}$. Em estudo multicêntrico europeu, Giang e colaboradores estudaram a perfusão miocárdica pela adenosina em 90 pacientes e verificaram uma sensibilidade de $93 \%$ e especificidade de $75 \%$ para o diagnóstico de DAC ${ }^{18}$. Paetsch e colaboradores também avaliaram os índices de acurácia da RMC para DAC em 79 pacientes, analisando a motilidade miocárdica sob estresse pela dobutamina e a motilidade e perfusão miocárdicas pela adenosina, e constataram uma sensibilidade de $89 \%, 40 \%, 91 \%$ e especificidade de $80 \%$, $96 \%, 62 \%$, respectivamente ${ }^{19}$.

A ressonância magnética permite igualmente, por meio da angiografia, a avaliação anatômica dos segmentos proximal e médio das artérias coronárias, apresentando uma sensibilidade para diagnóstico de estenose coronariana significativa de $92 \%$ para a artéria descendente anterior, de $79 \%$ para a coronária direita e de $13 \%$ para a circunflexa ${ }^{20}$.

As principais limitações da técnica em questão se referem à presença de artefatos nas imagens capturadas devido à motilidade cardíaca e ao movimento respiratório do paciente, como também à dificuldade de reconstrução de artérias pequenas e tortuosas. Porém, no momento, estão sendo desenvolvidas novas técnicas com a finalidade de minimizar essas limitações. 


\section{Ecocardiografia em repouso}

A alteração da motilidade do ventrículo esquerdo, expressa pela diminuição ou ausência do espessamento sistólico do miocárdio, é um fenômeno precoce no processo isquêmico, precedida apenas por alterações da perfusão miocárdica, do metabolismo cardíaco e da função diastólica do ventrículo esquerdo. Na presença de estenose coronariana significativa, ocorre vasodilatação distal compensatória, mantendo-se o fluxo coronariano normal em repouso até que se atinjam níveis críticos de estenose. Portanto, para que ocorram alterações isquêmicas com gravidade e extensão suficientes para serem detectadas pela ecocardiografia bidimensional em repouso, é preciso que haja uma redução do fluxo coronariano de no mínimo $50 \%$ em relação ao fluxo basal normal e o envolvimento de pelo menos $20 \%$ da espessura parietal e cerca de $5 \%$ do total da massa cardíaca ${ }^{21}$.

Assim, para o diagnóstico de DAC pela ecocardiografia, é preciso que a indução de isquemia seja provocada por meio de esforço físico ou do uso de estressores farmacológicos.

\section{Ecocardiografia sob estresse pelo esforço físico}

O diagnóstico de isquemia pela ecocardiografia sob estresse baseiase tanto na detecção de alterações transitórias da motilidade segmentar do ventrículo esquerdo, expressas pela diminuição ou ausência do 
espessamento sistólico do miocárdio durante o estresse, como na piora das alterações de motilidade segmentar previamente existentes.

A ecocardiografia sob estresse pelo esforço físico induz isquemia miocárdica pelo aumento de consumo de oxigênio pelo miocárdio e permite a análise de variáveis importantes, obtidas exclusivamente por esforço físico, como duração do exercício, carga máxima alcançada, freqüência cardíaca máxima e duplo produto máximo. Apresenta acurácia diagnóstica superior à ergometria, com uma sensibilidade de $87 \%$ e especificidade de $82 \%$ versus uma sensibilidade de $63 \%$ e especificidade de $74 \%$ pela ergometria no diagnóstico de DAC ${ }^{22}$. Ao comparar esse método com a cintilografia miocárdica tomográfica por emissão de fótons (SPECT) com tálio 201, Quinones e colaboradores observaram acurácia diagnóstica similar entre os dois testes ${ }^{23}$.

\section{Ecocardiografia sob estresse farmacológico}

A ecocardiografia sob estresse farmacológico combina a indução de estresse pelo uso de fármacos com a ecocardiografia bidimensional, podendo usar como agentes estressores estimulantes adrenérgicos (dobutamina) ou vasodilatadores (dipiridamol e adenosina). A dobutamina é uma catecolamina com meia-vida de dois a três minutos; apresenta boa tolerância e, devido ao seu efeito inotrópico e cronotrópico positivo, causa aumento do consumo de oxigênio pelo miocárdio, sendo, atualmente, o agente farmacológico mais utilizado durante a ecocardiografia sob estresse. 
Já, os fármacos vasodilatadores, aumentam o fluxo sangüíneo coronariano e podem levar a uma perfusão miocárdica heterogênea devido ao fenômeno de roubo de fluxo coronariano que, em alguns pacientes, é suficiente para causar isquemia miocárdica. A adenosina leva à vasodilatação coronária por meio de estímulo aos receptores $A_{2}$, contribuindo, assim, para o controle do fluxo miocárdico. Em pacientes sem obstrução coronária significativa, ela aumenta de três a cinco vezes o valor basal do fluxo sangüíneo miocárdico por meio de vasodilatação coronária. Por outro lado, em pacientes com obstrução coronariana significativa já existe vasodilatação compensatória no leito arterial distal à obstrução, mantendo-se a pressão capilar constante. Assim, a infusão de adenosina leva a uma vasodilatação significativa apenas no leito arterial suprido por coronária sem obstruções estenóticas, criando-se uma heterogeneidade do fluxo sangüíneo com hipoperfusão relativa em territórios supridos pela artéria com estenose em comparação com as regiões com o leito arterial normal ${ }^{24}$.

Vários estudos avaliaram a segurança e a acurácia da ecocardiografia pela dobutamina. No estudo EDIC (Echo Dobutamine Internacional Cooperative Study), foram realizados 2.949 testes em 2.799 pacientes para se determinar a segurança do método, tendo-se observado: ocorrência de taquicardia ventricular sustentada em $0,1 \%$ dos testes, fibrilação ventricular em $0,07 \%$, infarto agudo do miocárdio em $0,07 \%$ e nenhum óbito ${ }^{25}$. Dagianti e colaboradores estudaram 100 pacientes e compararam a acurácia diagnóstica da ecocardiografia sob estresse pelo esforço físico com a ecocardiografia sob estresse pela dobutamina e pelo dipiridamol. Os autores 
descreveram uma sensibilidade de $76 \%, 72 \%$, e $52 \%$ e uma especificidade de $94 \%, 97 \%$, e $97 \%$, respectivamente, com uma acurácia diagnóstica da ecocardiografia sob esforço físico igual à da dobutamina (87\%) e superior à do dipiridamol $(78 \%)^{26}$.

Em uma metanálise incluindo 28 estudos e um total de 2.246 pacientes submetidos à angiografia coronariana e à ecocardiografia sob estresse pela dobutamina, demonstraram-se uma sensibilidade, especificidade e acurácia para o diagnóstico de DAC de $80 \%, 84 \%$ e $81 \%$, respectivamente ${ }^{12}$.

Novos protocolos de ecocardiografia sob estresse pela dobutamina têm sido propostos na tentativa de aumentar a acurácia diagnóstica e de diminuir a porcentagem de testes ineficazes. Recentemente, nosso grupo demonstrou, numa avaliação envolvendo 100 pacientes, que a injeção intravenosa rápida de metoprolol, no pico do estresse pela dobutamina, foi capaz de aumentar a acurácia diagnóstica do teste para a detecção de DAC. A sensibilidade, especificidade e acurácia para o diagnóstico de DAC das imagens de pico de estresse foram de $86 \%, 92 \%$ e $88 \%$, respectivamente, enquanto que, para as imagens capturadas após injeção de metoprolol, foram de $92 \%, 89 \%$, e $91 \%$. A melhor detecção de isquemia subendocárdica, que ocorre quando se diminui a freqüência cardíaca, e a redução abrupta do fluxo coronariano, mediada por um estímulo desbalanceado dos receptores alfa, durante breve período de alta demanda de oxigênio pelo miocárdio, foram possíveis explicações para esses $\operatorname{achados}^{27}$. 
Em outra importante contribuição, nosso grupo avaliou, também recentemente, a eficácia, segurança e acurácia diagnóstica da infusão precoce de atropina durante a ecocardiografia sob estresse pela dobutamina-atropina. Foram comparados dois grupos de estudo: um com 3.163 exames de ecocardiografia com dobutamina-atropina, injetando-se de forma convencional a atropina ao final do protocolo; e outro com 1.664 exames, em que a atropina foi injetada na dose de $20 \mu \mathrm{g} / \mathrm{kg} / \mathrm{min}$ de dobutamina, caso a freqüência cardíaca não atingisse 100 bpm. Demonstramos que a injeção precoce de atropina resultou em menor duração do tempo de teste, maior porcentagem de exames eficazes e diminuição dos efeitos colaterais, mantendo-se acurácia diagnóstica similar à do protocolo convencional de ecocardiografia sob estresse pela dobutamina $(86 \% \text { versus } 82 \%, p=n s)^{28}$.

Ao estudar vasodilatadores, avaliando-se 422 pacientes submetidos à ecocardiografia sob estresse pelo dipiridamol, constataram-se sensibilidade de $65 \%$, especificidade de $89 \%$ e acurácia diagnóstica de $72 \%$ para a detecção de DAC ${ }^{12}$. Zoghbi e colaboradores estudaram 73 pacientes submetidos à ecocardiografia pela adenosina e a angiografia coronariana; e demonstraram sensibilidade de $85 \%$ e especificidade de $92 \%{ }^{29}$. Ao comparar a ecocardiografia sob estresse pela dobutamina com a ecocardiografia sob estresse pela adenosina sem o uso de contraste ecocardiográfico, Martin e colaboradores verificaram maior especificidade (93\% versus $76 \%$ ) e menor sensibilidade (59\% versus $76 \%$ ) da adenosina em relação à dobutamina ${ }^{30}$. 
Vale ressaltar que a acurácia dos vários testes provocativos para a detecção de DAC é influenciada por fatores relativos à população de pacientes, aos critérios angiográficos, aos métodos indutores de estresse e aos critérios de interpretação dos exames. Adicionalmente, a sensibilidade da ecocardiografia sob estresse pela dobutamina é maior em pacientes com DAC multiarterial e com estenoses acima de $70 \%$ de obstrução luminal. Por outro lado, resultados falsos negativos podem ocorrer principalmente em casos de doença uniarterial, estenoses coronarianas de grau intermediário (50 a $69 \%$ de obstrução luminal), presença de bloqueio de ramo esquerdo, pacientes com geometria ventricular caracterizada como remodelamento concêntrico e pacientes com janela acústica inadequada.

Portanto, os métodos que utilizam inotrópicos e vasodilatadores apresentam acurácia semelhante; porém, em geral, pode-se dizer que a ecocardiografia pela dobutamina é um método mais sensível e que a ecocardiografia pela adenosina ou dipiridamol é mais específico para o diagnóstico de obstruções coronarianas. Mesmo que ambos os métodos apresentem acurácia semelhante, o dilema para se optar por um exame de maior sensibilidade ou maior especificidade traz significativo desconforto para o clínico no cuidado para com os pacientes. Além disso, essa acurácia diagnóstica ainda não é ótima. Apesar de alguns estudos terem demonstrado semelhante acurácia diagnóstica para os métodos que utilizam a ecocardiografia e a cintilografia, os mesmos também têm demonstrado, de forma consistente, que a ecocardiografia sob estresse pode subestimar a extensão da doença coronária e apresenta menor sensibilidade para 
pacientes com doença uniarterial ${ }^{31,32}$. Para a demonstração do significado funcional da estenose na hemodinâmica coronariana, torna-se essencial a avaliação da reserva de fluxo coronariano. Assim, as regiões supridas por vasos com estenoses significativas demonstram uma reserva de fluxo coronariano reduzida, o que parece resultar em defeitos de perfusão reversíveis durante o estresse devido ao efeito de roubo de fluxo.

Desse modo, é alentador o aparecimento de novas técnicas, como o uso de contrastes ecocardiográficos durante a infusão de dobutamina ou adenosina, na tentativa de se diminuir o número de exames falsos positivos e negativos por aumentarem a visibilidade da borda endocárdica, como também permitindo a análise da perfusão miocárdica, possivelmente melhorando, assim, a acurácia diagnóstica desses testes ${ }^{33,34}$.

\section{Ecocardiografia com contrastes miocárdicos}

A ecocardiografia com contraste baseia-se na injeção intravascular de agentes de contrastes para aumentar a reflexão dos sinais ultra-sônicos. Os agentes atualmente utilizados como contrastes ecocardiográficos são constituídos por microbolhas encapsuladas contendo perfluorocarbonos, medindo cerca de um a quatro mícrons de diâmetro. As microbolhas aumentam o sinal acústico refletido no meio que as contém por apresentarem a característica de expandir-se e retrair-se de forma não 
uniforme na presença do ultra-som, gerando sinais que contêm freqüências múltiplas da freqüência original (harmônicas).

Os agentes de contraste de segunda geração utilizados atualmente possuem estabilidade suficiente para, quando injetados por via intravenosa, atravessar a barreira pulmonar e contrastar as cavidades cardíacas esquerdas e a circulação coronariana, permitindo um excelente delineamento de bordas endocárdicas, mapeando toda a microcirculação miocárdica.

Vários estudos demonstraram que as microbolhas melhoram a definição de bordas endocárdicas, aumentando a visibilidade de alterações da motilidade segmentar do ventrículo esquerdo e diminuindo a variabilidade interobservador durante a ecocardiografia sob estresse ${ }^{33,35,36,37}$. Mathias e colaboradores, em 1999, estudaram 68 pacientes que foram submetidos à ecocardiografia sob estresse pela dobutamina-atropina associada ao uso de contraste ecocardiográfico. Do total, 23 (34\%) pacientes apresentavam janela acústica inadequada (menos de 12 segmentos miocárdicos visibilizados) sem o uso de contraste. Após o uso de contraste, nenhum paciente apresentou janela acústica inadequada, portanto ${ }^{35}$.

O uso de contraste ecocardiográfico está recomendado pela Sociedade Americana de Ecocardiografia durante a ecocardiografia sob estresse quando pelo menos dois dos sete segmentos em um plano apical não é adequadamente visibilizado nas imagens de repouso ${ }^{38,39}$. 
Entretanto, uma das principais aplicações atuais dos agentes de contraste ocorre na avaliação da perfusão miocárdica.

A utilização das microbolhas para estudo da perfusão miocárdica foi inicialmente prejudicada porque a alta energia ultra-sônica (índice mecânico $>1,0)$ requerida para a geração de imagens contrastadas causava destruição dessas microbolhas, tornando necessário o uso de imagem intermitente (Imagem Harmônica Intermitente). A imagem harmônica intermitente permitia a visibilidade da perfusão miocárdica, porém, com imagens sincronizadas ao eletrocardiograma e adquiridas de forma intermitente, com perda da informação simultânea sobre a motilidade ventricular.

O recente desenvolvimento de novas modalidades de imagens como a energia Doppler com imagem em pulso invertido ou em pulso modulado, que utilizam baixa energia acústica, diminuiu de forma significativa a destruição das microbolhas. Assim, a denominada ecocardiografia com perfusão miocárdica em tempo real (EPMTR) - que utiliza baixa energia ultra-sônica, ou seja, índice mecânico em torno de 0,2, e baixa freqüência de pulsos ultra-sônicos, ao redor de 25 pulsos por segundo - possui alta sensibilidade para a detecção das microbolhas no miocárdio. A EPMTR permite a observação da perfusão miocárdica e da motilidade segmentar de forma simultânea e em tempo real. Adicionalmente, por meio de programas computacionais específicos, permite a quantificação de vários parâmetros do fluxo microvascular. 


\section{Acurácia da análise qualitativa da ecocardiografia com contraste miocárdico para a detecção de doença arterial coronariana}

Kaul e colaboradores foram os primeiros a demonstrar uma excelente concordância (90 a 92\%, kappa = 0,88 a 0,99) entre a localização e o tipo de defeito de perfusão detectado pelo SPECT e pela ecocardiografia com contraste miocárdio, utilizando imagem harmônica intermitente ${ }^{40}$. Posteriormente, Porter e colaboradores avaliaram 40 pacientes submetidos à EPMTR sob estresse pela dobutamina e demonstraram uma concordância global entre a perfusão miocárdica e a angiografia quantitativa de $83 \%$ dos territórios (kappa $=0,65$ ), enquanto que a concordância entre as alterações da motilidade segmentar e a angiografia quantitativa foi de $72 \%^{41}$. Mais recentemente, Elhendy e colaboradores avaliaram a acurácia diagnóstica da perfusão miocárdica e motilidade segmentar, durante a EPMTR sob estresse pela dobutamina, em 170 pacientes com suspeita de DAC. A sensibilidade (91\% versus $70 \% ; p<0,001)$ e a acurácia global $(81 \%$ versus $71 \% ; p<0,01)$ da perfusão miocárdica foram maiores que as da motilidade segmentar para a detecção de DAC; porém, a especificidade foi menor (51\% versus $74 \%$; $p$ $<0,01)$. Neste estudo, a sensibilidade para a detecção de doença multiarterial baseada na presença de alterações em mais de dois territórios vasculares foi maior para a análise da perfusão miocárdica que para a análise da motilidade segmentar $(67 \% \text { versus } 28 \% ; p<0,01)^{42}$.

A acurácia diagnóstica da ecocardiografia com contraste utilizando diferentes modalidades de agentes estressores também tem sido descrita. Heinle e colaboradores estudaram 123 pacientes com DAC, suspeita ou 
conhecida, por meio de ecocardiografia com contraste miocárdico e estresse pela adenosina e compararam os resultados com aqueles obtidos pela cintilografia miocárdica. A concordância global entre as duas técnicas foi de $81 \%$ para a detecção de perfusão normal, $81 \%$ para a detecção de defeitos de perfusão no território da ADA, $76 \%$ para o território da CD e $72 \%$ para o território da $\mathrm{CX}^{43}$. Em outro estudo, o valor da ecocardiografia com contraste sob estresse pelo dipiridamol para a detecção de DAC foi avaliado em 55 pacientes com probabilidade intermediária de doença. Nele, a sensibilidade para detectar DAC, por território coronariano e por paciente, da ecocardiografia com contraste miocárdico utilizando imagem harmônica intermitente foi significativamente maior que a do SPECT (86\% versus $43 \%$; $p<0,01)$ e $(83 \%$ versus $49 \% ; p<0,05)$, respectivamente, enquanto que as especificidades foram semelhantes. De modo interessante, os autores descreveram que a ecocardiografia com contraste miocárdico foi consistentemente mais sensível que o SPECT quando a gravidade da estenose encontrava-se entre 40 e $80 \%$; porém, a diferença reduziu-se quando a estenose era $>80 \%{ }^{44}$.

Tsutsui e colaboradores avaliaram a acurácia diagnóstica da EPMTR para detectar anormalidades de perfusão miocárdica em 36 pacientes submetidos ao estresse pelo dipiridamol. Houve boa concordância entre o SPECT e a EPMTR para detectar pacientes $(75 \%$, kappa $=0,50)$ e territórios $(85 \%$, kappa $=0,61)$ com defeitos de perfusão. A acurácia diagnóstica da EPMTR para a detecção de pacientes com lesão $>50 \%$ pela angiografia quantitativa foi de $79 \%$, enquanto que a do SPECT foi de $65 \%{ }^{45}$. 
Embora tais estudos tenham demonstrado que a análise qualitativa da perfusão miocárdica pode ser útil para a detecção de DAC durante o estresse por agentes inotrópicos positivos ou vasodilatadores ${ }^{40,41,42}$ essa técnica ainda requer grande experiência do observador para a interpretação das imagens de perfusão, limitando sua ampla aplicação na prática clínica. Mais recentemente, o desenvolvimento de programas computacionais tem permitido a quantificação do fluxo sangüíneo miocárdico por meio da utilização da ecocardiografia com contraste miocárdico.

\section{Quantificação do fluxo miocárdico pela ecocardiografia com perfusão miocárdica em tempo real}

Em 1998, Wei e colaboradores propuseram e validaram (in vitro e in vivo) um método para quantificação da perfusão miocárdica pela ecocardiografia com contraste miocárdico ${ }^{46}$. O método baseava-se na hipótese de que, se as microbolhas fossem administradas em infusão contínua, sua destruição dentro do miocárdio por meio de um pulso de alta energia de ultra-som, associada à mensuração da sua taxa de repreenchimento, proporcionaria uma medida da velocidade média das microbolhas, sendo tal medida proporcional à velocidade de fluxo miocárdico. Adicionalmente, a concentração das microbolhas no miocárdio, após ter atingido o equilíbrio de infusão de contraste, seria proporcional ao volume de sangue no miocárdio. 


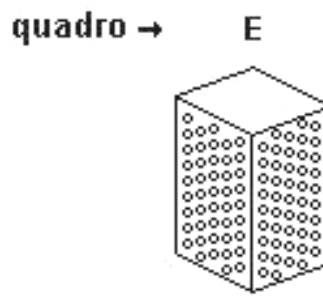

tempo $\rightarrow-\mathrm{t} 2$

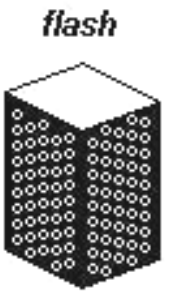

$-\mathbf{t 1}$

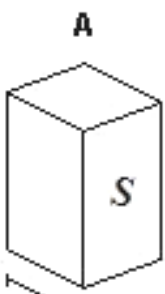

$W^{-1}$

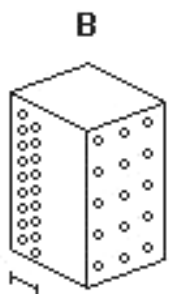

d1

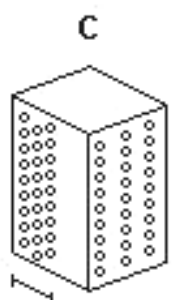

$\mathrm{d} 2$

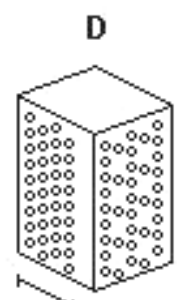

d3 $\mathrm{d} 4=W^{\mathrm{r}}$

E

t1

$\mathbf{t 3}$

Figura 1 - Ilustração do modelo de avaliação da perfusão miocárdica proposto por Wei e colaboradores. Com infusão contínua de contraste, ocorre saturação do miocárdio pelas microbolhas (quadro E). A aplicação de pulsos ultra-sônicos de alta energia (flash) permite a destruição das microbolhas no miocárdio (quadro $A$ ) e $O$ subseqüente repreenchimento (quadros $B$ a $E$ ). $S=$ região de interesse considerada; $W$ = espessura do campo ultra-sônico; $d$ = distância percorrida pelas microbolhas; $\mathrm{t}=$ tempo; $\mathrm{T}=$ tempo onde houve saturação das microbolhas no campo ultra-sônico.

Portanto, como ilustrado na Figura 1, durante a infusão contínua de contraste (concentração e taxa de infusão constantes das microbolhas), uma saturação (platô) de microbolhas é alcançada no miocárdio (quadro $E$ do instante -t2). Na seqüência, pode-se aplicar uma média de um a cinco pulsos de ultra-som com alta energia para se destruir as microbolhas no miocárdio (denominado flash). Após a aplicação do flash as microbolhas são destruídas (quadro A). A manutenção de uma imagem de ultra-som com baixa energia para que ocorra destruição mínima das microbolhas permite a detecção do repreenchimento das microbolhas no miocárdio (quadro B), e sua concentração aumentaria nos batimentos subseqüentes (quadros C e D) até que nova saturação fosse atingida (quadro $E$ do instante t4). 
O repreenchimento das microbolhas no miocárdio em função do tempo (quadros $A$ até $E$ da Figura 1) pode, então, ser medido pelo aumento da intensidade acústica a cada quadro da seqüência de imagens, o que resulta em uma curva de intensidade acústica pelo tempo de repreenchimento do miocárdio pelas microbolhas e que pode ser matematicamente aproximada pela função abaixo: $y=A \cdot\left(1-e^{-B \cdot t}\right)$ onde,

- $\boldsymbol{t}$ é o instante de tempo;

- $y$ é a intensidade acústica no instante de tempo $t$;

- $\boldsymbol{A}$ é a intensidade acústica no platô (concentração máxima das microbolhas);

- ß é a taxa de repreenchimento das microbolhas (taxa de crescimento de $y$ );

Assim, conforme demonstrado por Wei e colaboradores, o parâmetro A é proporcional ao volume e o parâmetro $ß$, à velocidade sangüínea na microcirculação miocárdica, sendo que o produto $A x ß$ seria, conseqüentemente, proporcional ao fluxo sangüíneo miocárdico ${ }^{46}$.

A partir de tais princípios, desenvolveram-se, programas computacionais específicos para a quantificação do contraste miocárdico que nos permite a análise de seqüências de imagens e a quantificação do fluxo miocárdico regional (Figura 2), tanto em estado de repouso como após a indução de estresse cardiovascular, fornecendo, desse modo, a quantificação da reserva de fluxo miocárdico (reserva Axß). 


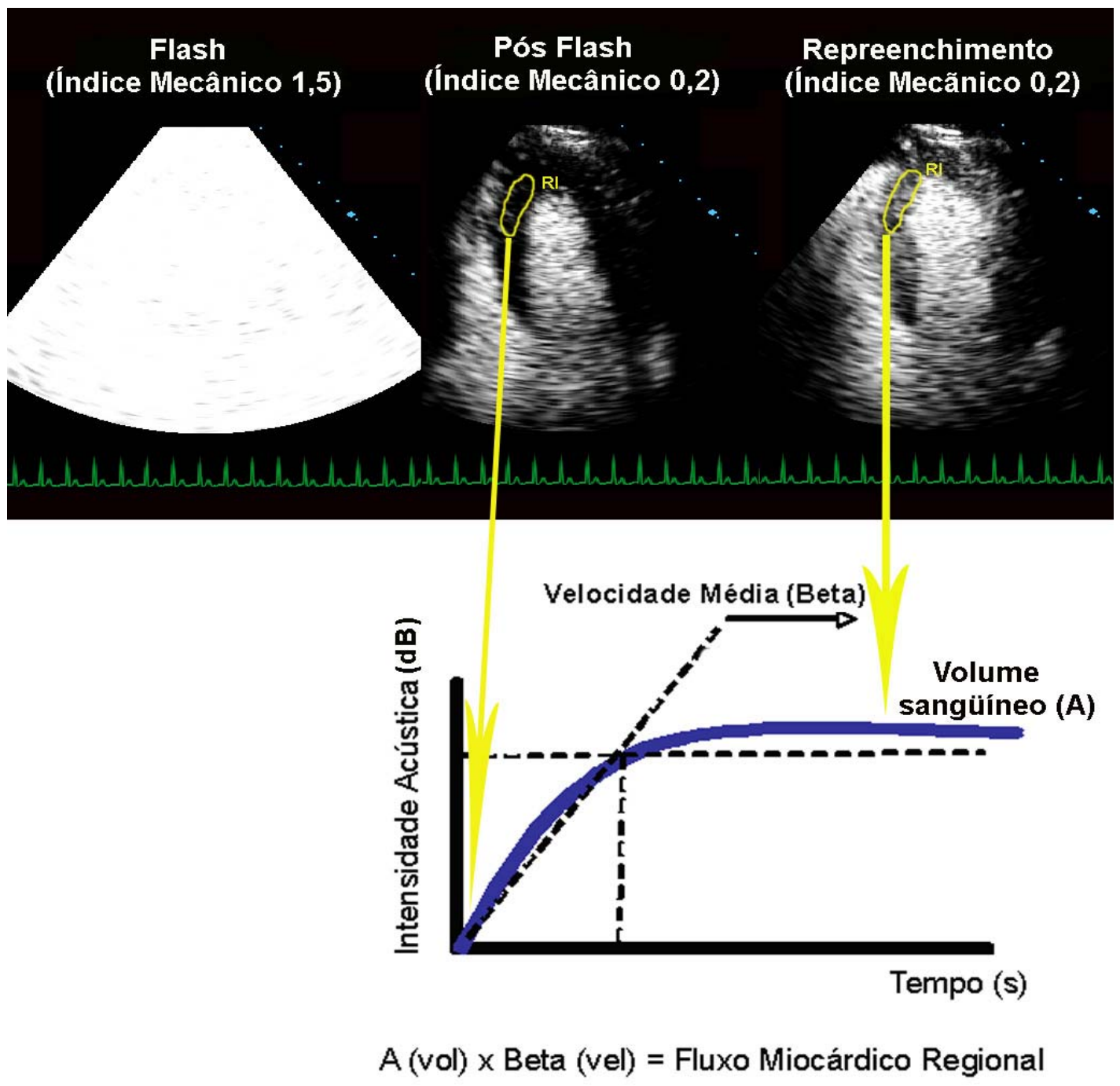

Figura 2 - Demonstração do repreenchimento miocárdico pelas microbolhas nos batimentos posteriores a um flash e método de cálculo do fluxo miocárdico regional pela ecocardiografia com perfusão miocárdica em tempo real. $\mathrm{RI}$ = região de interesse; vol = volume; vel = velocidade.

Atualmente, existem poucos estudos clínicos sobre a utilização dessa técnica para a avaliação de pacientes com DAC. Korosoglou e colaboradores, em 2004, avaliaram 50 pacientes pela EPMTR pela adenosina e com SPECT, verificando que a análise visual da ecocardiografia teve boa correlação com o SPECT (kappa $=0,67)$. A EPMTR apresentou 
sensibilidade de $64 \%$, especificidade de $97 \%$ e acurácia global de $87 \%$ para detectar defeitos de perfusão miocárdica. Quando o fluxo sangüíneo miocárdio foi analisado quantitativamente, observaram-se sensibilidade, especificidade e acurácia diagnóstica de 80\%, 78\% e 79\%, respectivamente, em relação ao SPECT ${ }^{47}$. Peltier e colaboradores, em 2004, estudaram 35 pacientes utilizando a EPMTR sob estresse pelo dipiridamol e o SPECT. Os autores demonstraram que houve um menor aumento da velocidade e do fluxo sangüíneo miocárdico nos territórios supridos por artéria coronariana com estenose significativa, definida por obstrução coronariana $>70 \%$. A acurácia para detecção de DAC por território foi de $87 \%$, quando se utilizou a quantificação da velocidade do fluxo sangüíneo miocárdico, e de 85\%, quando se utilizou a quantificação do fluxo sangüíneo miocárdico. A EPMTR sob estresse pelo dipiridamol foi capaz de identificar $97 \%$ dos territórios com DAC, enquanto que o SPECT foi capaz de identificar $71 \%$ deles ${ }^{48}$.

Um outro ponto que permanece em discussão é qual o melhor agente estressor quando se considera a avaliação da perfusão pela ecocardiografia com contraste miocárdico. Bin e colaboradores, utilizando a quantificação de fluxo miocárdico pela ecocardiografia com contraste e com microesferas radioativas em um modelo animal, constataram que o volume sangüíneo miocárdico aumenta tanto nos leitos supridos por artérias normais como no leito suprido por artérias estenóticas, na presença de dobutamina e de dipiridamol. De modo interessante, os autores demonstraram que o aumento do volume sangüíneo miocárdico é maior com o uso da dobutamina que do dipiridamol, aumento que está diretamente relacionado com o consumo 
miocárdico de oxigênio. Os leitos vasculares supridos por artérias estenóticas exibem um número menor de capilares em relação aos leitos supridos por artérias normais, o que poderia explicar a ocorrência de defeitos reversíveis da perfusão com o uso da dobutamina ${ }^{49}$. Na presença de estenose coronariana não-crítica, a diminuição da resistência vascular pode levar à alteração da perfusão miocárdica, precedendo as alterações da motilidade segmentar ${ }^{50}$.

Em um outro estudo experimental, os mesmos autores demonstraram que a administração intracoronariana de baixas doses de dobutamina resulta em vasodilatação coronariana, levando a um aumento conseqüente da velocidade do fluxo sangüíneo miocárdico, dado pela ação da dobutamina nos receptores $ß_{2}$. Com o aumento da dose da dobutamina e, conseqüentemente, aumento de consumo de oxigênio pelo miocárdio, observou-se um aumento do volume de sangue no miocárdio, ocasionado por um maior recrutamento de capilares.

Por outro lado, quando se estudou a infusão intracoronariana de adenosina, verificou-se que ela levou a um aumento da velocidade do fluxo sangüíneo miocárdico, decorrente de seu efeito vasodilatador direto, sem alterações significativas no volume de sangue miocárdico. Porém, quando a adenosina foi administrada por via intravenosa, observou-se um aumento de $50 \%$ do volume de sangue miocárdico, dado pelo aumento do consumo miocárdico de oxigênio, conseqüente à ocorrência de hipotensão sistêmica acompanhada por taquicardia reflexa. Ao comparar ambos os fármacos em leito arterial com estenose não-crítica, caracterizada por não apresentar 
alterações da perfusão no estado basal, demonstrou-se que o fluxo sangüíneo miocárdico não aumenta como nos territórios normais, tanto com o uso de dobutamina como com o de adenosina. Apesar da maior diminuição da resistência vascular coronariana com o uso de adenosina, a administração intravenosa desse fármaco provocou uma diminuição da pressão de perfusão capilar devido aos seus efeitos hemodinâmicos sistêmicos. Para manter a pressão capilar constante nessa situação, ocorre uma redução do recrutamento capilar, resultando em diminuição do volume sangüíneo capilar. Isso explica o achado de menor aumento do volume de sangue no miocárdio e que foi semelhante para a dobutamina e a adenosina no leito distal à estenose ${ }^{51}$.

Apesar do conhecimento fisiopatológico das alterações isquêmicas miocárdicas dadas pela adenosina e dobutamina em estudos animais, ainda não se definiu qual seria o melhor agente a ser utilizado na EPMTR em humanos. Além disso, não se conhece ainda, em seres humanos e com os protocolos de estresse atualmente utilizados, qual o comportamento de variáveis importantes do fluxo microvascular em condições normais e patológicas. 
Objetivos 
1- Determinar, em um mesmo grupo de pacientes, a exeqüibilidade da avaliação qualitativa e quantitativa da EPMTR sob estresse pela dobutamina e da EPMTR sob estresse pela adenosina.

2- Comparar, em um mesmo grupo de pacientes, a acurácia da análise quantitativa da perfusão miocárdica obtida pela EPMTR sob estresse pela dobutamina à daquela pela adenosina, para a detecção de estenose arterial coronariana angiograficamente significativa .

3- Determinar o valor adicional da análise quantitativa da perfusão miocárdica sobre o eletrocardiograma em 12 derivações, da análise da motilidade segmentar, e da análise qualitativa da perfusão miocárdica, obtidas pela EPMTR sob estresse pela dobutamina e pela adenosina. 
Métodos

$\overline{\underline{2}}$ 


\section{População de estudo}

No período de março de 2003 a setembro de 2004, estudamos 73 pacientes consecutivos de forma prospectiva. Todos os pacientes foram submetidos à EPMTR sob estresse pela adenosina e pela dobutamina, em um intervalo mínimo de três horas e máximo de cinco horas. Os pacientes foram selecionados com base na indicação de angiografia coronariana pela equipe clínica que os acompanhava no Ambulatório de Coronariopatias Crônicas do Instituto do Coração (InCor).

O protocolo de estudo foi aprovado pela Comissão de Ética em Pesquisa do Hospital das Clínicas da Faculdade de Medicina da Universidade de São Paulo. Todos os participantes foram informados sobre os procedimentos a serem realizados e assinaram $o$ Termo de Consentimento Livre e Esclarecido.

\section{Critérios de inclusão}

Foram incluídos pacientes com idade acima de 18 anos e que realizaram angiografia coronariana com intervalo máximo de um mês da EPMTR, os quais tinham função sistólica ventricular esquerda global (fração 
de ejeção do ventrículo esquerdo maior que 55\%) e segmentar normal em repouso.

\section{Critérios de exclusão}

Foram excluídos pacientes submetidos à intervenção percutânea ou cirúrgica entre a angiografia coronariana e a EPMTR; pacientes com angina instável; com história de infarto do miocárdio prévio ou no intervalo de tempo entre a angiografia coronariana e o estudo ecocardiográfico; com cirurgia de revascularização miocárdica prévia; com história de alergia a componentes do contraste ecocardiográfico; com doença pulmonar obstrutiva crônica ou asma brônquica; com arritmia ventricular grave ou de difícil controle; com bloqueio atrioventricular de segundo ou terceiro graus no eletrocardiograma em repouso; com doença valvar com repercussão hemodinâmica significativa; com hipertensão arterial sistêmica não controlada, definida por

pressão arterial sistólica maior que $180 \mathrm{mmHg}$ e diastólica maior que 110 $\mathrm{mmHg}$ em repouso; mulheres gestantes ou em período de amamentação; uso de xantinas ou derivados 24 horas antes da EPMTR pela adenosina e casos de recusa ou incapacidade de assinar o termo de consentimento livre e esclarecido.

Os antecedentes de hipertensão arterial sistêmica, diabetes melito, hipercolesterolemia, tabagismo e angina estável foram obtidos pela história clínica e dados de prontuário. 


\section{Protocolo de Estudo}

\section{Ecocardiografia com perfusão miocárdica em tempo real}

A avaliação ecocardiográfica foi realizada por meio do ecocardiógrafo SONOS 5500 (Philips Medical Systems, Andover, MA), equipado com transdutor de banda larga de 4-2 MHz e com capacidade para a realização de imagens por meio de tecnologia denominada Energia Modulada (Power Modulation) para o estudo da perfusão miocárdica.

Os pacientes foram submetidos, inicialmente, a um estudo ecocardiográfico basal, com medidas lineares das estruturas cardíacas e dos fluxos valvares obtidas de acordo com as recomendações da Sociedade Americana de Ecocardiografia ${ }^{40}$. A fração de ejeção do ventrículo esquerdo foi calculada pelo método de Simpson ${ }^{52,53,54}$.

Para o estudo da perfusão miocárdica, o agente de contraste utilizado foi o PESDA (Perfluorocarbon-Exposed Sonicated Dextrose and Albumin), preparado em nosso laboratório, com validação prévia ${ }^{55}$. O contraste foi preparado pela mistura de $8 \mathrm{ml}$ de gás decafluorobutano (FluoroMed, L.P., Houston, TX), $1 \mathrm{ml}$ de albumina humana a 20\% (Baxter Healthcare Corporation, Glendale, CA) e $12 \mathrm{ml}$ de soro glicosado a $5 \%$ (Baxter Heathcare Corpoation, Glendale, CA). Tal mistura era submetida à sonificação eletromecânica por 80 segundos, a uma freqüência de $20 \mathrm{kHz}$, com o sonificador (Heat Systems Inc, Farmingdale, NY) em máxima 
potência, resultando em solução estável de microbolhas com diâmetro de aproximadamente 3,0 mícrons e concentração média de $10^{9}$ microbolhas $/ \mathrm{ml}$.

A dose de PESDA utilizada foi de $0,1 \mathrm{ml} / \mathrm{kg}$ diluído em $80 \mathrm{ml}$ de solução salina $(0,9 \%)$. Essa solução foi infundida de forma contínua à taxa de 2 a $5 \mathrm{ml} / \mathrm{min}$ por via intravenosa periférica. A dose ideal de infusão de PESDA foi ajustada de acordo com a obtenção visual de saturação adequada do contraste no miocárdio, caracterizada pela presença de sombra acústica ao nível da porção média do átrio esquerdo.

Ajustes específicos do aparelho foram então realizados e incluíram índice mecânico baixo $(0,2)$ e freqüência de repetição de pulsos de $25 \mathrm{~Hz}$. Todos os ajustes e velocidade de infusão de contraste eram otimizados no estado basal e eram mantidos constantes para permitir comparação válida entre imagens obtidas em repouso e sob estresse farmacológico. Um rápido pulso ultra-sônico com utilização de índice mecânico elevado $(1,5)$, de quatro a cinco quadros (flash), foi manualmente disparado no pico de intensidade do contraste para destruir microbolhas dentro do miocárdio. Na seqüência, analisaram-se as imagens com baixo índice mecânico $(0,2)$ por pelo menos 15 ciclos cardíacos consecutivos para permitir o repreenchimento miocárdico e, conseqüentemente, possibilitar os cálculos de velocidade das microbolhas na microcirculação e sua concentração máxima. Todas as imagens ecocardiográficas foram gravadas em videoteipe e em disco óptico, com formato digital, para posterior análise. 


\section{Protocolo de estresse pela adenosina}

Após a realização dos ajustes iniciais do aparelho e também da velocidade da infusão intravenosa do contraste PESDA, era iniciada a captura das imagens padrão no estado basal, incluindo imagens nos planos apical quatro, duas e três câmaras. Em seguida, administrava-se adenosina (Adenocard®, Libbs Farmacêutica Ltda) por via intravenosa periférica, de forma contínua e na dose de $140 \mu \mathrm{g} / \mathrm{kg} / \mathrm{min}$, durante seis minutos. A infusão de adenosina era realizada em um segundo acesso venoso periférico, diferente do acesso utilizado para infusão do contraste ecocardiográfico.

Durante a infusão de adenosina, sob infusão contínua de PESDA, as imagens ecocardiográficas nos planos apical quatro, duas e três câmaras eram adquiridas novamente entre o quarto e sexto minuto da infusão (Figura 3). 


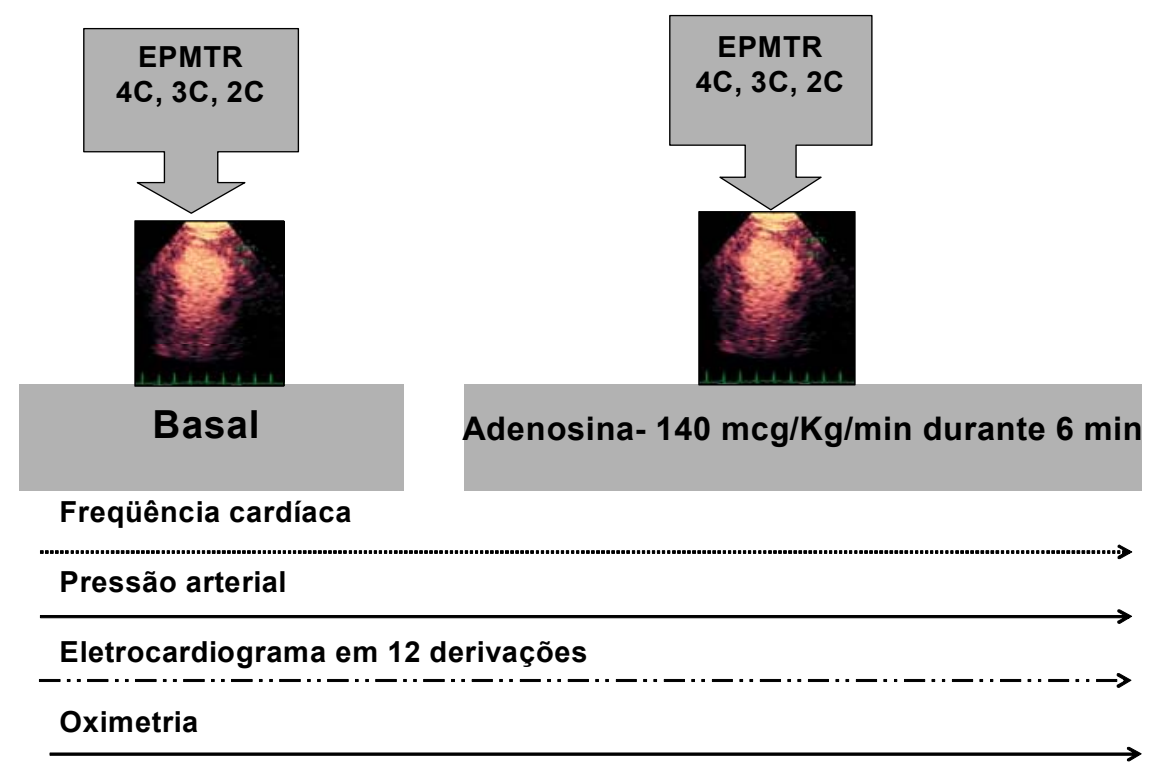

Figura 3 - Protocolo de estudo de ecocardiografia com perfusão miocárdica em tempo real (EPMTR), sob estresse pela adenosina. As imagens nos planos apical quatro câmaras (4C), três câmaras (3C) e duas câmaras (2C) eram adquiridas no estado basal e durante a infusão de adenosina, com monitorização da freqüência cardíaca, pressão arterial sistêmica, eletrocardiograma e oximetria de pulso.

Foram registradas a pressão arterial sistêmica, freqüência cardíaca e eletrocardiograma em 12 derivações no estado basal, a cada dois minutos, durante a infusão intravenosa de adenosina e após o término do teste. Registros adicionais eram realizados em caso de alterações ecocardiográficas ou de sintomatologia clínica.

Para que o teste fosse considerado eficaz, era necessário que o estudo tivesse atingido um dos seguintes objetivos: 
1- presença de sinais ecocardiográficos de isquemia (novas alterações na motilidade do ventrículo esquerdo e/ou alterações nítidas da perfusão miocárdica);

2- término do protocolo de infusão.

Quando não eram observados sinais ecocardiográficos e eletrocardiográficos de isquemia miocárdica grave durante o estresse pela adenosina, assim como sintomatologia significativa ou efeito colateral importante, os pacientes eram submetidos à EPMTR pela dobutamina após um intervalo mínimo de três horas e máximo de cinco horas.

\section{Protocolo de estresse pela dobutamina}

Após aquisição das imagens padrão no estado basal nos planos apical quatro, duas e três câmaras, iniciava-se a infusão intravenosa de dobutamina com dose inicial de $5 \mu \mathrm{g} / \mathrm{kg} / \mathrm{min}$, com incrementos crescentes de 10, 20, 30 e $40 \mu \mathrm{g} / \mathrm{kg} / \mathrm{min}$ a cada três minutos. Caso o paciente não apresentasse sinais ecocardiográficos de isquemia miocárdica e não tivesse atingido a freqüência cardíaca de no mínimo 100 bpm no estágio de 20 $\mu \mathrm{g} / \mathrm{kg} / \mathrm{min}$, era administrada atropina em doses de $0,25 \mathrm{mg}$ por minuto, até a dose máxima acumulativa de 2 mg, como demonstrado na Figura $4^{27}$. 


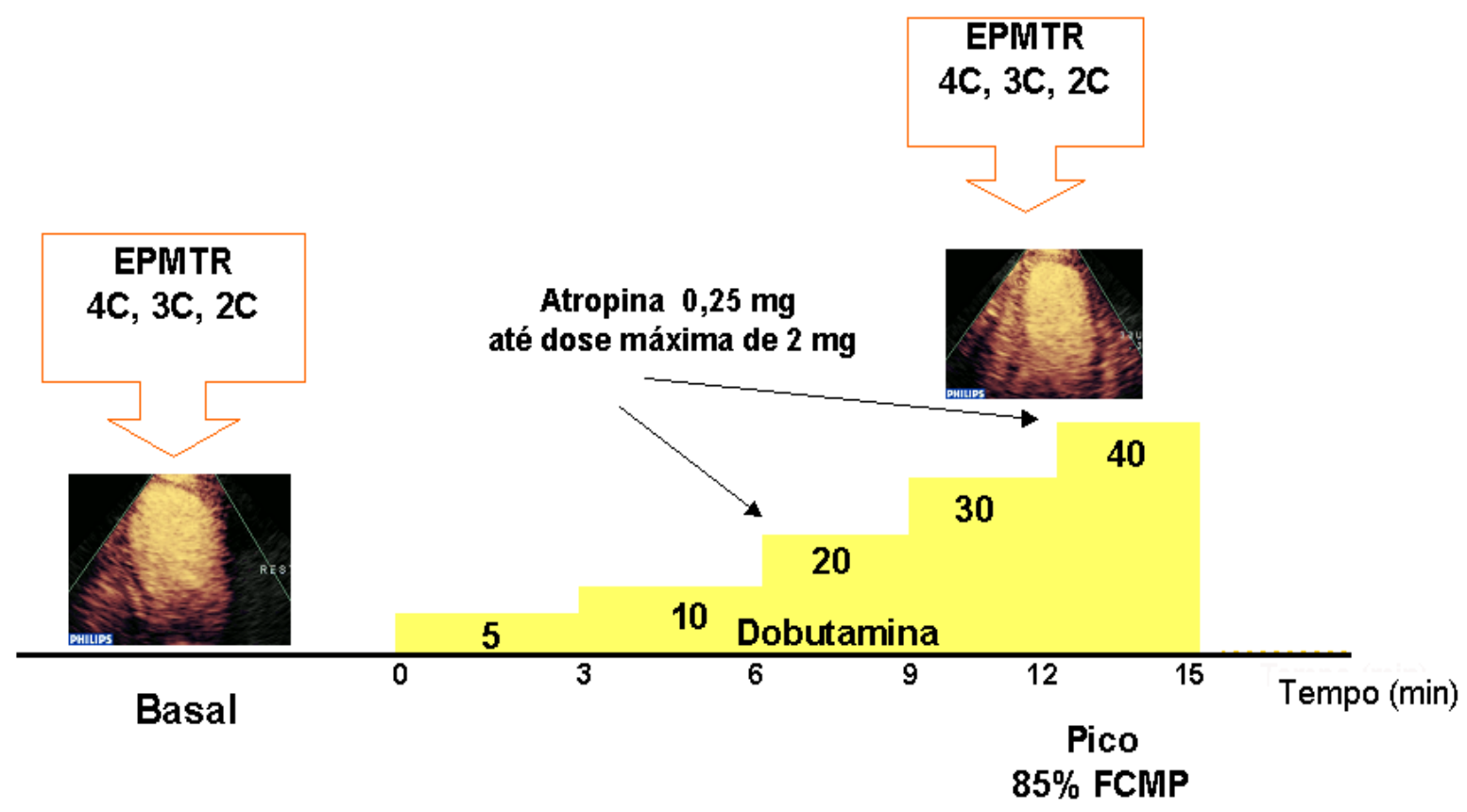

Figura 4 - Protocolo de estudo de ecocardiografia com perfusão miocárdica em tempo real (EPMTR) sob estresse pela dobutamina. As imagens nos planos apicais quatro câmaras (4C), três câmaras (3C) e duas câmaras (2C) eram adquiridas no estado basal e no pico do estresse pela dobutamina quando se atingia no mínimo $85 \%$ da freqüência cardíaca máxima predita para a idade (FCMP) ou na presença de sinais ecocardiográficos de isquemia.

Os pacientes eram mantidos sob monitorização clínica, eletrocardiográfica e pressórica contínuas, sendo registradas as medidas de pressão arterial, freqüência cardíaca e eletrocardiograma em 12 derivações antes, no estado basal, ao final de cada estágio e durante a fase de recuperação. Traçados ou medidas adicionais eram realizados a qualquer momento a pedido do médico responsável (autor). A sintomatologia dos pacientes era registrada de acordo com questionamento direto ou queixa direta do paciente, a qualquer momento do estudo. 
A EPMTR pela dobutamina foi considerada eficaz quando o estudo alcançava um dos seguintes objetivos:

1- mínimo de $85 \%$ da freqüência cardíaca máxima predita para a idade, calculada pelo número 220 menos o valor numérico da idade;

2- observação de sinais ecocardiográficos de isquemia (novas alterações na motilidade do ventrículo esquerdo e/ou alterações nítidas da perfusão miocárdica);

3- término do protocolo de infusão.

A ocorrência de arritmia cardíaca grave ou efeito colateral significativo antes de se atingir um dos objetivos do exame era critério para a interrupção do estudo, sendo então considerado ineficaz.

Para ambos os testes de EPMTR sob estresse pela dobutamina e pela adenosina, efeitos adversos menores foram definidos como aqueles auto-limitados, que responderam rapidamente à interrupção do teste, não sendo necessária a admissão hospitalar do paciente. Efeitos adversos maiores foram definidos como aqueles que poderiam potencialmente provocar uma situação de risco à vida, ou que levaram a uma nova admissão hospitalar. A hipotensão foi definida como uma queda da pressão arterial sistólica abaixo de $100 \mathrm{mmHg}$ ou acompanhada de sintomas significativos. A hipertensão foi definida como pressão arterial sistólica >240 mmHg ou pressão arterial diastólica $>120$ mmHg. 


\section{Análise eletrocardiográfica durante a ecocardiografia sob estresse}

A interpretação eletrocardiográfica foi realizada por um revisor independente, que não tinha conhecimento dos dados clínicos, ecocardiográficos ou angiográficos dos pacientes. Analisaram-se os eletrocardiogramas em 12 derivações realizados em repouso e durante cada estágio do estresse pela dobutamina e adenosina. O eletrocardiograma foi considerado positivo para isquemia na presença de infradesnivelamento do segmento ST de $1 \mathrm{~mm}$, medido no ponto $\mathrm{J}$ nos casos de infradesnivelamento horizontal ou descendente, ou no ponto $\mathrm{Y}$, a $80 \mathrm{~ms}$ do ponto $\mathrm{J}$, nos casos de infradesnivelamento ascendente, conforme recomendações do American College of Cardiology ${ }^{56}$. O padrão ascendente lento foi considerado como uma resposta anormal.

Foram considerados como critérios de não interpretabilidade a presença de bloqueio de ramo esquerdo, sobrecarga ventricular esquerda ou infradesnivelamento do segmento ST maior que $2 \mathrm{~mm}$ no eletrocardiograma em repouso. Na presença de bloqueio de ramo direito, os critérios de positividade foram validados somente em parede posterior ou lateral, sendo que as derivações frontais de V1 a V4 não foram analisadas. 


\section{Determinação qualitativa da motilidade e perfusão miocárdicas}

O ventrículo esquerdo foi dividido em 17 segmentos miocárdicos, segundo as recomendações do Joint Committee on American Heart Association $^{39}$ (Figura 5). Para a análise ecocardiográfica, consideraram-se os territórios da artéria descendente anterior (ADA), artéria coronária direita (CD), e artéria coronária circunflexa (CX). Os segmentos apical, médio e basal das paredes anterior e ântero-septal, segmento médio e apical do septo posterior foram atribuídos ao território da ADA. Os segmentos apical, médio e basal da parede inferior e segmento basal do septo posterior foram atribuídos ao território da $C D$, e os segmentos médio, apical e basal da parede lateral e segmentos médio e basal da parede posterior foram atribuídos ao território da CX. 


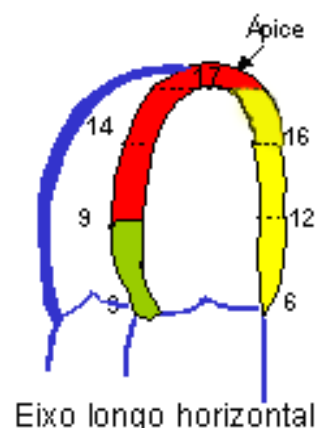

(4 câmaras)

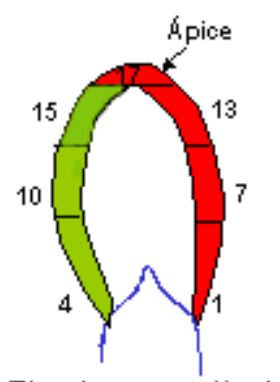

Eixo longo vertic al

(2 câmaras)

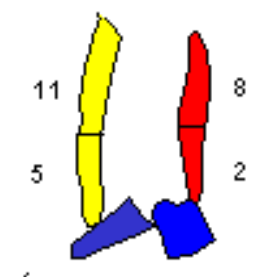

Ápical longitudinal

(3 câmaras)

Figura 5 - Divisão do ventrículo esquerdo em 17 segmentos nos planos apical quatro, três e duas câmaras, segundo as recomendações do Joint Committee on American Heart Association. ADA = artéria coronária descendente anterior; $C D=$ artéria coronária direita; $C X=$ artéria coronária circunflexa.

A interpretação qualitativa da motilidade segmentar e perfusão miocárdicas foi realizada por um revisor independente que não tinha conhecimento dos dados clínicos, eletrocardiográficos, ou angiográficos dos pacientes.

A análise qualitativa da motilidade miocárdica segmentar baseou-se na avaliação visual do espessamento miocárdico e no grau de motilidade da parede graduada em um sistema de escores, dando a cada um dos segmentos a seguinte pontuação: 1 - normal; 2 - hipocinesia; 3 - acinesia, 4 
- discinesia. A motilidade normal foi definida como aumento uniforme da excursão e espessamento adequado do miocárdio. A presença e diminuição da excursão e do engrossamento miocárdico foi classificada como hipocinesia. A acinesia foi estabelecida como ausência do movimento e espessamento do miocárdio, enquanto a discinesia foi definida pela excursão paradoxal e ausência de espessamento da parede. Considerou-se motilidade miocárdica segmentar positiva para isquemia a presença nítida de alteração de motilidade miocárdica segmentar em um ou mais segmentos do ventrículo esquerdo, durante o estresse farmacológico. Como todos os pacientes possuíam motilidade normal em repouso, adotou-se considerado como critério de positividade para a análise qualitativa a presença de hipocinesia (escore 2), acinesia (escore 3) ou discinesia (escore 4) durante o estresse pela dobutamina ou adenosina. A presença de nova alteração segmentar restrita ao segmento basal da parede inferior não foi considerada critério de positividade ${ }^{57}$.

A análise qualitativa da perfusão baseou-se na avaliação visual das imagens que apresentavam a melhor opacificação miocárdica após o repreenchimento miocárdico de microbolhas, a qual se segue ao flash ecocardiográfico. A opacificação miocárdica foi graduada visualmente em: grau 1, como intensa (normal ou homogênea); grau 2, como diminuída (heterogênea); ou grau 3, como ausente. Definiu-se como critério de positividade para análise qualitativa a presença de um defeito de perfusão (graus 2 ou 3) em um ou mais segmentos miocárdicos, durante o estresse pela dobutamina ou pela adenosina, quando comparado com as imagens em 
repouso. Quando as bordas endocárdica e epicárdica de um determinado segmento não podiam ser visibilizadas e, portanto, tal segmento não podia ser claramente distinguido de tecidos ao redor, ele foi considerado como artefato de imagem e, logo, não interpretável.

\section{Determinação quantitativa da perfusão miocárdica}

A determinação quantitativa da perfusão miocárdica foi realizada por meio de um software específico (Q-Lab 3.0, Philips Medical Systems, Bothell, WA, USA). A intensidade acústica de sinal e a velocidade de repreenchimento da microcirculação pelas microbolhas foram quantificadas nos planos apical de quatro, duas e três câmaras, tanto em repouso como durante o estresse pela dobutamina e adenosina, no final da sístole. Foram analisadas seqüências de imagens digitais contendo um mínimo de 15 ciclos cardíacos, desde o flash ecocardiográfico até o $15^{\circ}$ batimento. Inicialmente, era feito um alinhamento das imagens ao final da sístole, e, então, foram colocadas regiões de interesse transmurais nos diferentes territórios arteriais, com o cuidado de evitar as bordas endocárdicas e epicárdicas para que a intensidade do sinal fosse analisada de forma correta, não refletindo a intensidade acústica de regiões não pertencentes ao miocárdio, como exemplificado na Figura 6. 


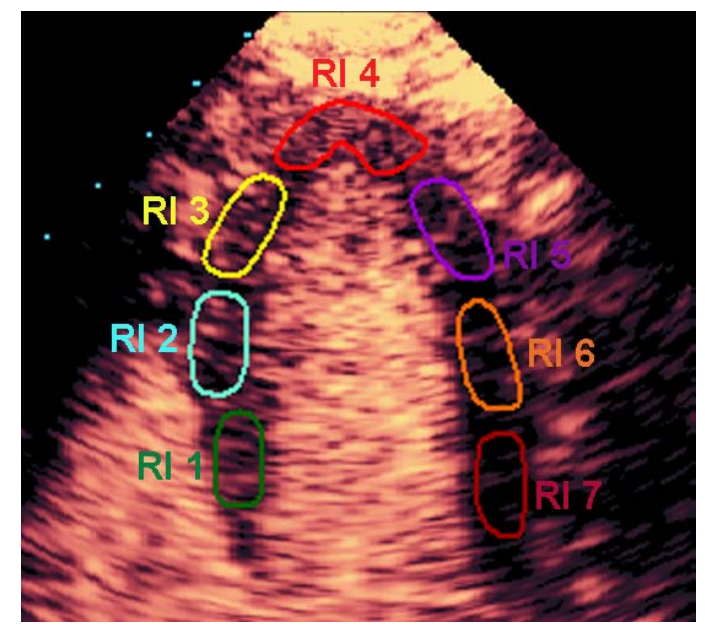

Figura 6 - Imagem do plano apical de quatro câmaras, obtido pela ecocardiografia com perfusão miocárdica em tempo real, mostrando a colocação de regiões de interesse (RI) nos diferentes segmentos miocárdicos.

A intensidade de sinal a cada quadro após o flash era colocada em uma função exponencial descrita como: $y=A \cdot\left(1-\mathrm{e}^{-B t}\right)$, onde y é a intensidade acústica no tempo $t, A$ é a intensidade acústica no platô e representa o volume sangüíneo miocárdico, e ß reflete a taxa de aumento da intensidade acústica e representa a velocidade de repreenchimento do miocárdio pelas microbolhas, como exemplificado na Figura 1. O fluxo sangüíneo miocárdico foi obtido pelo produto $A x ß$. A razão entre o fluxo sangüíneo miocárdico durante a infusão de dobutamina ou adenosina e o fluxo sangüíneo miocárdico no estado basal reflete a reserva do fluxo sangüíneo miocárdico (reserva Axß). Também, determinou-se a reserva de velocidade de fluxo miocárdico (reserva ß), calculada como a razão entre o valor de $ß$ durante a infusão de dobutamina ou adenosina e o valor de $ß$ no estado basal. 
Os valores médios dos índices de reserva para cada variável analisada ( $ß$ e $A x ß)$ foram obtidos por território arterial, a partir da soma do valor de cada segmento pertencente àquele determinado território dividido pelo número de segmentos analisados.

\section{Exeqüibilidade e acurácia diagnóstica da EPMTR}

As exeqüibilidades da análise qualitativa da motilidade segmentar e perfusão miocárdicas, bem como da análise quantitativa das variáveis $ß, \mathrm{e}$ Axß foram calculadas nos pacientes submetidos à ecocardiografia sob estresse pela dobutamina e pela adenosina eficazes para pesquisa de isquemia, todas com base nas imagens em tempo real e baixo índice mecânico (EPMTR). Para essas análises qualitativas foram consideradas as exeqüibilidades de cada território arterial (ADA, CD e CX). As análises foram definidas como exeqüíveis no território da ADA quando cinco dos oito segmentos miocárdicos foram adequadamente avaliados. As análises foram definidas como exeqüíveis no território da CD quando dois dos quatro segmentos miocárdicos foram adequadamente avaliados e, para o território da CX, quando dois dos cinco segmentos miocárdicos foram adequadamente avaliados. Para a análise quantitativa, valores inferiores a $20 \%$ e maiores que duas vezes a média obtida em toda população, no estado basal, foram considerados não interpretáveis. Somente os segmentos que possuíam todas as medidas interpretáveis (basal e pico) foram considerados exeqüíveis. 
A acurácia diagnóstica da EPMTR sob estresse pela dobutamina e pela adenosina para detecção de DAC angiograficamente significativa foi determinada para cada parâmetro qualitativo (motilidade e perfusão miocárdica) e quantitativo (variáveis $ß$, e $A x ß$ ). A acurácia foi determinada por paciente, baseada na presença ou não de isquemia em cada território arterial (ADA, CD e CX).

\section{Variabilidade intra e interobservador}

A variabilidade intra e interobservador da medida quantitativa da reserva $\beta$ e $A x ß$ foi realizada por dois pesquisadores experientes, tendo por base dez casos escolhidos aleatoriamente, tanto nos pacientes com quanto nos pacientes sem lesão coronariana significativa, feita nos casos selecionados acima, em um intervalo de três meses entre a primeira e a segunda avaliação. A variabilidade intra-observador da análise qualitativa da motilidade e perfusão miocárdica foi validada previamente, no nosso laboratório de ecocardiografia, havendo uma concordância de 0,98 e 0,92, respectivamente ${ }^{58}$. 


\section{Angiografia coronariana}

A análise angiográfica foi feita no Serviço de Hemodinâmica do Instituto do Coração (InCor). A angiografia coronariana foi realizada pela técnica de Sones, por dissecção braquial, ou pela técnica de Judkins, por

punção femoral ${ }^{59,60}$. Após a cateterização seletiva das artérias coronárias, realizaram-se injeções manuais de contraste radiológico $(5-15 \mathrm{ml}$ em cada injeção) para a delimitação da anatomia coronária. Múltiplas injeções em diferentes planos ortogonais foram feitas com o intuito de demonstrar os diversos segmentos arteriais coronários sem a superposição de ramos.

O registro angiográfico foi efetuado com taxa de aquisição de 15 quadros por segundo, utilizando-se equipamento para estudo hemodinâmico Integris H-3000 (Phillips, Holanda) com processamento digital das imagens. Após a aquisição, as imagens foram arquivadas para uso posterior em disco óptico LDA (analógico) ou em formato DICOM (Digital Imaging and Communication), conforme padrão internacional ${ }^{61}$.

A interpretação das imagens foi realizada observando-se a anatomia coronária e a presença de estenoses luminais nos diversos segmentos coronários dos três ramos arteriais principais (CD, $A D A$, e $C X)$ e de seus ramos secundários. A angiografia coronariana quantitativa ( $A C Q)$ foi feita por meio de sistema computadorizado CAAS II (Cardiovascular Angiography Analysis System II ${ }^{\circledR}$, Pie Medical Inc. Maastricht, Holanda), previamente validado em estudos experimentais e clínicos ${ }^{62}$. Trata-se de um sistema que 
utiliza algoritmo matemático de detecção automática de bordos para a delimitação do contorno arterial. A calibração foi efetuada por meio do diâmetro externo do cateter angiográfico, sem contraste como padrão de referência. Considerou-se significativa a presença de obstrução $>50 \%$ do diâmetro luminal. Pacientes que apresentaram lesão significativa em apenas um território arterial foram considerados como uniarteriais e aquele com lesão em dois ou mais territórios arteriais, como multiarteriais.

\section{Análise estatística}

As variáveis classificatórias foram apresentadas em freqüências absolutas e relativas (\%). Sua associação foi avaliada por meio do teste quiquadrado ou do teste exato de Fisher. As variáveis quantitativas foram apresentadas descritivamente como média e desvio padrão. Os grupos foram comparados com o teste t-Student ou com o teste não paramétrico da soma de postos de Wilcoxon.

Construiu-se uma curva ROC (receiver operator characteristic) adotando-se vários cortes hipotéticos de probabilidade de reserva $\beta$ e $A x ß$, com as respectivas sensibilidades e especificidades. Pela construção da curva ROC, identificou-se o valor de corte utilizando-se os parâmetros $ß$ e $A x ß$, o qual representou o ponto de melhor performance do método para 
identificação de territórios arteriais com e sem lesão coronariana obstrutiva $>50 \%$. A partir do valor de corte, foram determinadas a sensibilidade, especificidade e acurácia da EPMTR sob estresse pela dobutamina e pela adenosina para detecção de pacientes e de territórios arteriais com lesão coronariana obstrutiva $>50 \%$. Os valores de sensibilidade, especificidade e acurácia foram calculados de forma padrão. Também se calculou a sensibilidade da EPMTR sob estresse pela dobutamina e adenosina para detecção de doença uniarterial e multiarterial.

Para a análise do fator adicional dos testes, foram criados quatro modelos acrescidos em ordem das seguintes variáveis: eletrocardiograma; eletrocardiograma e motilidade segmentar; eletrocardiograma, motilidade segmentar e análise qualitativa da perfusão miocárdica; e, finalmente, eletrocardiograma, motilidade segmentar, análise qualitativa da perfusão miocárdica e análise quantitativa da perfusão miocárdica. Calculou-se a probabilidade acrescida à cada variável no modelo estudado. Também se utilizou um modelo de regressão logística calculando-se o acréscimo de cada variável obtida pela EPMTR sob estresse pela dobutamina e pela adenosina.

Os valores de $p<0,05$ foram considerados estatisticamente significativos. 
Resultados 
Dos 73 pacientes inicialmente incluídos no estudo, 54 completaram o protocolo de EPMTR pela dobutamina e adenosina. Dentre os pacientes excluídos, um apresentou isquemia miocárdica acometendo grande extensão do ventrículo esquerdo durante o estresse pela adenosina, sendo, portanto, contra-indicada a realização do estresse pela dobutamina. Dezoito pacientes apresentaram EPMTR sob estresse pela dobutamina nãodiagnóstica para pesquisa de isquemia miocárdica devido à incompetência cronotrópica em seis casos e interrupção do teste por hipertensão arterial m 12 casos.

As características clínicas dos 54 pacientes que constituíram nossa população final de estudo estão descritas na Tabela 1. Todos os pacientes apresentavam função ventricular esquerda sistólica global e segmentar normal em repouso, com fração de ejeção média de $66 \pm 4 \%$. 
Tabela 1 - Características clínicas dos pacientes submetidos à ecocardiografia com perfusão miocárdica em tempo real, sob estresse pela dobutamina e pela adenosina.

\section{Característica Clínica}

Idade (anos)

Sexo masculino

Tabagismo

Hipercolesterolemia

Hipertensão arterial sistêmica

Diabetes melito

História familiar para DAC

Obesidade

Angina estável

Dor precordial atípica

Medicações em uso

Nitrato

Betabloqueador

Bloqueador de canal de cálcio

Aspirina

$$
60 \pm 9
$$

33 (61\%)

$11(20 \%)$

$37(68 \%)$

$46(85 \%)$

$17(31 \%)$

$17(31 \%)$

$16(30 \%)$

$33(61 \%)$

$21(39 \%)$

$21(39 \%)$

$37(68 \%)$

$6(11 \%)$

$43(80 \%)$

Valores expressos como média \pm desvio padrão ou número $(\%)$ de pacientes. $\mathrm{DAC}=$ doença arterial coronariana. 


\section{Angiografia Coronariana Quantitativa}

Do total de 54 pacientes estudados, 25 (46\%) apresentaram lesão coronariana $>50 \%$ em pelo menos um território arterial pela ACQ; 29 (54\%) pacientes não apresentaram lesão coronariana significativa. Dentre os 25 pacientes com DAC, 22 apresentaram lesão no território da ADA, 12 pacientes apresentaram lesão no território da CD e 11 pacientes apresentaram lesão no território da CX. Assim, 14 pacientes apresentaram lesão multiarterial e 11 uniarterial.

\section{Eletrocardiografia}

A análise eletrocardiográfica foi inconclusiva devido à presença de bloqueio de ramo esquerdo em cinco pacientes e sobrecarga ventricular esquerda em cinco pacientes. Portanto, a exeqüibilidade da análise do eletrocardiograma foi de $81 \%(44 / 54)$.

Durante o estresse pela dobutamina, o eletrocardiograma foi negativo

para isquemia em 26 pacientes e positivo em 18 pacientes. Durante o 
estresse pela adenosina, o eletrocardiograma foi negativo em 36 pacientes e positivo em oito pacientes.

Os resultados da sensibilidade, especificidade e acurácia do eletrocardiograma para o diagnóstico de DAC estão descritos na Tabela 2.

TABELA 2 - Parâmetros diagnósticos da avaliação eletrocardiográfica durante a ecocardiografia com perfusão miocárdica em tempo real, sob estresse pela dobutamina e pela adenosina, para detecção global de lesão obstrutiva $>50 \%$.

\begin{tabular}{lcc}
\hline & Dobutamina $(\mathbf{n}=44)$ & Adenosina $(\mathbf{n}=\mathbf{4 4})$ \\
\hline Sensibilidade & $9 / 17 ; 53 \%(29-77 \%)$ & $6 / 17 ; 35 \%(13-58 \%)$ \\
Especificidade & $18 / 27 ; 67 \%(49-84 \%)$ & $25 / 27 ; 93 \%(83-100 \%)$ \\
Acurácia & $27 / 44 ; 61 \%(47-76 \%)$ & $31 / 44 ; 70 \%(57-84 \%)$ \\
\hline
\end{tabular}

Valores expressos como número de pacientes e porcentagem, com respectivos intervalos de confiança de $95 \%$.

\section{EPMTR sob Estresse pela Dobutamina e pela Adenosina}

A dose média de dobutamina utilizada durante a EPMTR sob estresse pela dobutamina foi $30 \pm 6 \mu \mathrm{g} / \mathrm{kg} / \mathrm{min}$. A atropina foi administrada em 49 (91\%) pacientes, com uma dose média de 0,7 $\pm 0,5 \mathrm{mg}$. A porcentagem da freqüência cardíaca máxima atingida no pico do estresse foi de $89 \% \pm 7 \%$. A dose de adenosina utilizada em todos os pacientes foi $140 \mu \mathrm{g} / \mathrm{kg} / \mathrm{min}$. 
Nenhum paciente necessitou receber aminofilina após o estresse pela adenosina.

\section{Dados hemodinâmicos}

O comportamento hemodinâmico no estado basal, no pico do estresse e na recuperação, observado durante a EPMTR sob estresse pela dobutamina e pela adenosina, está demonstrado na Tabela 3. Não houve diferença significativa na freqüência cardíaca e pressão arterial em repouso entre os grupos. A EPMTR pela dobutamina resultou em maior aumento do duplo produto no pico do estresse que a EPMTR pela adenosina.

Os efeitos adversos observados durante ambos os testes estão descritos na Tabela 4. Cinco (9,3\%) pacientes apresentaram hipotensão arterial durante a infusão de adenosina e três (5,6\%) pacientes durante a infusão de dobutamina. A incidência de hipertensão arterial e extra-sístoles ventriculares foi maior durante o estresse pela dobutamina. Os exames foram bem tolerados e nenhum paciente apresentou complicações maiores relacionados com o estresse. 
Tabela 3 - Dados hemodinâmicos dos pacientes submetidos à ecocardiografia com perfusão miocárdica em tempo real, sob estresse pela dobutamina e pela adenosina.

\begin{tabular}{lccc}
\hline Variável & $\begin{array}{c}\text { Dobutamina } \\
(\mathbf{n}=\mathbf{5 4})\end{array}$ & $\begin{array}{c}\text { Adenosina } \\
(\mathbf{n}=\mathbf{5 4})\end{array}$ & $\mathbf{p}$ \\
\hline FC Basal (bpm) & $66 \pm 11$ & $69 \pm 12$ & 0,151 \\
PAS Basal (mmHg) & $132 \pm 21$ & $138 \pm 21$ & 0,127 \\
PAD Basal (mmHg) & $77 \pm 13$ & $81 \pm 12$ & 0,102 \\
DP Basal (mmHg/min) & $8795 \pm 2257$ & $9590 \pm 2205$ & 0,067 \\
FC Pico (bpm) & $142 \pm 15^{*}$ & $87 \pm 16^{*}$ & $<0,001$ \\
PAS Pico (mmHg) & $153 \pm 27^{*}$ & $128 \pm 19^{*}$ & $<0,001$ \\
PAD Pico (mmHg) & $77 \pm 17$ & $73 \pm 14^{*}$ & 0,133 \\
DP Pico (mmHg/min) & $21488 \pm 4299^{*}$ & $11212 \pm 2630^{*}$ & $<0,001$ \\
FC Recuperação (bpm) & $91 \pm 10^{*}$ & $76 \pm 12^{*}$ & $<0,001$ \\
PAS Recuperação (mmHg) & $123 \pm 21^{*}$ & $129 \pm 20^{*}$ & 0,168 \\
PAD Recuperação (mmHg) & $76 \pm 14$ & $74 \pm 12^{*}$ & 0,581 \\
\hline
\end{tabular}

Valores expressos em média e desvio padrão. $F C=$ freqüência cardíaca; PAS=pressão arterial sistólica; $\mathrm{PAD}=$ pressão arterial diastólica; $\mathrm{DP}=$ duplo produto. ${ }^{*} \mathrm{p}<0,05$ comparado com os respectivos parâmetros no estado basal. 
Tabela 4 - Efeitos adversos observados durante a ecocardiografia com perfusão miocárdica em tempo real, sob estresse pela dobutamina e pela adenosina.

\begin{tabular}{lcc}
\hline Variáveis & Dobutamina $(\mathbf{n}=\mathbf{5 4})$ & Adenosina $(\mathbf{n}=\mathbf{5 4})$ \\
\hline Arritmias & $16(29,6 \%)$ & $3(5,7 \%)^{*}$ \\
Extra-sístoles ventriculares & $3(5,6 \%)$ & $0(0 \%)$ \\
Extra-sístoles supraventriculares & $0(0 \%)$ & $1(1,8 \%)$ \\
$\quad$ Bloqueio atrioventricular & $20(37 \%)$ & $17(31,5 \%)$ \\
Dor precordial & $3(5,6 \%)$ & $5(9,3 \%)$ \\
Hipotensão & $5(9,3 \%)$ & $0(0 \%)^{*}$ \\
Hipertensão & & \\
\hline
\end{tabular}

Valores expressos como número (\%) de pacientes. ${ }^{*} p<0,05$ entre os grupos.

\section{Exeqüibilidade}

A análise da motilidade segmentar foi realizada em todos os territórios arteriais dos 54 pacientes estudados (exeqüibilidade de 100\%). A análise qualitativa da perfusão miocárdica foi realizada em 147 dos 162 territórios arteriais, durante o estresse pela dobutamina (exeqüibilidade de $91 \%$ ), e em 149 territórios arteriais, durante o estresse pela adenosina (exeqüibilidade de 92\%). A quantificação do fluxo miocárdico foi realizada em 146 territórios arteriais, durante o estresse pela dobutamina (exeqüibilidade de $90 \%$ ) e em 147 territórios arteriais, durante o estresse pela adenosina (exeqüibilidade de $91 \%)$. 


\section{Acurácia diagnóstica da análise qualitativa}

Pela análise qualitativa da motilidade miocárdica foram detectadas novas alterações da motilidade segmentar em 22 pacientes durante a ecocardiografia sob estresse pela dobutamina e em 15 pacientes durante a ecocardiografia sob estresse pela adenosina. Os parâmetros diagnósticos obtidos pela análise qualitativa da motilidade segmentar estão na Tabela 5.

Tabela 5 - Parâmetros diagnósticos da motilidade miocárdica obtidos pela ecocardiografia com perfusão miocárdica em tempo real, sob estresse pela dobutamina e pela adenosina, para detecção global de lesão obstrutiva $>50 \%$.

\begin{tabular}{lll}
\hline & Dobutamina $(\mathbf{n}=\mathbf{5 4})$ & Adenosina $(\mathbf{n}=\mathbf{5 4})$ \\
\hline Sensibilidade & $17 / 25 ; 68 \%(50-86 \%)$ & $12 / 25 ; 48 \%(28-68 \%)$ \\
Especificidade & $24 / 29 ; 83 \%(69-96 \%)$ & $26 / 29 ; 90 \%(79-100 \%)$ \\
Acurácia & $41 / 54 ; 76 \%(64-87 \%)$ & $38 / 54 ; 70 \%(58-82 \%)$ \\
\hline
\end{tabular}

Valores expressos como número de pacientes e porcentagem, com respectivos intervalos de confiança de $95 \%$.

Pela análise qualitativa da perfusão miocárdica, foram detectados defeitos de perfusão miocárdica em 22 pacientes, durante a ecocardiografia sob estresse pela dobutamina, e em 18 pacientes, durante a ecocardiografia sob estresse pela adenosina. Os parâmetros diagnósticos obtidos pela análise qualitativa da perufsão miocárdica estão descritos na Tabela 6. 
Tabela 6 - Parâmetros diagnósticos da avaliação qualitativa da perfusão miocárdica na ecocardiografia com perfusão miocárdica em tempo real, sob estresse pela dobutamina e pela adenosina, para detecção global de lesão obstrutiva $>50 \%$.

\begin{tabular}{lll}
\hline & Dobutamina $(\mathbf{n}=\mathbf{5 4})$ & Adenosina $(\mathbf{n}=\mathbf{5 4})$ \\
\hline Sensibilidade & $17 / 25 ; 68 \%(50-86 \%)$ & $15 / 25 ; 60 \%(41-79 \%)$ \\
Especificidade & $24 / 29 ; 83 \%(69-96 \%)$ & $26 / 29 ; 90 \%(79-100 \%)$ \\
Acurácia & $41 / 54 ; 76 \%(64-87 \%)$ & $41 / 54 ; 76 \%(64-87 \%)$ \\
\hline
\end{tabular}

Valores expressos como número de pacientes e porcentagem, com respectivos intervalos de confiança de $95 \%$.

\section{Análise Quantitativa do Fluxo Sangüíneo Miocárdico}

A variabilidade interobservador para a medida da reserva $B$ foi de $6,8 \%(r=0,98)$ e para a medida da reserva $A x ß$ foi de $5,5 \%(r=0,97)$. A variabilidade intra-observador para a medida da reserva $\beta$ foi de $2,1 \%$ ( $r=$ $0,99)$ enquanto que para a medida da reserva $A x ß$ foi de $7,4 \%(r=0,95)$.

Os parâmetros $\beta$ e AXß foram quantificados no estado de repouso e durante $\mathrm{o}$ pico de estresse pela dobutamina e adenosina a fim de se determinar a reserva de velocidade de fluxo (reserva $ß$ ) e a reserva de fluxo sangüíneo miocárdico (reserva $A X ß)$. Do total de 162 territórios arteriais analisados, 44 apresentavam lesão coronariana obstrutiva $>50 \%$ e 118 não apresentavam lesão significativa. A quantificação do fluxo sangüíneo miocárdico foi realizada em 41 dos 44 territórios com lesão >50\% e em 104 dos 118 territórios sem lesão, durante o estresse pela dobutamina. Por outro lado, a quantificação do fluxo sangüíneo miocárdico foi realizada em 42 dos 
44 territórios com lesão $>50 \%$ e em 106 dos 118 territórios sem lesão, durante o estresse pela adenosina.

Os resultados das reservas, obtidos pelos parâmetros quantitativos $\beta$ e Axß nos territórios com e sem lesão angiograficamente significativa, estão descritos nas Tabelas 7 e 8 .

Tabela 7 - Parâmetros de medidas quantitativas obtidas pela ecocardiografia com perfusão miocárdica em tempo real, sob estresse pela dobutamina, nos territórios arteriais com e sem lesão angiograficamente significativa.

\begin{tabular}{lccc}
\hline Variável & $\begin{array}{c}\text { Territórios com } \\
\text { lesão }>\mathbf{5 0 \%} \\
(\mathbf{n}=\mathbf{4 1})\end{array}$ & $\begin{array}{c}\text { Territórios sem } \\
\text { lesão significativa } \\
(\mathbf{n}=\mathbf{1 0 4})\end{array}$ & $\mathbf{p}$ \\
\hline ß basal (1/s) & $0,48 \pm 0,07$ & $0,47 \pm 0,07$ & 0,362 \\
ß pico (1/s) & $0,80 \pm 0,39^{*}$ & $1,17 \pm 0,47^{*}$ & $<0,001$ \\
Reserva $ß(1 / \mathrm{s})$ & $1,67 \pm 0,77$ & $2,63 \pm 1,11$ & $<0,001$ \\
Axß basal (dB/s) & $2,53 \pm 1,53$ & $2,47 \pm 0,96$ & 0,781 \\
Axß pico (dB/s) & $5,34 \pm 3,53^{*}$ & $6,95 \pm 3,94^{*}$ & 0,021 \\
Reserva Axß (dB/s) & $2,42 \pm 1,40$ & $3,24 \pm 1,54$ & 0,003 \\
\hline
\end{tabular}

Valores expressos como média e desvio padrão. $ß=$ velocidade do fluxo sangüíneo miocárdico; $A x ß=$ fluxo sangüíneo miocárdico. * $p<0,05$ comparado com os respectivos parâmetros no estado basal. 
Tabela 8 - Parâmetros de medidas quantitativas obtidas pela ecocardiografia com perfusão miocárdica em tempo real, sob estresse pela adenosina, nos territórios arteriais com lesão $>50 \%$ e sem lesão significativa.

\begin{tabular}{lccc}
\hline Variável & $\begin{array}{c}\text { Território com } \\
\text { Lesão }>\mathbf{5 0 \%} \\
(\mathbf{n}=\mathbf{4 2})\end{array}$ & $\begin{array}{c}\text { Território sem lesão } \\
\text { significativa } \\
(\mathbf{n}=\mathbf{1 0 6})\end{array}$ & $\mathbf{p}$ \\
\hline ß basal (1/s) & $0,47 \pm 0,11$ & $0,46 \pm 0,08$ & 0,339 \\
ß pico (1/s) & $0,83 \pm 0,40^{*}$ & $1,10 \pm 0,47^{*}$ & 0,001 \\
Reserva ß (1/s) & $1,72 \pm 0,78$ & $2,48 \pm 1,09$ & $<0,001$ \\
Axß basal (dB/s) & $2,61 \pm 1,08$ & $2,37 \pm 0,99$ & 0,192 \\
Axß pico (dB/s) & $5,11 \pm 3,24^{*}$ & $6,22 \pm 2,88^{*}$ & 0,044 \\
Reserva Axß (dB/s) & $2,01 \pm 1,01$ & $2,81 \pm 1,56$ & 0,002 \\
\hline
\end{tabular}

Valores expressos como média e desvio padrão. $ß=$ velocidade do fluxo sangüíneo miocárdico; $A x ß=$ fluxo sangüíneo miocárdico. * $p<0,05$ comparado com os respectivos parâmetros no estado basal.

Ambas a reserva de velocidade de fluxo (ß) e reserva de fluxo sangüíneo miocárdico (reserva $A x ß)$ foram menores nos territórios arteriais com lesão $>50 \%$ que nos territórios arteriais sem lesão significativa, durante a EPMTR sob estresse pela dobutamina e pela adenosina (Figuras 7 e 8). 


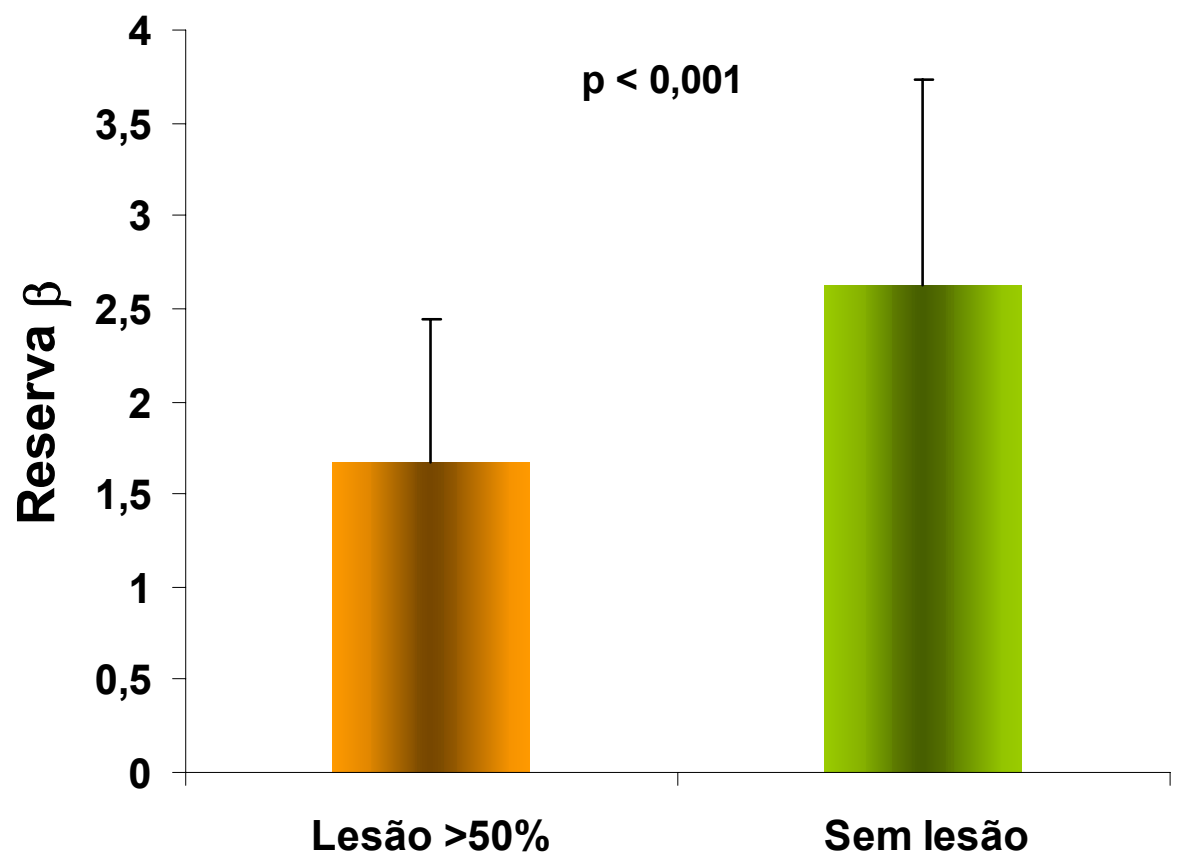

Figura 7 - Reserva de velocidade de fluxo (ß) nos territórios arteriais com lesão $>50 \%$ e sem lesão significativa obtidos pela ecocardiografia com perfusão miocárdica em tempo real, sob estresse pela dobutamina.

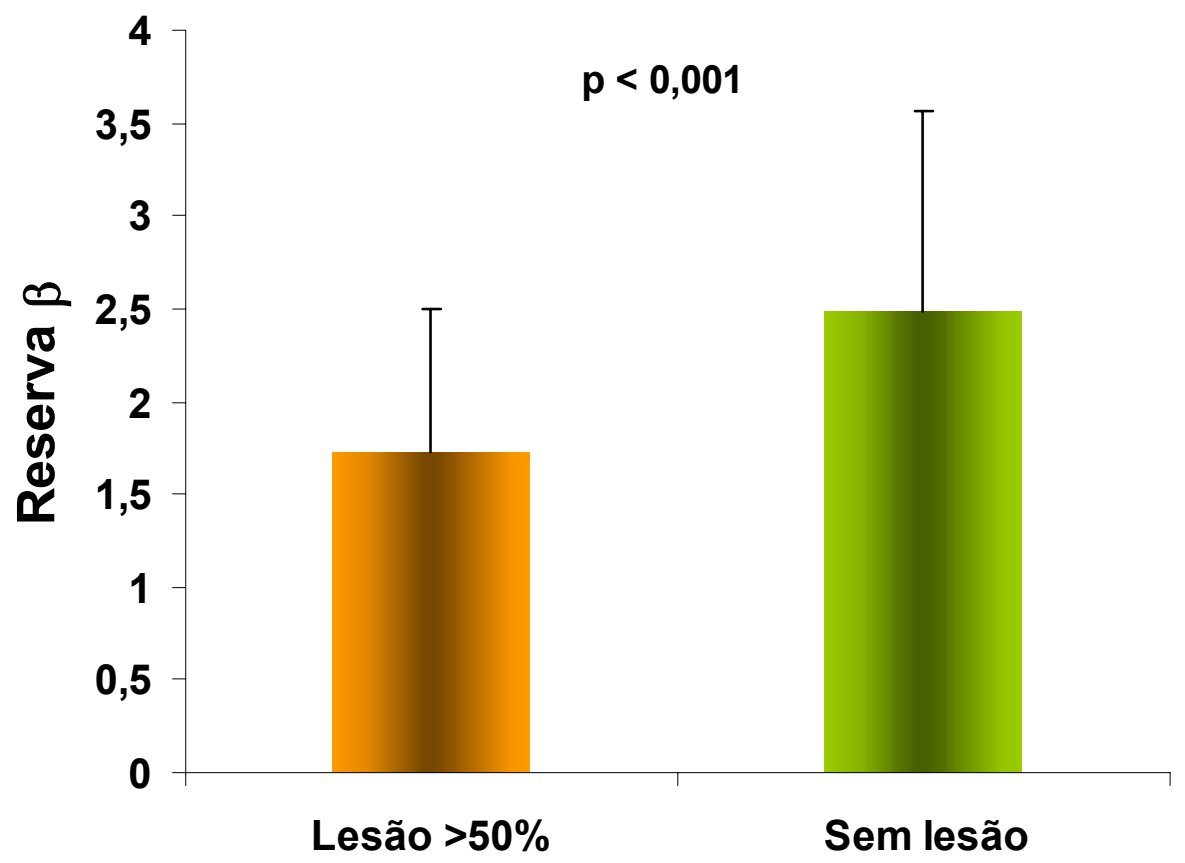

Figura 8 - Reserva de velocidade de fluxo (ß) nos territórios arteriais com lesão $>50 \%$ e sem lesão significativa obtidos pela ecocardiografia com perfusão miocárdica em tempo real, sob estresse pela adenosina. 


\section{Parâmetros diagnósticos para deteccão de DAC}

Pela construção da curva ROC, demonstrou-se que o melhor valor de corte da reserva $ß$, obtida pela EPMTR pela dobutamina para diferenciar os territórios com e sem lesão $>50 \%$ foi de 2,0 , enquanto que, para a reserva Axß, o melhor valor de corte foi de 2,6 (Figura 9).

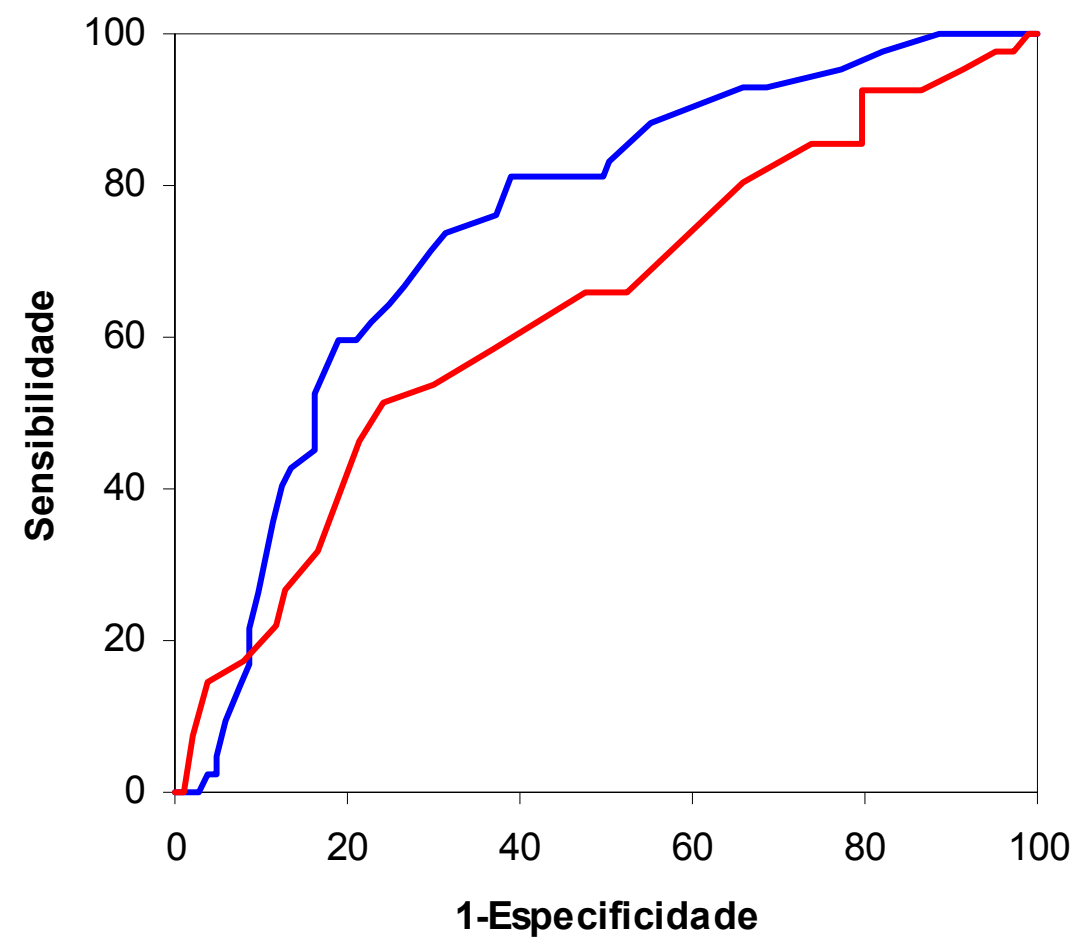

Dobutamina - reserva B Dobutamina- reserva AxB

Figura 9 - Curva ROC realizada para a determinação do melhor valor de corte da reserva da velocidade de fluxo miocárdico ( $($ ) e reserva do fluxo miocárdico (Axß) para a presença de DAC, utilizando-se a ecocardiografia com perfusão miocárdica em tempo real, sob estresse pela dobutamina. 
Pela construção da curva ROC, demonstrou-se que o melhor valor de corte da reserva $ß$, obtida pela EPMTR pela adenosina para diferenciar os territórios com e sem lesão $>50 \%$ foi de 2,0 , enquanto que, para a reserva Axß, o melhor valor de corte foi de 2,2 (Figura 10).

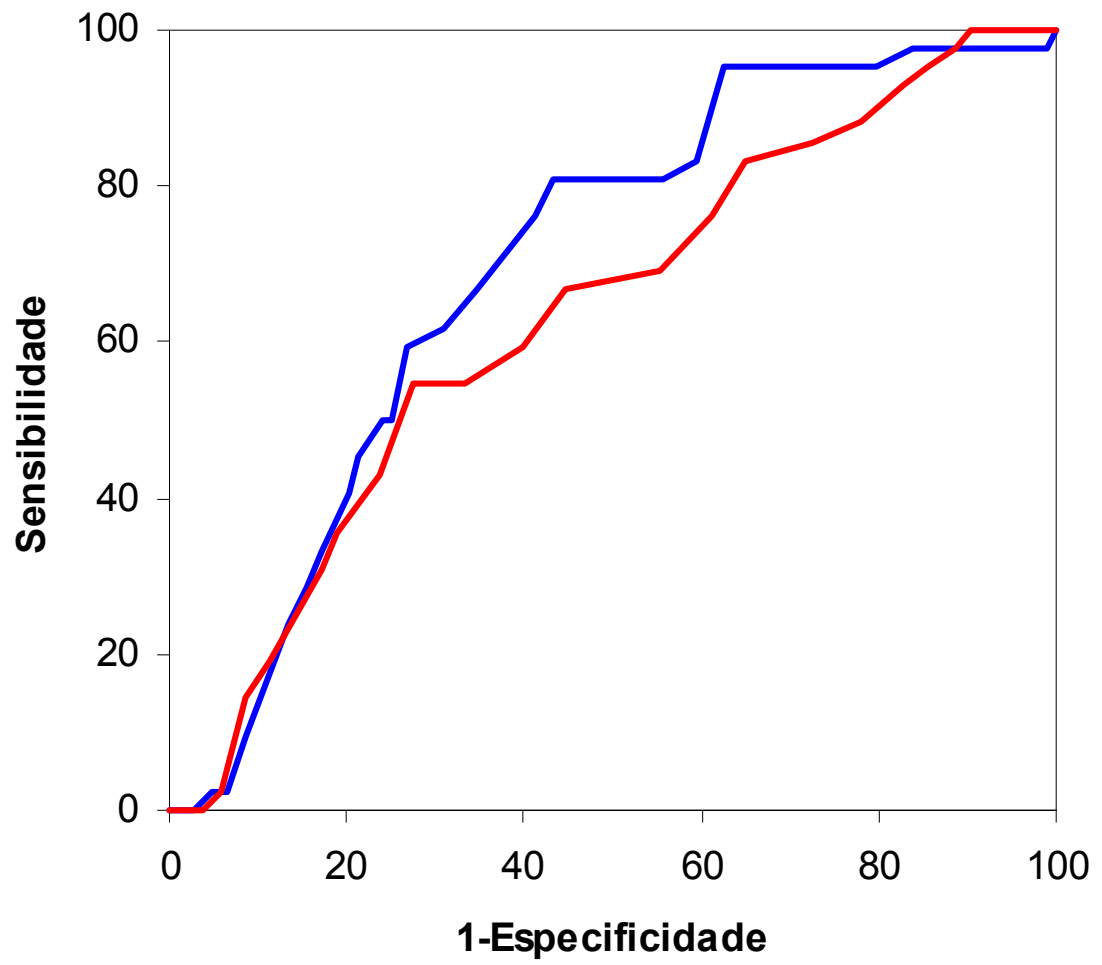

—Adenosina - reserva B —Adenosina - reserva AxB

Figura 10 - Curva ROC realizada para a determinação do melhor valor de corte da reserva da velocidade de fluxo miocárdico ( $($ ) e reserva do fluxo miocárdico (Axß) para a presença de DAC, utilizando-se a ecocardiografia com perfusão miocárdica em tempo real, sob estresse pela adenosina.

Com base nesses valores de corte, a sensibilidade, especificidade e acurácia da EPMTR, sob estresse pela dobutamina e pela adenosina para detecção global de obstrução coronariana $>50 \%$, estão descritos na Tabela 9. 
Tabela 9 - Parâmetros diagnósticos da ecocardiografia com perfusão miocárdica em tempo real, sob estresse pela dobutamina e pela adenosina, para detecção de pacientes com e sem lesão angiograficamente significativa.

\begin{tabular}{lcccc}
\hline & \multicolumn{2}{c}{ Reserva B } & \multicolumn{2}{c}{ Reserva Axß } \\
& Dobutamina & Adenosina & Dobutamina & Adenosina \\
\hline Sensibilidade & $21 / 25 ; 84 \%$ & $22 / 25 ; 88 \%$ & $23 / 25 ; 92 \%$ & $22 / 25 ; 88 \%$ \\
& $(70-98 \%)$ & $(75-100 \%)$ & $(81-100 \%)$ & $(75-100 \%)$ \\
Especificidade & $22 / 29 ; 76 \%$ & $21 / 29 ; 72 \%$ & $19 / 29 ; 65 \%$ & $12 / 29 ; 41 \%$ \\
& $(60-91 \%)$ & $(56-89 \%)$ & $(48-83 \%)$ & $(23-59 \%)$ \\
Acurácia & $43 / 54 ; 80 \%$ & $43 / 54 ; 80 \%$ & $42 / 54 ; 78 \%$ & $34 / 54 ; 63 \%$ \\
& $(69-90 \%)$ & $(69-90 \%)$ & $(67-89 \%)$ & $(50-76 \%)$ \\
\hline
\end{tabular}

Valores expressos como porcentagem, com respectivos intervalos de confiança de $95 \%$.

Não houve diferença nos parâmetros diagnósticos entre a dobutamina e adenosina, considerando-se a reserva ß. Entretanto, a acurácia diagnóstica da reserva $A \times ß$, obtida pela EPMTR sob estresse pela dobutamina, foi maior que pela adenosina. (Figura 11). 


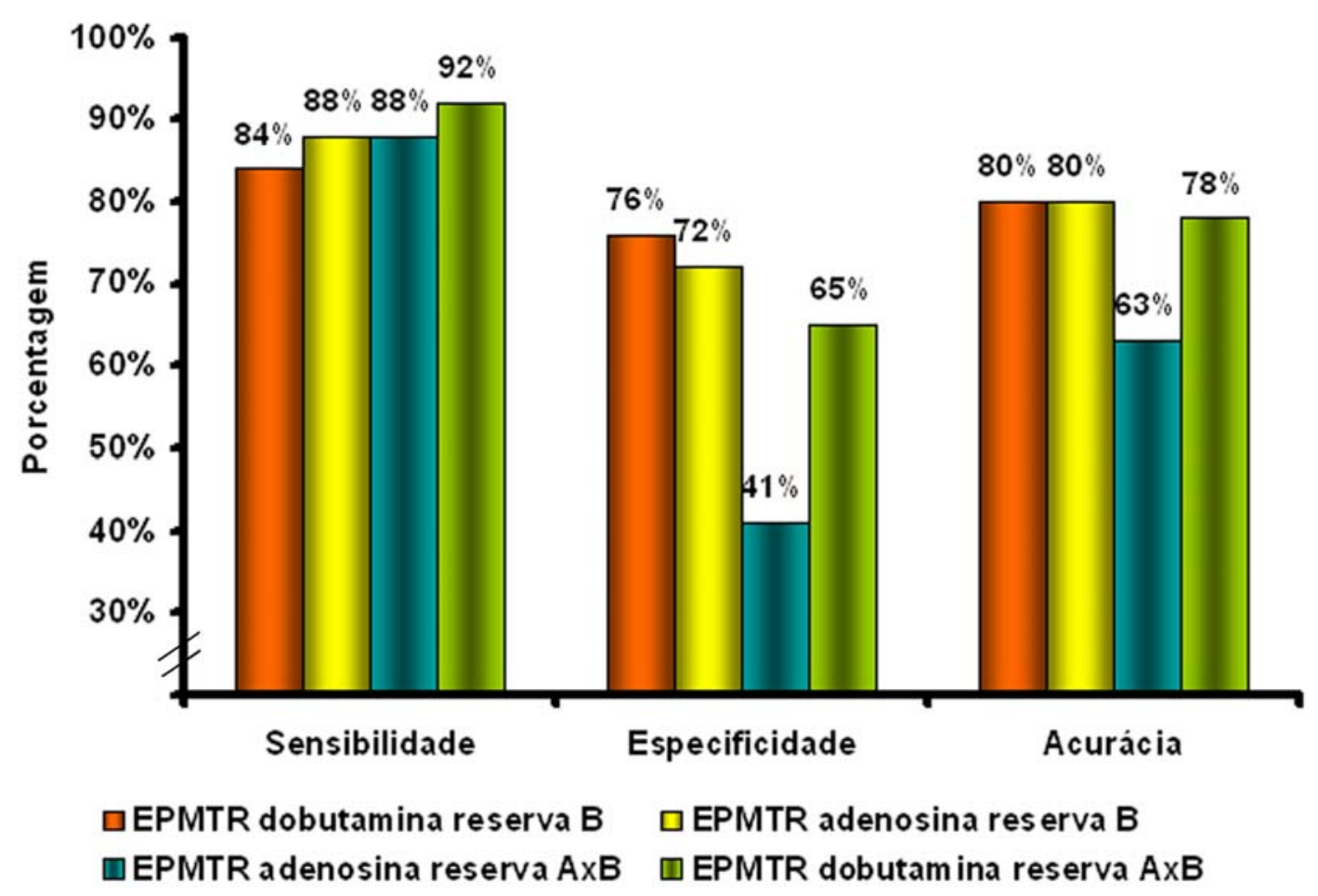

Figura 11 - Comparação dos parâmetros diagnósticos de sensibilidade, especificidade e acurácia da ecocardiografia com perfusão miocárdica em tempo real, sob estresse pela dobutamina e pela adenosina, para detecção de pacientes com lesão angiograficamente significativa.

Comparação da acurácia diagnóstica entre as variáveis obtidas durante a EPMTR, sob estresse pela dobutamina e pela adenosina

Devido ao seu melhor desempenho diagnóstico, o parâmetro ß foi utilizado como variável quantitativa em comparação com ECG e outras variáveis ecocardiográficas qualitativas.

A Figura 12 demonstra os parâmetros diagnósticos do eletrocardiograma em 12 derivações, da motilidade segmentar, da perfusão 
qualitativa e da perfusão quantitativa, obtidos durante a EPMTR pela dobutamina.

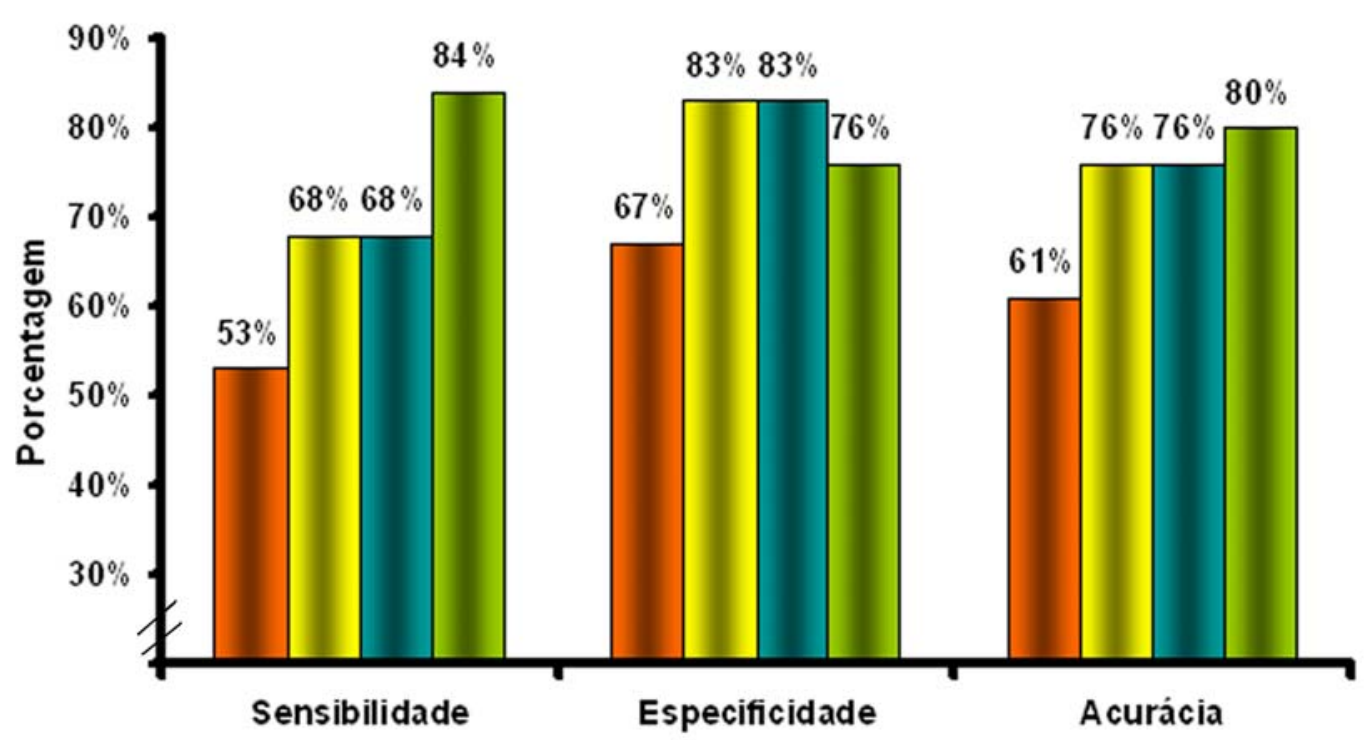

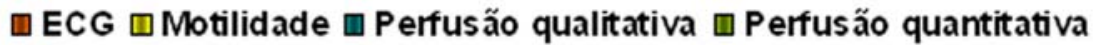

Figura 12 - Parâmetros diagnósticos de sensibilidade, especificidade e acurácia para detecção de pacientes com lesão angiograficamente significativa, baseados nas análises do eletrocardiograma em 12 derivações (ECG), motilidade segmentar, perfusão qualitativa e perfusão quantitativa, obtidas pela ecocardiografia com perfusão miocárdica em tempo real, sob estresse pela dobutamina.

A análise quantitativa da perfusão miocárdica foi a variável que apresentou maior sensibilidade e acurácia para a detecção de pacientes com DAC, embora tenha apresentado menor especificidade que a análise qualitativa da motilidade e perfusão miocárdicas. O eletrocardiograma em 12 derivações apresentou baixa sensibilidade, especificidade e acurácia diagnósticas. Não houve diferença entre os parâmetros diagnósticos da análise qualitativa da motilidade e perfusão miocárdicas. 
A Figura 13 demonstra os parâmetros diagnósticos do eletrocardiograma em 12 derivações, da motilidade segmentar, da perfusão qualitativa e da perfusão quantitativa, obtidos durante a EPMTR pela adenosina.

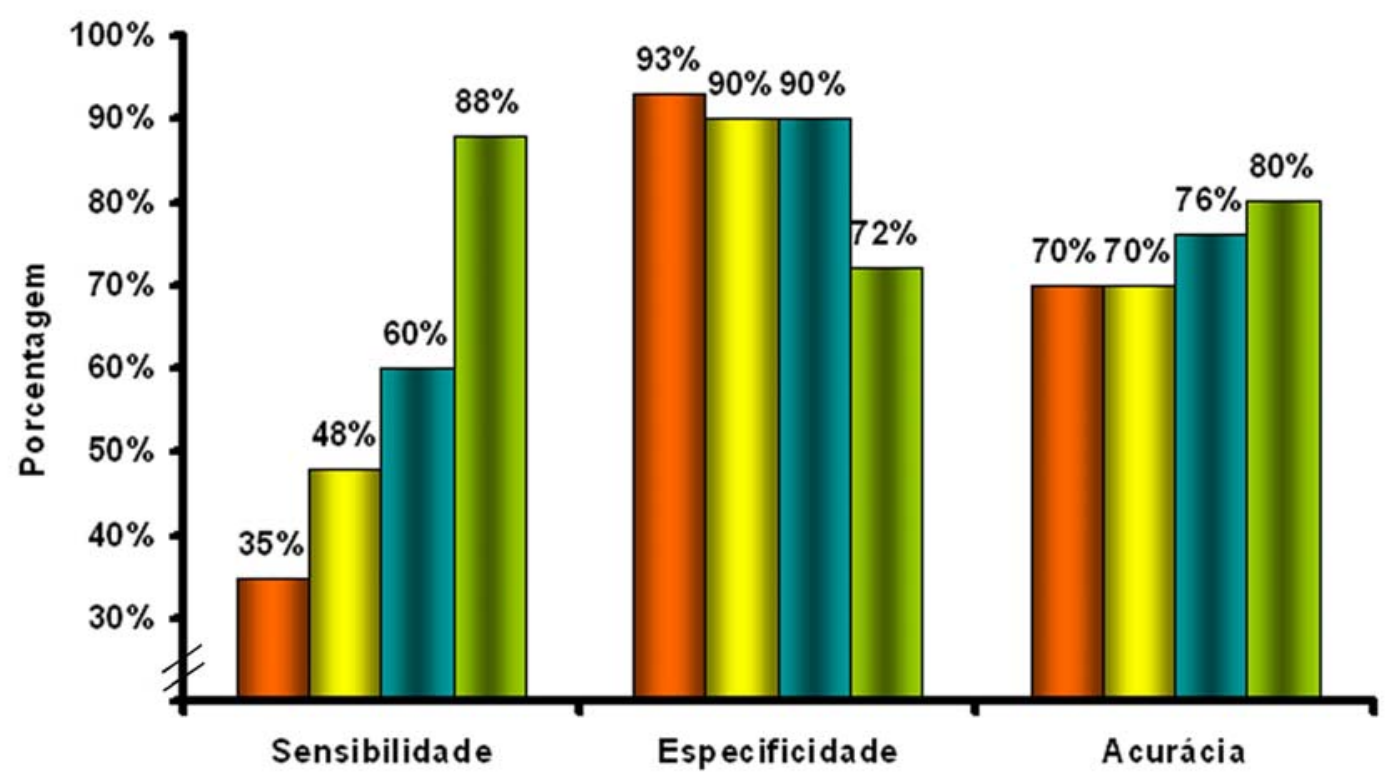

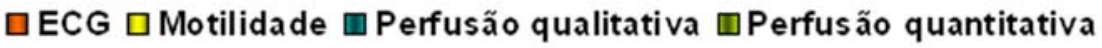

Figura 13 - Parâmetros diagnósticos de sensibilidade, especificidade e acurácia para detecção de doença arterial coronariana, baseados nas análises do eletrocardiograma em 12 derivações (ECG), motilidade segmentar, perfusão qualitativa e perfusão quantitativa, obtidas pela ecocardiografia com perfusão miocárdica em tempo real, sob estresse pela adenosina.

A análise quantitativa da perfusão miocárdica foi a variável que apresentou maior sensibilidade e acurácia diagnósticas para a detecção de DAC. O eletrocardiograma em 12 derivações apresentou baixa sensibilidade; porém, alta especificidade. A análise qualitativa da perfusão miocárdica 
apresentou maior sensibilidade que a análise da motilidade segmentar, mantendo especificidade semelhante.

A Figura 14 mostra um exemplo de imagem obtida pela EPMTR em um paciente de 35 anos, com hipercolesterolemia e obesidade e com sintomas de angina estável. O paciente apresentava motilidade segmentar e perfusão miocárdica normais em repouso, sendo observada hipocinesia e defeito de perfusão miocárdica na região apical do ventrículo esquerdo durante o estresse pela adenosina (Figura 14, painel superior). Durante o pico do estresse pela dobutamina, observaram-se discinesia apical e defeito de perfusão miocárdica em região apical e lateral do ventrículo esquerdo (Figura 14, painel superior). O eletrocardiograma em 12 derivações foi negativo para isquemia miocárdica (Figura 14, painel inferior). A análise quantitativa da perfusão miocárdica revelou diminuição da reserva coronariana, no território da ADA durante o estresse pela dobutamina (reserva $\beta=1,24$ e reserva $A x ß=2,05$ ) e durante o estresse pela adenosina (reserva $\beta=1,62$ e reserva $A x ß=2,15$ ) (Figura 15). $A$ angiografia coronariana confirmou lesão significativa (suboclusiva) na ADA (Figura 16). 

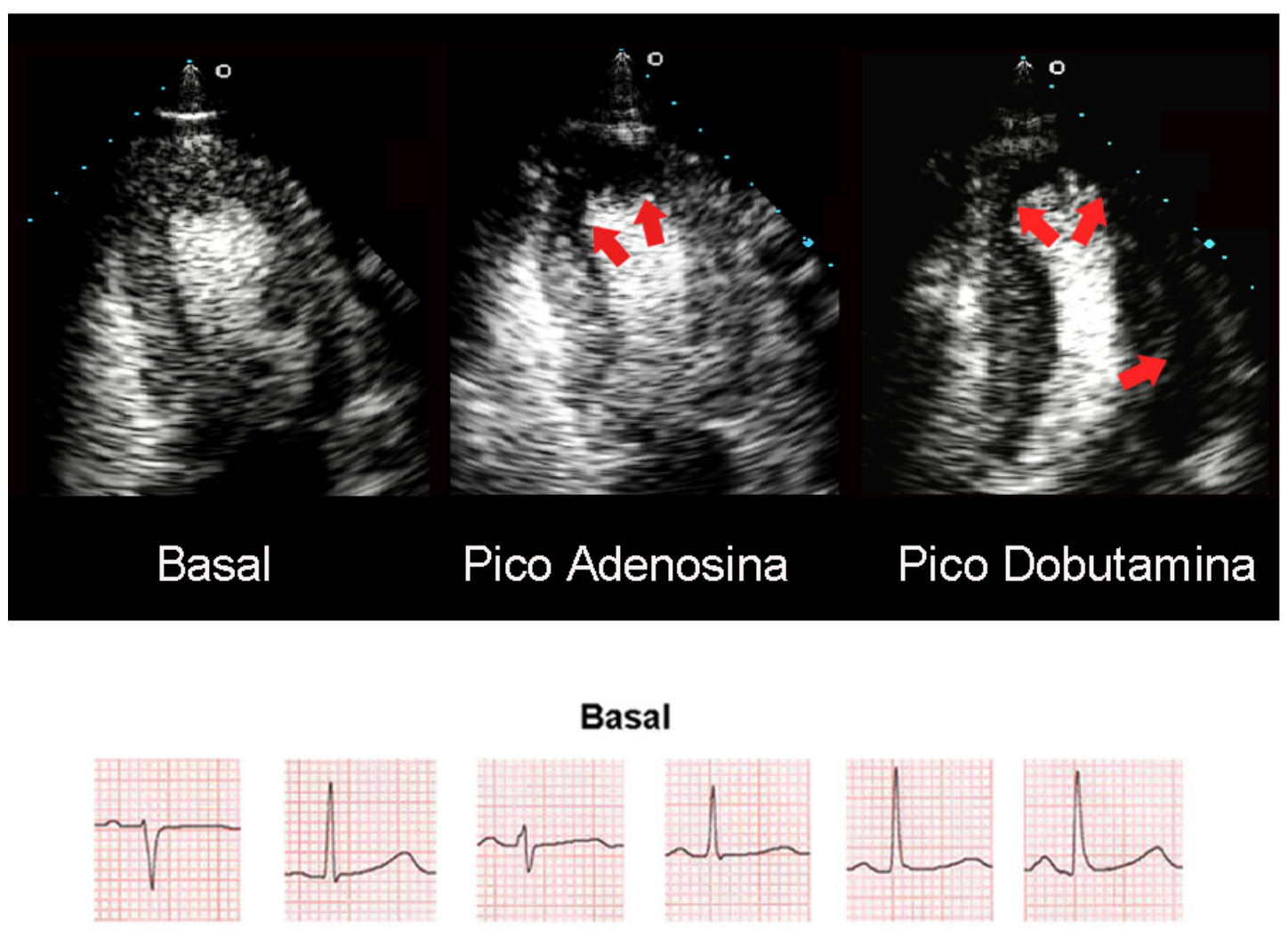

Pico do Estresse pela Adenosina
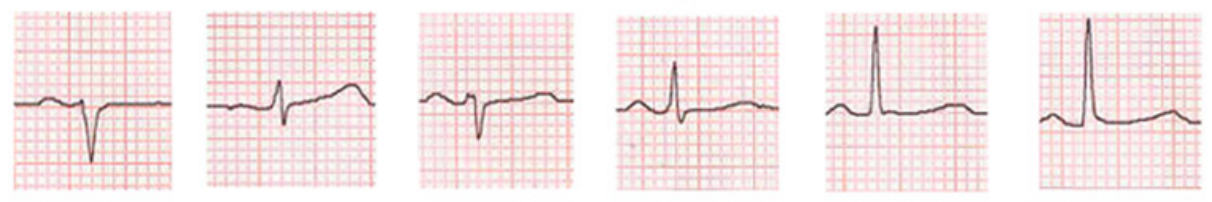

Pico do Estresse pela Dobutamina

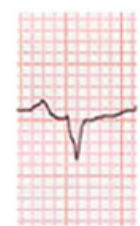

V1

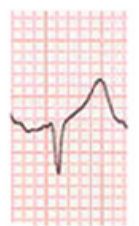

V2

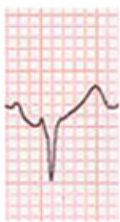

V3

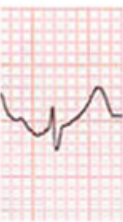

V4

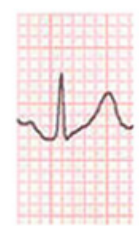

V5

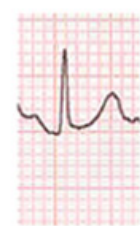

V6

Figura 14 - No painel superior, apresentam-se, como exemplos, imagens em plano apical de quatro câmaras obtidas pela ecocardiografia com perfusão miocárdica em tempo real, mostrando perfusão miocárdica normal no estado basal (imagem à esquerda), nítido defeito de perfusão miocárdica na região apical durante o estresse pela adenosina (imagem do meio, setas) e discinesia apical com defeito de perfusão em toda a região apical e parede lateral do ventrículo esquerdo (imagem à direita, setas), com estudo pela dobutamina. $O$ eletrocardiograma foi negativo para isquemia miocárdica durante o estresse pela adenosina e pela dobutamina (painel inferior). 

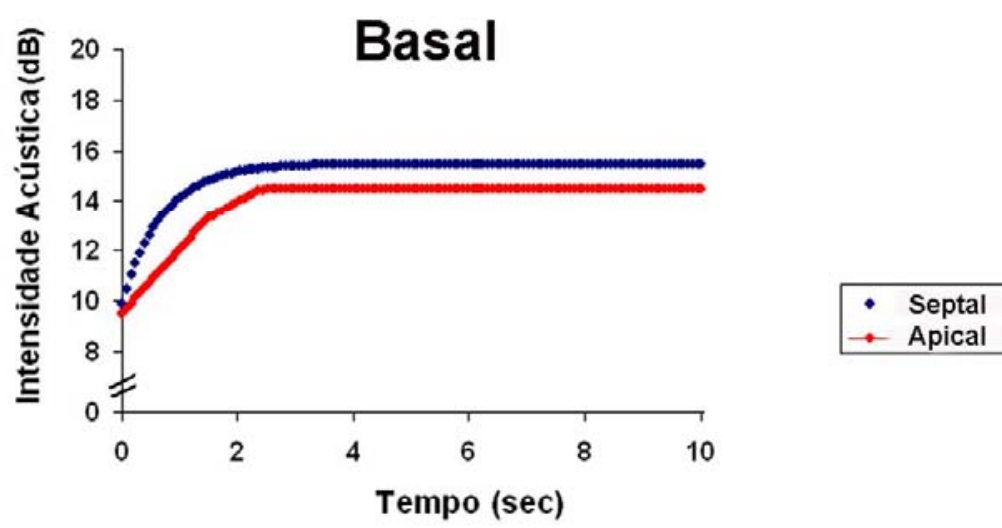

Adenosina
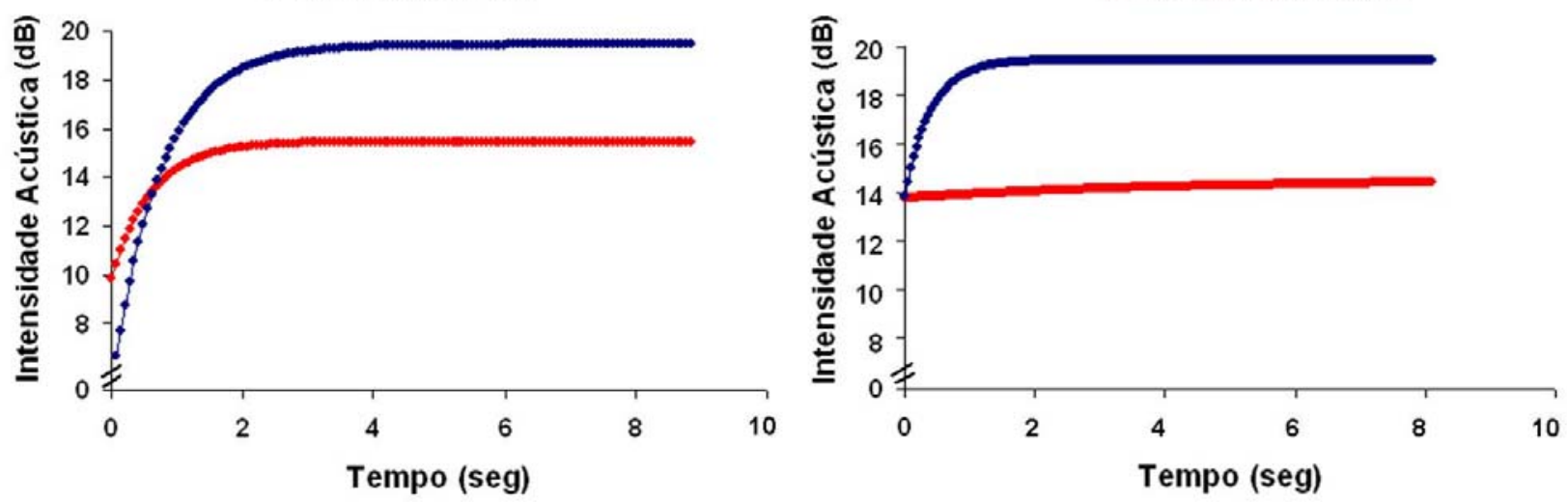

Figura 15 - Curvas de quantificação acústica obtidas a partir das imagens do paciente da Figura 14, na região basal do septo com perfusão miocárdica normal (azul) e na região apical com defeito de perfusão miocárdica (vermelho) no estado basal (painel superior), durante o estresse pela adenosina (painel inferior à esquerda) e durante o estresse pela dobutamina (painel inferior à direita). 


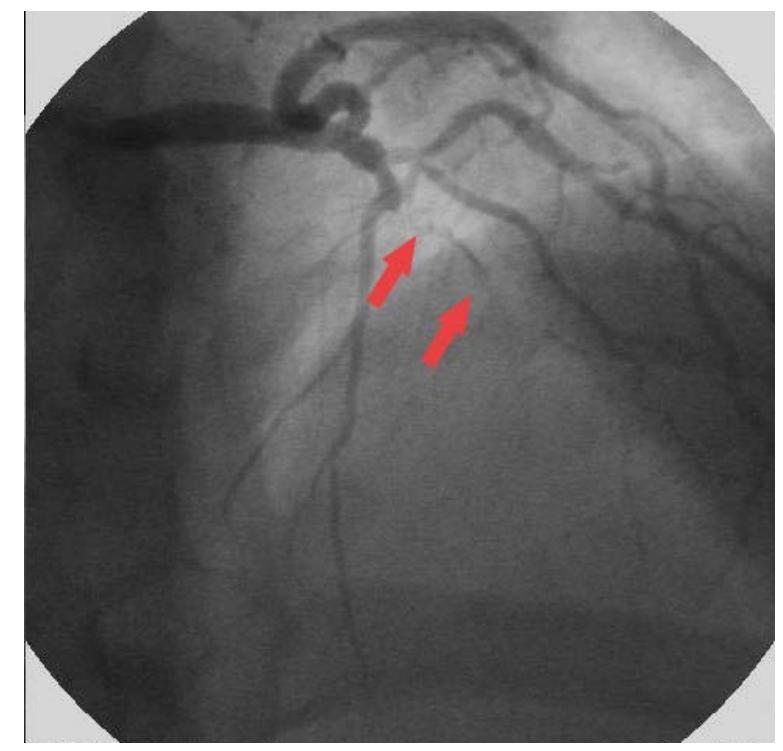

Figura 16 - Angiografia coronariana do paciente das figuras 14 e 15, demonstrando lesão significativa (suboclusiva) na artéria coronária descendente anterior (setas).

\section{Valor adicional da EPMTR para a detecção de DAC}

A Figura 17 ilustra o valor adicional dos parâmetros obtidos pela EPMTR sob estresse pela dobutamina. Comparada ao eletrocardiograma em 12 derivações ( $\chi^{2}$ de 4,9), a análise da motilidade segmentar $\left(\chi^{2}\right.$ de 20,1) acrescentou valor diagnóstico para a detecção de DAC. A análise qualitativa da perfusão miocárdica ( $\chi^{2}$ de 23,7$)$ não acrescentou valor diagnóstico à associação do eletrocardiograma e motilidade segmentar. Por outro lado, com a análise quantitativa da perfusão miocárdica pela reserva $ß$, houve um aumento significativo no valor diagnóstico para a detecção de DAC $\left(\chi^{2}\right.$ de $38,4)$. 


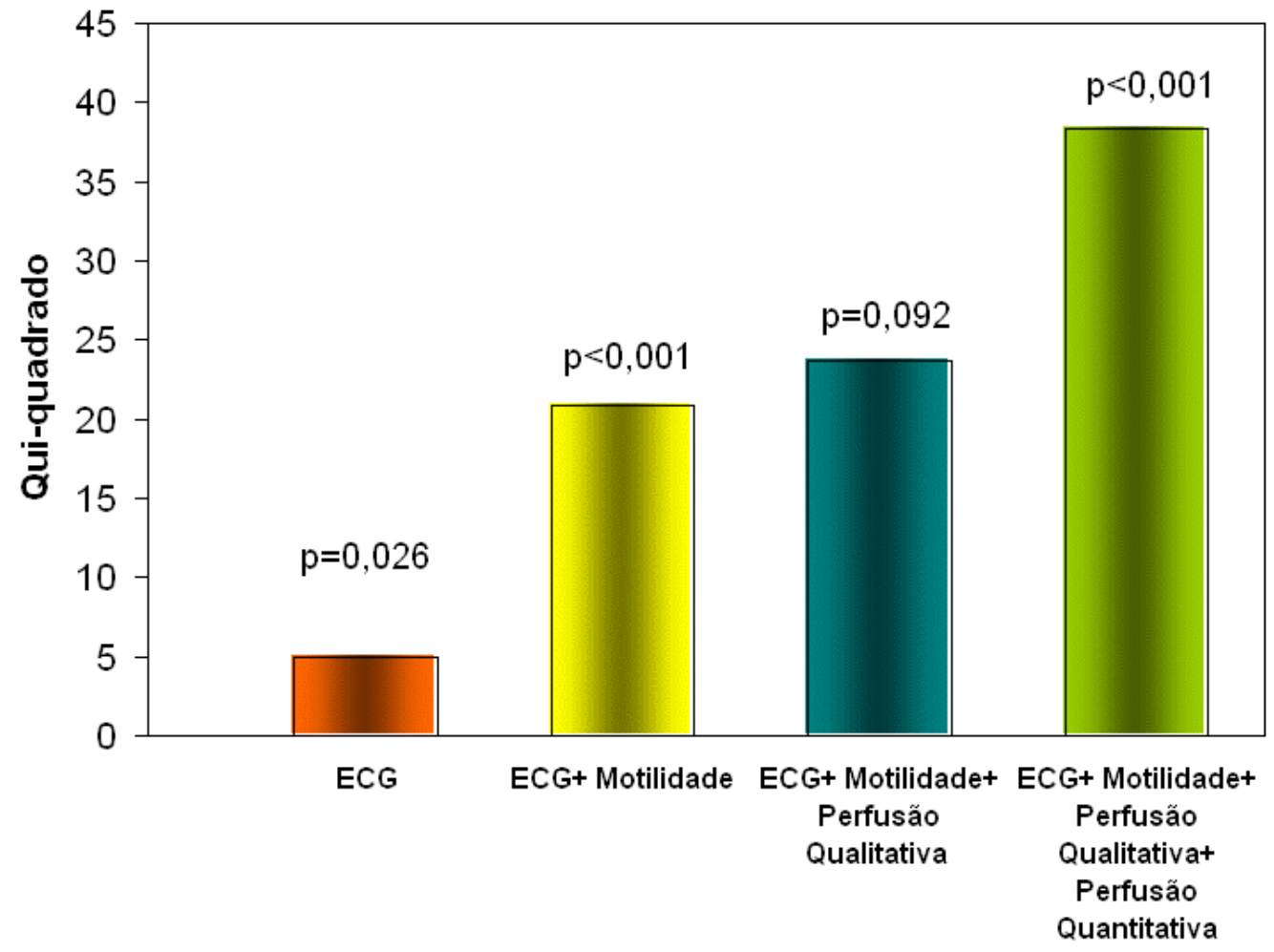

Figura 17 - Valor adicional dos diferentes parâmetros obtidos pela ecocardiografia com perfusão miocárdica em tempo real, sob estresse pela dobutamina. ECG = eletrocardiograma em 12 derivações.

A Figura 18 ilustra o valor incremental dos parâmetros obtidos pela EPMTR sob estresse pela adenosina. Comparada ao eletrocardiograma em 12 derivações ( $\chi^{2}$ de 9,9$)$, a análise da motilidade segmentar $\left(\chi^{2}\right.$ de 20,1$)$ acrescentou valor diagnóstico para a detecção de DAC, a análise qualitativa da perfusão miocárdica $\left(\chi^{2}\right.$ de 26,7$)$ acrescentou valor diagnóstico à associação do eletrocardiograma e motilidade segmentar e, finalmente, a análise quantitativa da perfusão miocárdica pela reserva $ß$ aumentou, significativamente, o valor diagnóstico para a detecção de DAC ( $\chi^{2}$ de 59,4). 


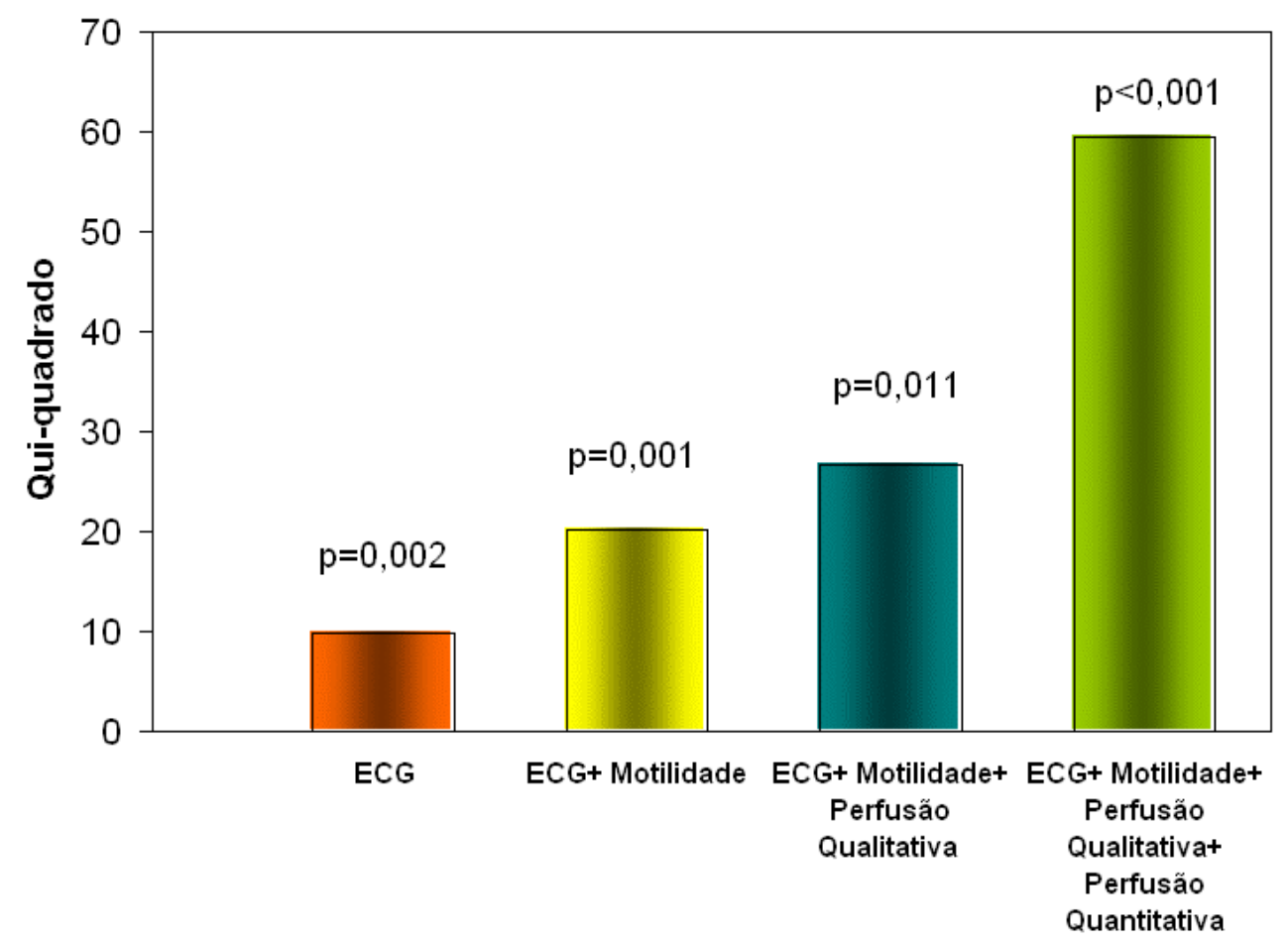

Figura 18 - Valor adicional dos diferentes parâmetros obtidos pela ecocardiografia com perfusão miocárdica em tempo real, sob estresse pela adenosina. ECG = eletrocardiograma em 12 derivações.

Acurácia diagnóstica da EPMTR para a detecção de doença uniarterial e multiarterial

Dentre os 25 pacientes com DAC, 11 apresentavam lesão >50\% em apenas um território arterial, enquanto 14 apresentavam lesão em mais de um território arterial. A análise quantitativa da perfusão miocárdica, obtida pela EPMTR sob estresse pela dobutamina (Figura 19) e pela adenosina (Figura 20) apresentou maior sensibilidade para o diagnóstico de pacientes 
com DAC uniarterial, quando comparada ao eletrocardiograma, motilidade segmentar, e análise qualitativa da perfusão miocárdica.

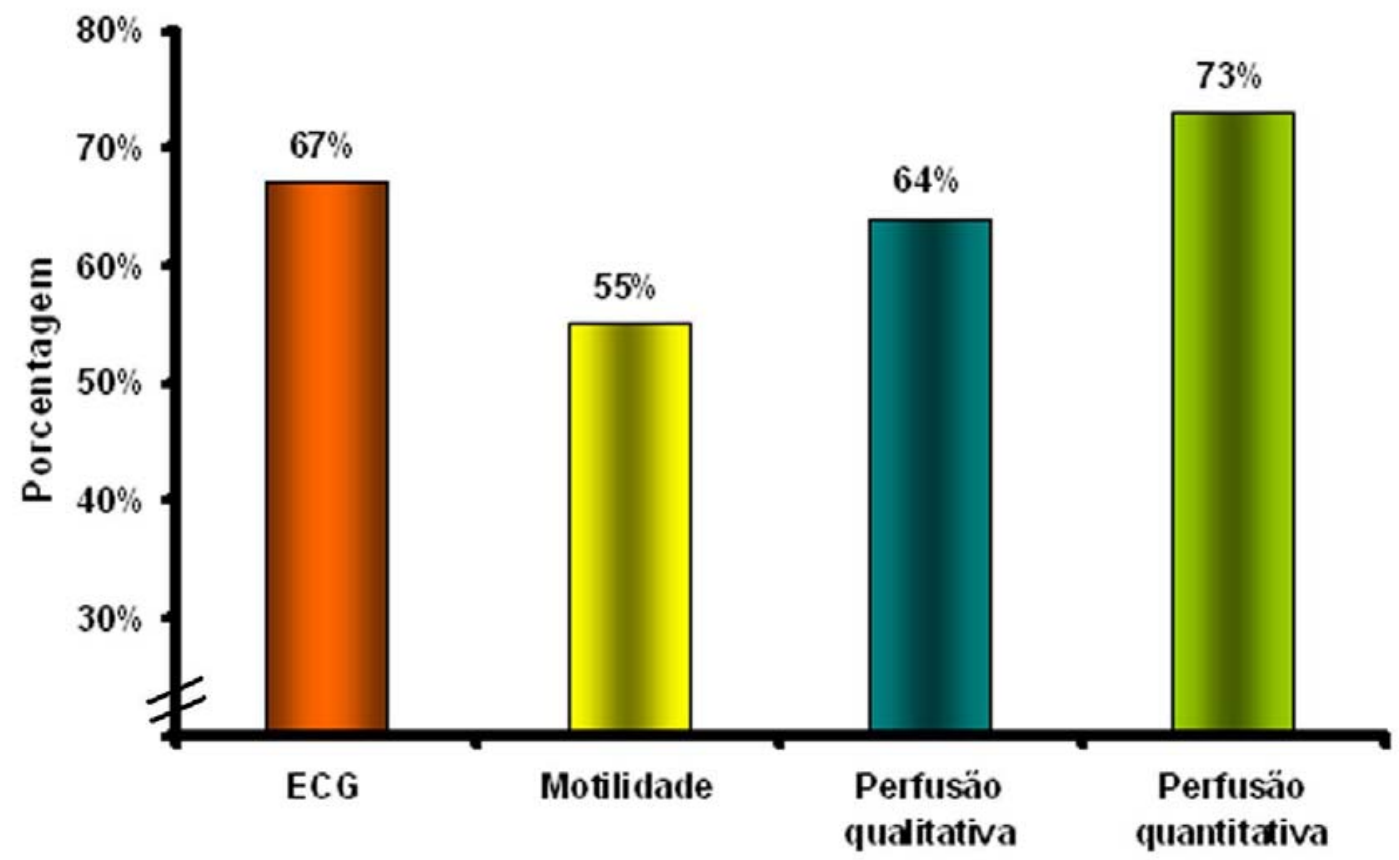

Figura 19 - Sensibilidade do eletrocardiograma em 12 derivações (ECG), motilidade segmentar, perfusão qualitativa e perfusão quantitativa, obtidas pela ecocardiografia com perfusão miocárdica em tempo real, sob estresse pela dobutamina, para detecção de doença coronariana uniarterial. 


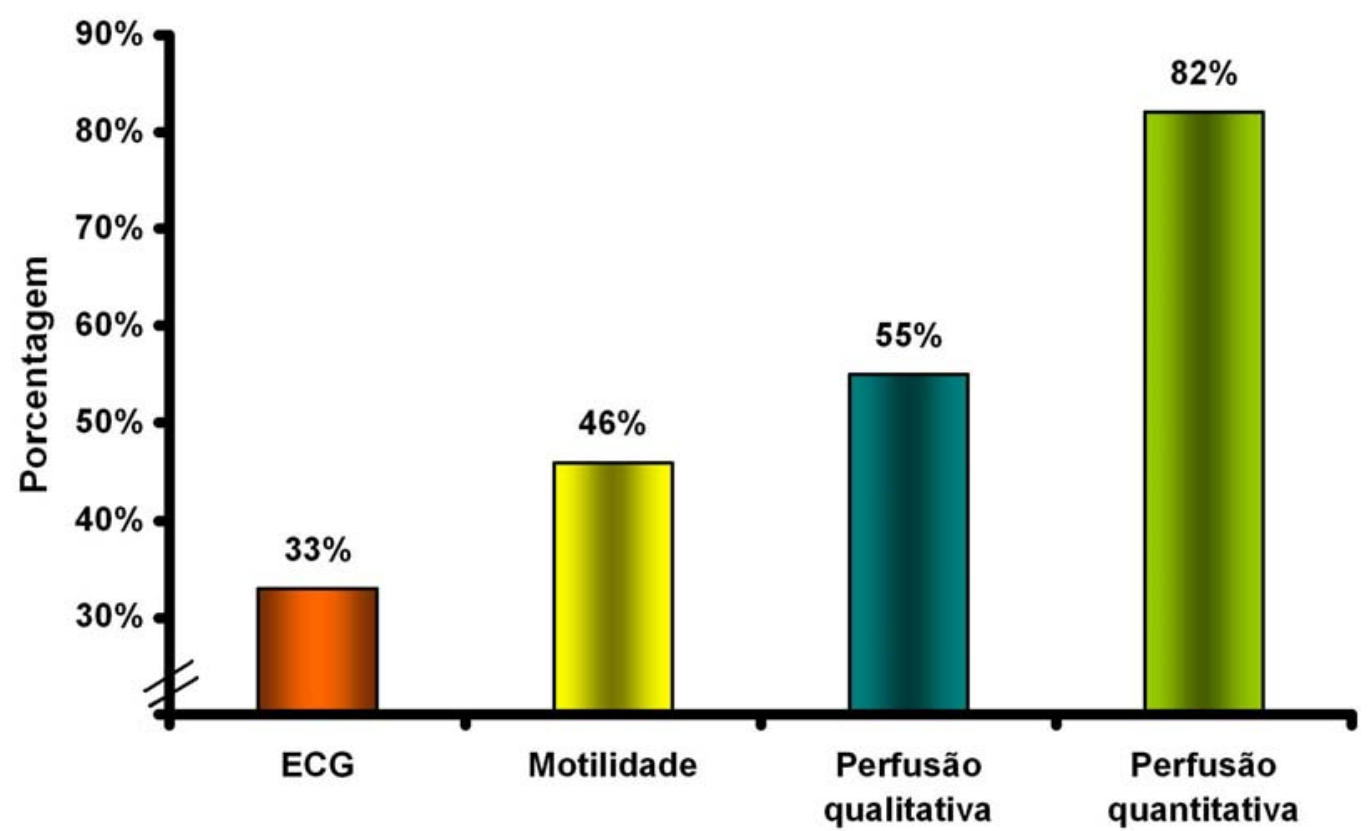

Figura 20 - Sensibilidade do eletrocardiograma em 12 derivações (ECG), motilidade segmentar, perfusão qualitativa e perfusão quantitativa, obtidas pela ecocardiografia com perfusão miocárdica em tempo real, sob estresse pela adenosina para detecção de doença coronariana uniarterial.

A análise quantitativa da perfusão miocárdica obtida pela EPMTR sob estresse pela dobutamina e pela adenosina apresentou sensibilidade similar para a detecção de doença multiarterial (Figuras 21 e 22). Essa sensibilidade foi maior nos pacientes com doença multiarterial que nos pacientes com doença uniarterial, tanto durante a EPMTR pela dobutamina (93\% versus $73 \%$ ) quanto pela adenosina (93\% versus $82 \%)$. 


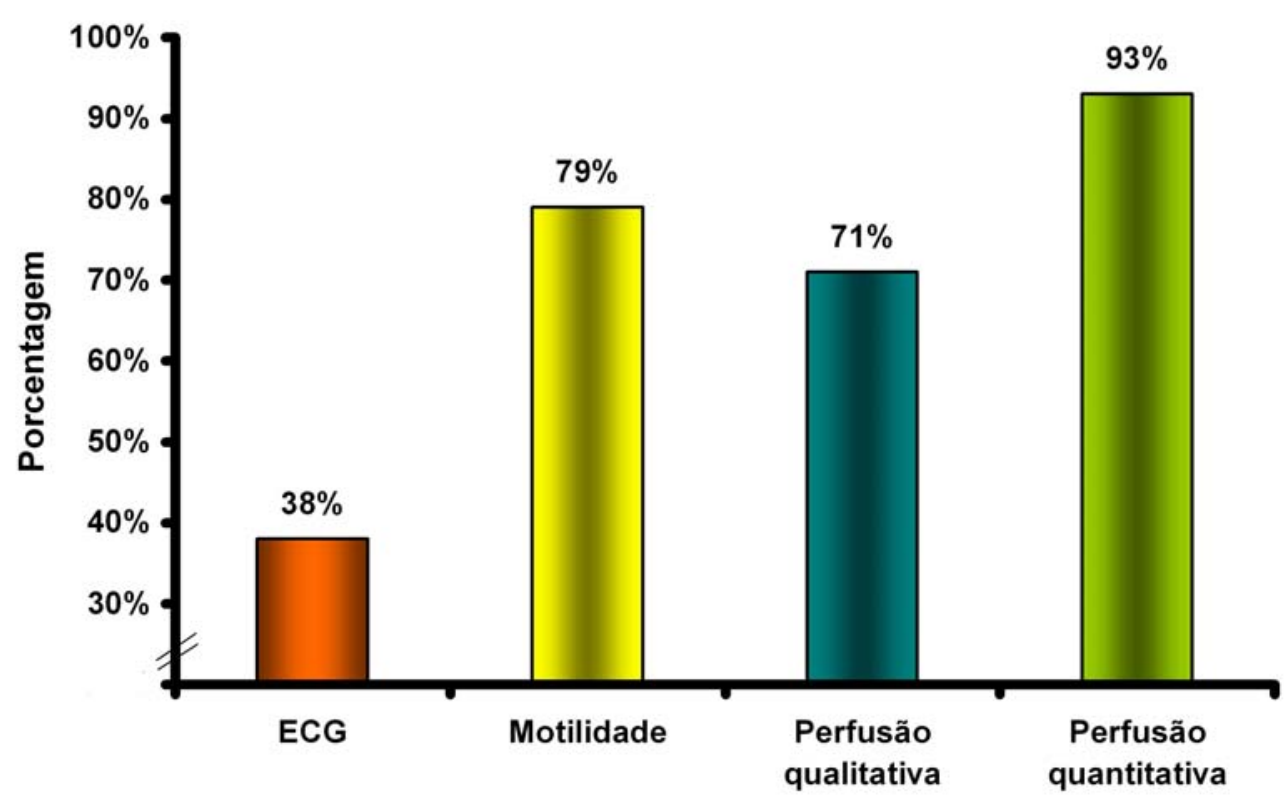

Figura 21 - Sensibilidade do eletrocardiograma em 12 derivações (ECG), motilidade segmentar, perfusão qualitativa e perfusão quantitativa, obtidas pela ecocardiografia com perfusão miocárdica em tempo real, sob estresse pela dobutamina, para detecção de doença coronariana multiarterial.

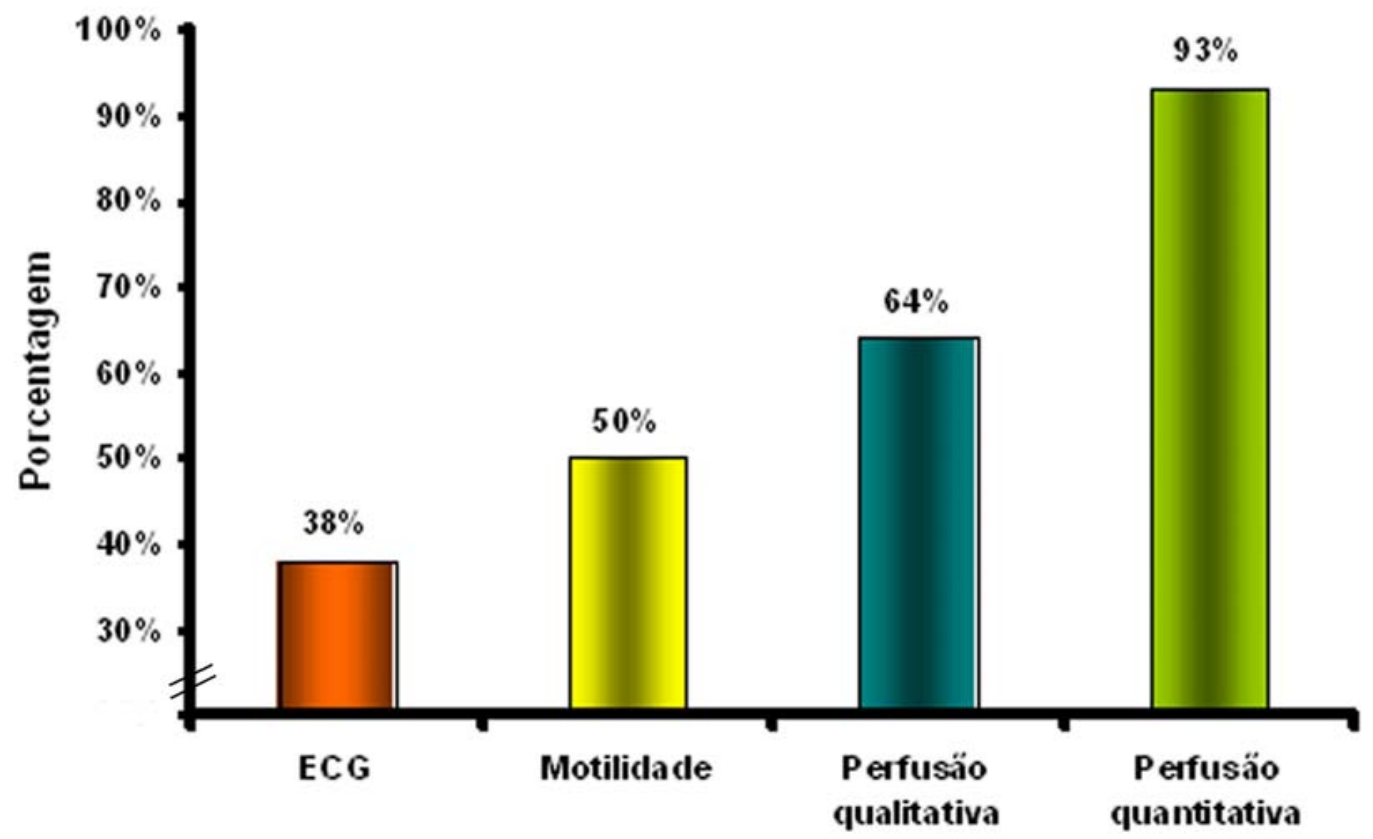

Figura 22 - Sensibilidade do eletrocardiograma em 12 derivações (ECG), motilidade segmentar, perfusão qualitativa e perfusão quantitativa, obtidas pela ecocardiografia com perfusão miocárdica em tempo real, sob estresse pela adenosina, para detecção de doença coronariana multiarterial. 
Discussão 
A ecocardiografia sob estresse farmacológico com agentes simpaticomiméticos ou vasodilatadores, a fim de diagnosticar DAC pela indução de isquemia miocárdica, tem sido extensivamente utilizada na prática cardiológica clínica.

A adenosina é um vasodilatador; é produzida pelo miócito e tem o nível intersticial elevado em resposta ao aumento do consumo de oxigênio pelo miocárdio e em resposta à isquemia ${ }^{63,64,65}$. Sua administração exógena, ou seja, diretamente na artéria coronária ou via intravenosa periférica por meio de sua ação direta em receptores $A_{2}$ localizados no endotélio dos vasos de resistência, leva a uma dilatação coronariana e, assim, a um aumento na velocidade do fluxo sangüíneo miocárdico, aumentando, portanto, o fluxo coronariano total. No leito arterial normal, observa-se um aumento desse fluxo sangüíneo de até cinco vezes o valor basal e, na presença de estenose, um aumento do fluxo relativamente menor como conseqüência da resistência imposta pela estenose. Para que a pressão hidrostática capilar se mantenha constante - e, portanto, também a perfusão microvascular - ocorre uma redução do recrutamento dos capilares, mantendo-se a perfusão desse território parcialmente preservada a despeito da conseqüente isquemia. Essa má distribuição de fluxo miocárdico 
ocasionada pela adenosina é o marcador patognomônico da gravidade de uma estenose coronariana e pode ser documentada pela EPMTR.

Diferentemente, a dobutamina é um agente simpatomimético que leva à vasodilatação coronariana e ao aumento do consumo de $\mathrm{O}_{2}$ por ação nos receptores $\aleph_{2}$, aumentando a velocidade e o fluxo sangüíneo miocárdico total. Adicionalmente, após exaurir a capacidade vasodilatadora de forma semelhante à adenosina ${ }^{51}$, promove, por estímulos gerados pelo aumento do consumo de $\mathrm{O}_{2}$, maior recrutamento capilar e, portanto, um aumento do volume sangüíneo microvascular. Porém, na presença de obstrução coronariana, o fluxo coronariano tende a aumentar menos, devido a aumento na resistência coronariana imposta pela estenose e a diminuição do recrutamento dos capilares.

Com base em tais conhecimentos fisiopatológicos, esses fármacos têm sido utilizados conjuntamente com a EPMTR para o diagnóstico da doença arterial coronariana. Essa nova técnica permitiu a análise qualitativa da presença de defeitos de perfusão e de alterações na motilidade cardíaca em tempo real, como também a análise quantitativa da velocidade do fluxo e o fluxo miocárdico regional.

Tem-se observado que a análise quantitativa do fluxo sangüíneo miocárdico tem o potencial de aumentar a reprodutibilidade e a acurácia do método ${ }^{48}$. Ao se quantificar, afastam-se limitações inerentes à capacidade de nossa visão em imputar diferenças regionais na velocidade do fluxo sangüíneo, como também de distinguir a presença de artefatos de defeitos reais na perfusão miocárdica. Alterações sutis de intensidade acústica, que 
são variáveis dependentes da profundidade das microbolhas em relação ao feixe ultra-sônico ou de seu posicionamento mais medial ou mais lateral, reduzem a acurácia desse método subjetivo e aumentam as variações nas interpretações.

\section{Exeqüibilidade da EPMTR}

Este é o primeiro estudo que comparou a EPMTR pela adenosina e pela dobutamina para o diagnóstico de DAC em seres humanos. Dos 73 pacientes participantes do estudo, 19 foram excluídos por apresentarem incompetência cronotrópica (6), hipertensão arterial sistêmica (12) e isquemia miocárdica importante durante a EPMTR pela adenosina (1). Todos os pacientes excluídos, por apresentarem EPMTR pela dobutamina ineficazes, faziam uso de betabloqueadores. Tal fato enfatiza a necessidade de implementação de estratégias que permitam a suspensão segura desses agentes vários dias antes da realização do exame.

Não foi observada diferença significativa entre a pressão arterial e freqüência cardíaca em repouso antes dos dois exames, porém se observou um maior aumento do duplo produto durante o teste com dobutamina devido ao seu efeito cronotrópico e inotrópico positivo, fato claramente esperado.

Na população deste estudo (54), a exeqüibilidade da interpretação visual por território arterial da motilidade, da perfusão e da quantificação da perfusão foi de $100 \%, 91 \%$ e $90 \%$ para a EPTMR pela dobutamina e de 
$100 \%, 92 \%$ e $91 \%$ para a EPTMR pela adenosina, demonstrando que, uma vez eficaz, todas essas formas de análise são altamente exeqüíveis na prática clínica.

\section{Avaliação quantitativa do eletrocardiograma e qualitativa da motilidade e da perfusão miocárdica}

A acurácia da eletrocardiografia pela adenosina foi maior que a da pela dobutamina (61\% versus $70 \%)$. Estes dados são semelhantes aos de Mairesse e colaboradores que, em 121 pacientes submetidos à eletrocardiografia sob estresse pela dobutamina, apresentaram uma acurácia de $50 \%{ }^{66}$, e aos de Marshall e colaboradores que verificaram uma acurácia diagnóstica do eletrocardiograma sob estresse pela adenosina de $71 \%$ em 550 pacientes ${ }^{67}$. Tais resultados enfatizam o valor do eletrocardiograma no auxílio diagnóstico e na segurança do paciente durante os exames, pois anormalidades podem ser prontamente detectadas, independentemente de janela acústica e de grande experiência do médico executante, indicando, muitas vezes, a interrupção precoce do exame e evitanto complicações decorrentes da isquemia miocárdica.

Na avaliação da motilidade miocárdica pela EPMTR pela dobutamina, verificamos uma acurácia de $76 \%$ pouco superior ao estudo de Porter e colaboradores que, em 117 pacientes, verificaram uma acurácia diagnóstica para DAC de $72 \%{ }^{41}$ e ao estudo de Elhendy e colaboradores que, em 170 pacientes, apresentaram uma acurácia de $71 \%{ }^{42}$. Porém, a análise qualitativa da perfusão miocárdica nesses estudos aumentou a acurácia 
diagnóstica de $72 \%$ para $83 \%$ e de $71 \%$ para $81 \%$, respectivamente. 0 mesmo não foi observado em nosso estudo, onde a acurácia manteve-se em $76 \%$. As pequenas diferenças observadas nos referidos estudos podem estar diretamente relacionadas com as experiências de ambos os centros na avaliação qualitativa da motilidade e perfusão miocárdica, a despeito da população estudada e do contraste ecocardiográfico utilizado ou de seu método de infusão.

Em nosso material, quando analisamos os mesmos parâmetros qualitativos com a EPMTR pela adenosina, obtivemos uma acurácia de $70 \%$ e $76 \%$ para a avaliação de alterações induzidas na motilidade e na perfusão, respectivamente. Essa melhora na acurácia, proporcionada com o uso de vasodilatadores, em relação à avaliação da motilidade de parede, está relacionada, possivelmente, com a baixa sensibilidade do uso de vasodilatadores na detecção de alterações da motilidade e boa sensiblidade na detecção dos defeitos de perfusão ${ }^{48,68}$. 


\section{Avaliação quantitativa da perfusão miocárdica}

Os valores de $\beta$ e de $A x ß$ basais obtidos pela EPMTR pela dobutamina nos territórios sem e com lesão significativa foram semelhantes $(0,47 \pm 0,07$ e $0,48 \pm 0,07$ para os valores $ß$ e $2,47 \pm 0,96$ e $2,53 \pm 1,53$ para os valores $A x ß)$, como também o foram aqueles da EPMTR pela adenosina $(0,46 \pm 0,08$ e $0,47 \pm 0,11$ para os valores $ß$ e $2,37 \pm 0,99$ e $2,61 \pm 1,08$ para os valores $A x ß)$. Por outro lado, as reservas $\beta$ e $A x ß$ com a EPMTR pela dobutamina foram maiores $(2,63 \pm 1,11$ e $3,24 \pm 1,54)$ nos territórios arteriais sem lesão significativa que nos territórios arteriais com lesão significativa $(1,67 \pm 0,77$ e $2,42 \pm 1,40)$ e, como na EPMTR pela adenosina, as reservas $ß$ e Axß foram maiores nos territórios sem lesão coronariana $(2,48 \pm 1,09$ e $2,81 \pm 1,56)$ que nos territórios com lesão $(1,72 \pm 0,78$ e $2,01 \pm 1,01)$. Isso demonstra o que se conhece da fisiopatologia microvascular, indicando a presença de fenômeno de roubo de fluxo e aumento da resistência capilar distalmente à estenose por uma diminuição compensatória do recrutamento dos capilares.

Bin e colaboradores observaram, em modelo animal, um menor aumento da reserva $A x ß$ durante a infusão de dobutamina no leito arterial com lesão significativa em comparação com o leito suprido por coronárias normais $(209 \pm 118 \text { versus } 352 \pm 144)^{49}$. Latiffe e colaboradores também apresentaram resultado semelhante ao estudarem a reserva de fluxo miocárdico provocando graus diferentes de lesão coronariana em 14 cães, encontrando a velocidade do fluxo sangüíneo miocárdico significativamente 
menor $(0,79 \pm 0,32$ versus $0,48 \pm 0,12)$ nos territórios arteriais com redução de reserva de fluxo de $40 \%$ a $60 \%{ }^{69}$.

Esses resultados com uso de vasodilatadores também foram reproduzidos em seres humanos por Peltier e colaboradores, em 35 pacientes submetidos à EPMTR pelo dipiridamol e à angiocoronariografia. Os autores verificaram um menor aumento na reserva $ß(1,7 \pm 0,7$ versus $2,7 \pm 0,9)$ e na reserva $A x ß(1,6 \pm 0,7$ versus $2,7 \pm 0,9)$ nos pacientes com lesão coronariana $>70 \%$. Também verificaram, que um valor de corte de 2,00 para a reserva $\beta$ e de 1,96 para reserva $A x ß$, uma acurácia diagnóstica semelhante por paciente para DAC $(91 \%)^{48}$. Na mesma linha, Dawson e colaboradores, em estudo com EPMTR pelo dipiridamol comparada ao Gated SPECT TC ${ }^{-99}$, observaram um menor aumento da reserva $ß(1,5 \pm 0,79$ versus $2,8 \pm 1,5)$ e da reserva $A x ß(2,1 \pm 0,4$ versus $2,8 \pm 1,6)$ em 11 territórios com defeito de perfusão transitória, quando comparados com 143 territórios sem defeito de perfusão ${ }^{70}$.

Em nosso estudo, avaliando a EPMTR pela adenosina pela curva ROC, verificamos, com valores de corte para reserva $ß$ de 2,0 e de reserva Axß de 2,2, uma sensibilidade semelhante para as duas reservas (88\%), especificidade de $72 \%$ e $41 \%$ e acurácia global de $80 \%$ e $63 \%$ respectivamente, para o diagnóstico de DAC.

Por outro lado, Kim e colaboradores constataram uma sensibilidade e especificidade de $82 \%$ e $75 \%$ para o diagnóstico de DAC em uma metanálise envolvendo 1.066 pacientes e utilizando o SPECT TC $^{-99}$ e 
dobutamina como agente estressor ${ }^{68}$. Corroborando esses resultados, em nosso estudo, utilizando a EPTMR pela dobutamina, os valores de reserva $§$ de 2,0 e de reserva $A x ß$ de 2,6 permitiram o diagnóstico de DAC com uma sensibilidade de $84 \%$ e $92 \%$, especificidade de $76 \%$ e $65 \%$, e acurácia global de $80 \%$ e $78 \%$, respectivamente.

Portanto, parece que, por ser independente da baixa homogeneidade do feixe ultra-sônico, o parâmetro ß é o melhor e mais confiável para a avaliação quantitativa da perfusão no estado da arte da ecocardiografia, com acurácias semelhantes para ambos os fármacos (80\%). Adicionalmente, as comparações dos índices de fluxo miocárdico na EPMTR entre fármacos inotrópicos e vasodilatadores existentes na literatura foram até então somente realizadas somente em modelos animais ${ }^{49,51,69}$, o nosso sendo o primeiro em seres humanos.

Quando comparamos a sensibilidade do ECG, da motilidade, da perfusão qualitativa e quantitativa (ß), obtivemos maiores valores da última na detecção de pacientes com doença multiarterial, semelhantes para ambos (93\%). Em pacientes com doença uniarterial, a análise quantitativa da perfusão apresentou maior sensibilidade quando comparada com os outros métodos, tanto para a dobutamina (73\%) quanto para a adenosina $(82 \%)$.

Quando avaliamos especificamente os efeitos da dobutamina e da adenosina na microcirculação miocárdica, observamos que o aumento da velocidade do fluxo miocárdio nos territórios sem lesão coronariana foi semelhante para ambos os testes $(1,17 \pm 0,47$ versus $1,10 \pm 0,47)$. Esses 
dados diferem do estudo em modelo animal de Latiffe e colaboradores que verificaram, em territórios coronarianos normais, um maior aumento da velocidade sangüínea miocárdica durante a infusão da adenosina do que com dobutamina $(0,83 \pm 0,20$ versus $0,79 \pm 0,32 ; p<0,05){ }^{69}$. Cabe ressaltar que, no referido estudo, foi utilizada uma dose menor de dobutamina em relação ao nosso estudo $\left(12,5 \mu \mathrm{mol} / \mathrm{L}^{\mathrm{kg}}{ }^{-1} \cdot \mathrm{min}^{-1}\right)$, fato que pode explicar um menor aumento do parâmetro ß. Também, em nosso estudo, avaliando-se esse parâmetro no leito arterial estenótico, houve menor aumento semelhante para ambos os fármacos $(0,83 \pm 0,40$ versus $0,80 \pm 0,39)$.

Em nosso estudo, o parâmetro $A x ß$ apresentou um aumento semelhante com a infusão de dobutamina e com a infusão de adenosina nos territórios sem $(6,95 \pm 3,94$ versus $6,22 \pm 2,88)$ e com lesão coronariana $(5,34 \pm 3,53$ versus $5,11 \pm 3,24)$, respectivamente. Resultados semelhantes foram encontrados no estudo de Bin e colaboradores, onde não se observou diferença no aumento do parâmetro $A x ß$ em modelo experimental, durante a infusão intracoronária de dobutamina em comparação com a adenosina, nos

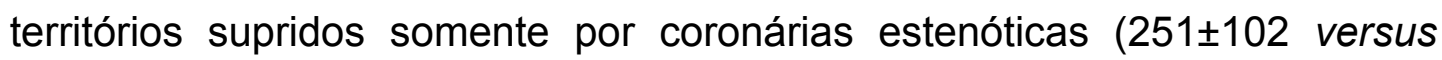
$243 \pm 74 ; p=n s)$ e nos territórios supridos por coronárias normais $(640 \pm 281$ versus $720 \pm 193 ; p=n s)^{51}$.

Quando comparamos o valor adicional dos parâmetros obtidos pela EPMTR pela dobutamina e adenosina, a avaliação da perfusão de forma quantitativa demonstrou um valor adicional diagnóstico significativo em relação aos outros modelos diagnósticos avaliados para a detecção de DAC em ambos testes $\left(\chi^{2}\right.$ de 38,4 e $\chi^{2}$ de 59,4, respectivamente). Assim, a 
avaliação quantitativa da perfusão oferece um valor adicional menos dependente do observador, objetivo e quantitativo, sendo uma importante ferramenta para o diagnóstico não invasivo de DAC pela ecocardiografia.

\section{Limitações deste estudo}

Na população estudada, houve alta prevalência de fatores de risco para doença coronariana, tendo assim, possivelmente, um grande número de pacientes com doença na microcirculação e alta prevalência de doença coronariana aterosclerótica discreta, o que pode influenciar os resultados aqui apresentados. Também houve um grande número de pacientes em uso de betabloqueadores, o que, sabidamente, pode limitar o resultado da acurácia diagnóstica dos estudos por ambos os métodos ${ }^{71,72}$. A utilização do contraste PESDA, de produção artesanal, pode apresentar diferentes concentrações para cada preparação, podendo, dessa forma, ter ocasionado uma ecogenicidade variável no miocárdio entre os estudos de adenosina e dobutamina, podendo, então, ter influenciado a quantificação da perfusão miocárdica. 


\section{Aplicações clínicas}

A EPMTR pela dobutamina e pela adenosina apresentam boa exeqüibilidade na quantificação da velocidade e do fluxo sangüíneo miocárdico; portanto, tornam-se importantes ferramentas para o diagnóstico da DAC na prática clínica. A dobutamina é amplamente utilizada na ecocardiografia sob estresse, com bons índices de acurácia. Já métodos ecocardiográficos com uso de vasodilatadores apresentam menor acurácia para detecção de DAC. Ambos, adicionalmente, apresentam a limitação de depender significativamente da experiência do observador na avaliação da motilidade. Os índices foram melhorados em ambas as técnicas com a avaliação quantitativa da perfusão miocárdica, diminuindo, assim, as variações de interpretação que são inerentes à avaliação da motilidade pela ecocardiografia sob estresse. Adicionalmente, como é sabido, o uso de betabloqueadores pode reduzir a acurácia da ecocardiografia sob estresse 71,72. A despeito de sua elevada utilização pela população estudada (68\%), os índices de acurácia das análises quantitativas da perfusão permaneceram adequados.

Desse modo, com o uso da avaliação quantitativa da perfusão miocárdica, promove-se um caráter mais objetivo e menos dependente do observador na avaliação de pacientes com suspeita de DAC. 
Conclusões 
1- As avaliações qualitativa e quantitativa da EPMTR apresentam boa exeqüibilidade e foram similares durante o estresse pela dobutamina e pela adenosina.

2- A reserva de velocidade de fluxo miocárdico obtida pela EPMTR por ambos os fármacos, apresentou acurácia semelhante para detecção de lesão coronariana.

3- A análise quantitativa da perfusão miocárdica pela EPMTR apresentou, para ambos os fármacos utilizados, um valor adicional significativo para o diagnóstico de DAC em relação à análise do eletrocardiograma em 12 derivações, à análise da motilidade segmentar e à análise qualitativa da perfusão . 
${ }^{1}$ De acordo com:

Adaptado de International Committee of Medical Journals Editors (Vancouver).

Universidade de São Paulo. Faculdade de Medicina. Serviço de Biblioteca e Documentação. Guia de apresentação de dissertações, teses e monografias da FMUSP. Elaborado por Anneliese Carneiro da Cunha, Maria Julia A.L. Freddi, Maria F. Crestana, Marinalva de S. Aragão, Suely C. Cardoso, Valéria Vilhena. São Paulo: Serviço de Biblioteca e Documentação, 2004.

Abreviaturas dos títulos dos periódicos de acordo com List of Journals Indexed in Index Medicus. 
1 Estatísticas Vitais - Mortalidade e nascidos vivos: mortalidade geral desde 1979. Pesquisa por "aterosclerose, infarto agudo do miocárdio, outras doenças isquêmicas do coração". Disponível em:vrl: http://www.datasus.gov.br. Acesso: 20 de novembro de 2004.

2 Morbidity \& Mortality 2002. Chartbook in cardiovascular, lung and blood diaseases - NIH, 2002.

3 Bousfield G. Angina pectoris: changes in electrocardiogram during paroxism. Lancet.1918;2:457.

4 Bruce RA, Horsten TR. Exercise stress testing in evaluation of patients with ischemic heart disease. Progr Cardiovasc Dis. 1969;11:371.

5 Sheffield LT, Perry MD, Larkin LN, Burdeshaw JA, Conroy DV, Rives TJ. Electrocardiographic signal analysis without averaging of complexes. In: Thomas CC, editor. Measurements in exercise electrocardiography. Springfield: Blackburn H;1967. p.108.

6 Winter DA. Noise measurement and quality control techniques in recording and processing of exercise electrocardiograms. In: Thomas $\mathrm{CC}$, editor .Measurements in exercise electrocardiography. Springfield: Blackburn H;1967. p.159.

7 Stuart RJ Jr, Ellestad MH. National survey of exercise stress testing facilities. Chest. 1980;77:94-7. 
8 Gibbons RJ, Balady GJ, Beasley JW, Bricker JT, Duvernoy WF, Froelicher VF, Mark DB, Marwick TH, McCallister BD, Thompson PD Jr, Winters WL, Yanowitz FG, Ritchie JL, Gibbons RJ, Cheitlin MD, Eagle KA, Gardner TJ, Garson A Jr, Lewis RP, O'Rourke RA, Ryan TJ. Jr.ACC/AHA guidelines for Exercise Testing. A report of the American College of Cardiology/American Heart Association Task Force on Practice Guidelines (Committee on Exercise Testing). J Am Coll Cardiol. 1997;30:260-311.

9 DePuey EG, Guertler-Krawczynska E, Perkins JV, Robbins WL, Whelchel JD, Clements SD. Alterations in myocardial thallium-201 distribution in patients with chronic systemic hypertension undergoing single photon emission computed tomography. Am $\mathrm{J}$ Cardiol. 1988;62:234-8.

10 Abreu A, Mahmarian JJ, Verani MS, Nishismura S, Boyce TM. Tolerance and safety of pharmacologic coronary vasodilation with adenosine in association with thallium-201 scintigraphy in patients with suspected coronary artery disease. J Am Coll Cardiol. 1991;18(3):7305.

11 Imran MB, Palinkas A, Picano E. Head-to-head comparison of dipyridamole echocardiography and stress perfusion scintigraphy for the detection of coronary artery disease: a meta-analysis. Comparison between stress echo and scintigraphy. Int $J$ Cardiovasc Imaging. 2003;19:23-8.

12 Geleijnse ML, Fioretti PM, Roelandt JR. Methodology, feasibility, safety and diagnostic accuracy of dobutamine stress echocardiography. Am J Cardiol. 1997;30:595-606. 
13 Houghton TL, Frank MJ, Carr AA, VonDohhlen TW, Prisant LM. Relations among impaired coronary flow reserve, left ventricular hypertrophy, and thallium perfusion defects in hypertensive patients without obstructive coronary artery disease. J Am Coll Cardiol. 1990;1543-51.

14 DePuey EG, Guertler-Krawczynska E, Robbins WL. Thallium-201 SPECT in coronary disease patients with left bundle branch block. $J$ Nucl Med. 1988;29:1479-85.

15 Becker CR, Knez A, Leber A, Treede H, Ohnesorge B, Schoepf UJ, Reiser MF. Detection of coronary artery stenoses with multislice helical CT angiography. J Comput Assist Tomogr. 2002;26:750-5.

16 Kopp AF, Schroeder S, Kuettner A, Baumbach A, Georg C, Kuzo R, Heuschmid M, Ohnesorge B, Karsch KR, Claussen CD. Non-invasive coronary angiography with high resolution multidetector-row computed tomography: results in 102 patients. Eur Heart J. 2002;23:1714-25.

17 Lee DC, Simonetti OP, Harris KR, Holly TA, Judd RM, Wu E, Klocke FJ. Magnetic resonance versus radionuclide pharmacological stress perfusion imaging for flow-limiting stenoses of varying severity. Circulation. 2004;110:58-65.

18 Giang TH, Nanz D, Coulden R, Friedrich M, Graves M, Al-Saadi N, Luscher TF, von Schulthess GK, Schwitter J. Detection of coronary artery disease by magnetic resonance myocardial perfusion imaging with various contrast medium doses: first European multi-centre experience. Eur Heart J. 2004;25:1657-65. 
19 Paetsch I, Jahnke C, Wahl A, Gebker R, Neuss M, Fleck E, Nagel E. Comparison of dobutamine stress magnetic resonance, adenosine stress magnetic resonance, and adenosine stress magnetic resonance perfusion. Circulation. 2004;110:835-42.

20 Bunce NH, Reyes E, Keegan J, Bunce C, Davies SW, Lorenz CH, Pennell DJ. Combined coronary and perfusion cardiovascular magnetic resonance for the assessment of coronary artery stenosis. $J$ Cardiovasc Magn Reson. 2004;6:527-39.

21 Armstrong WF. Echocardiography in coronary artery disease. Progr Cardiovasc Dis. 1988;30:267-288.

22 Marwich TH, Nemec JJ, Pashkow FJ, Stewart WJ, Salodo EE. Accuracy and limitations of exercice echocardiography in a routine clinical setting. J Am Coll Cardiol. 1992;19:74-81.

23 Quinones MA, Verani M, Haichin RM, Mahlmarian JJ, Suarez J, Zoghbi WA. Exercise echocardiography versus 201 TL single-photon emisson computed tomography in evaluation of coronary artery disease. Analysis of 292 patients. Circulation.1992;85:1026-31.

24 Braunwald E, Zipes D, Libby P. Heart Disease. A Textbook of cardiovascular medicine. $6^{\text {th }}$ edition. Philadelphia: W. B. Saunders Company; 2001.

25 Picano E, Mathias W Jr, Pigitore A, Bigi R, Previtoli M . Safety and tolerability of dobutamine-atropine stress echocardiography: a prospective, multicentre study. Echo Dobutamine International Cooperative Study Group. Lancet.1994;344:1190-2. 
26 Dagianti A, Penco M, Agati C, Sciomer S, Rosanio S, Fedele F. Stress echocardiography: comparison of exercise, dipyridamole and dobutamine in detecting and predicting the extent of coronary artery disease. J Am Coll Cardiol. 1995;26:18-25.

27 Mathias W Jr, Tsutsui JM, Andrade JL, Kowatsch I, Lemos PA, Leal $\mathrm{SMB}$, Khandheria BK, Ramires JF. Value of rapid beta-blocker injection at peak dobutamine-atropine stress echocardiography for detection of coronary artery disease. J Am Coll Cardiol. 2003;41:1583-9.

28 Tsutsui JM, Osório AFF, Lario FC, Fernandes DRA, Sodré G, Andrade JL, Ramires JAF, Mathias W Jr. Comparison of safety and efficacy of the early injection of atropine during dobutamine stress echocardiography with the conventional protocol. Am J Cardiol. 2004;94:1367-72.

29 Zoghbi WA, Cheirif J, Kleiman N, Verani MS, Trakhtenbroit A. Diagnosis of ischemic heart disease with adenosine echocardiography. $J$ Am Coll Cardiol. 1991;18:1271-9.

30 Martin TW, Seaworth JF, Johns JP, Pupa LE, Condos WR. Comparison of adenosine, dipyridamole, and dobutamine in stress echocardiography. Ann Intern Med. 1992;116:190-6.

31 Hauser AM, Gangadharan V, Ramos RG, Gordon S, Timmis GC. Sequence of mechanical, electrocardiographic and clinical effects of repeated coronary artery occlusion in human beings: Echocardiographic observations during coronary angioplasty. $J$ Am Coll Cardiol. 1985;5:193-7.

32 Nesto R, Kowalchunk G.The ischemic cascade: Temporal response of hemodynamic, electrocardiographic and symptomatic expression of ischemia. Am J Cardiol. 1987;57:23-7. 
33 Porter TR, XIE F, Kricksfield A, Chiou A, Dabestani A. Improved endocardial border resolution during dobutamine stress echocardiography with intravenous sonicated albumin. J Am Coll Cardiol. 1994;23:1440-3.

34 Prince CR, Stoddard MF, Morris GT, Ammash MN, Goad JL, Dawkins PR, Vogel RL. Dobutamine two dimensional transesophageal echocardiographic stress testing for detection of coronary artery disease. Am Heart J. 1994;128:36-41.

35 Mathias W Jr, Arruda ALM, Andrade JL, Filho OC, Porter TR. Endocardial border delineation during dobutamine infusion using contrast echocardiography. Echocardiography. 2002;19:109-14.

36 Uehara H, Yamamoto T, Hirano Y, Ozasa $Y$, Yamada S, Ikawa H, Ishikawa K. Contrast agent improves diagnostic value of dobutamine stress echocardiography. J Cardiol. 2001;37:135-41.

37 Rainbird AJ, Mulvagh SL, Oh JK, McCully RB, Klarich KW, Shub C, Mahoney DW, Pellikka PA. Contrast dobutamine stress echocardiography: clinical practice assessment in 300 consecutive patients. J Am Soc Echocardiogr. 2001;14:378-85.

38 Mulvagh SL, DeMaria AN, Feinstein SB, Burns PN, Kaul S, Miller JG, Monaghan M, Porter TR, Shaw LJ, Villanueva FS. Contrast echocardiography: current and future applications $J A m$ Soc Echocardiogr. 2000;13:331-42.

39 Cerqueira MD, Weissman NJ, Dilsizian V, Jacobs AK, Kaul S, Laskey WK, Pennell DJ, Rumberger JA, Ryan T, Verani MS. Standardized myocardial segmentation and nomenclature for tomographic imaging of the heart. Circulation. 2002;105:539-42. 
40 Kaul S, Senior R, Dittrich H, Raval U, Khattar R, Lahiri A. Detection of coronary artery disease with myocardial contrast echocardiography: comparison with $99 \mathrm{mTc}$-sestamibi single-photon emission computed tomography. Circulation.1997; 96:785-92.

41 Porter TR, Xie F, Silver M, Kricsfeld D, O'Leary E. Real-time perfusion imaging with low mechanical index pulse inversion Doppler imaging. $J$ Am Coll Cardiol. 2001; 37:748-53.

42 Elhendy A, O'leary EL, Xie F, McGrain AC, Anderson JR, Porter TR. Comparative accuracy of real-time myocardial contrast perfusion imaging and wall motion analysis during dobutamine stress echocardiography for the diagnosis of coronary artery disease. J Am Coll Cardiol. 2004;44:2185-91.

43 Heinle SK, Noblin J, Goree-Best P, Mello A, Ravad G, Mull S, Mammen P, Grayburn PA.. Assessment of myocardial perfusion by harmonic power Doppler imaging at rest and during adenosine stress: comparison with (99m)Tc-sestamibi SPECT imaging. Circulation. 2000;102:55-60.

44 Senior R, Lepper W, Pasquet A, Chung G, Hoffman R, Vanoverschelde $\mathrm{JL}$, Cerqueira M, Kaul S. Myocardial perfusion assessment in patients with medium probability of coronary artery disease and no prior myocardial infarction: comparison of myocardial contrast echocardiography with $99 \mathrm{mTc}$ single-photon emission computed tomography. Am Heart J. 2004;147:1100-5.

45 Tsutsui JM, Xie F, McGrain AC, Mahrous H, Hankins J, O'leary EL, Porter TR.. Comparison of low-mechanical index pulse sequence schemes for detecting myocardial perfusion abnormalities during vasodilator stress echocardiography. Am J Cardiol 2005;95:565-70. 
46 Wei K, Jayaweera AR, Firoozan S, Linka A, Skyba DM, Kaul S. Quantification of coronary blood flow reserve in humans using myocardial contrast echocardiography. Circulation. 2001;103:2560-5.

47 Korosoglou G, da Silva KG Jr, Labadze N, Dubart AE, Hansen A, Rosenberg M, Zehelein J, Kuecherer H. Real-time myocardial contrast echocardiography for pharmacologic stress testing: is quantitative estimation of myocardial blood flow reserve necessary?. J Am Soc Echocardiogr. 2004;17:1-9.

48 Peltier M, Vancraeynest D, Pasquet A, Ay T, Roelants V, D'hondt AM, Melin JA, Vanoverschelde $\mathrm{JL} \mathrm{J}$. Assessment of the physiologic significance of coronary disease with dipyridamole real-time myocardial contrast echocardiography. J Am Coll Cardiol. 2004;43:257-64.

49 Bin JP, Pelberg RA, Wei K, Le E, Goodman NC, Kaul S. Dobutamine versus dipyridamole for inducing reversible perfusion defects in chronic multivessel coronary artery stenosis. J Am Coll Cardiol. 2002;40:16774.

50 Leong-Poi H, Rim SJ, Le E, Fisher NG, Wei K, Kaul S. Perfusion versus function: the ischemic cascade in demand ischemia. Implications of single-vessel versus multivessel stenosis. Circulation. 2002;105:987-92.

51 Bin JP, Le DE, Jayaweera AR, Coggins MP, Wei K, Kaul S. Direct effects of dobutamine on the coronary microcirculation: comparison with adenosine using myocardial contrast echocardiography. J Am Soc Echocardiogr. 2003;16:871-9.

52 Folland ED, Parise AF, Moynihan PF, Jones DR, Feldman CL, Tow DE. Assessment of left ventricular ejection fraction and volumes by real-time two-dimensional echocardiography. A comparison of cineangiographic and radionuclide techniques. Circulation. 1979;60:760-6. 
53 Folland ED, Parise AF. Noninvasive evaluation of left ventricular function: the ejection fraction. Compr Ther.1979;5:47-54.

54 Wahr DW, Wang YS, Schiller NB. Left ventricular volumes determined by two-dimensional echocardiography in a normal adult population. $J$ Am Coll Cardiol. 1983;1:863-8.

55 Porter TR, Xie F. Transient myocardial contrast after initial exposure to diagnostic ultrasound pressures with minute doses of intravenously injected microbubbles. Demonstration and potential mechanisms. Circulation. 1995;92:2391-5.

56 Gibbons RJ, Balady GJ, Bricker JT, Chaitman BR, Fletcher GF, Froelicher VF, Mark DB, McCallister BD, Mooss AN, O'Reilly MG, Winters WL Jr, Gibbons RJ, Antman EM, Alpert JS, Faxon DP, Fuster V, Gregoratos G, Hiratzka LF, Jacobs AK, Russell RO, Smith SC Jr; American College of Cardiology/American Heart Association Task Force on Practice Guidelines (Committee to Update the 1997 Exercise Testing Guidelines).ACC/AHA 2002 guideline update for exercise testing: summary article: a report of the American College of Cardiology/American Heart Association Task Force on Practice Guidelines (Committee to Update the 1997 Exercise Testing Guidelines). Circulation. 2002;106:1883-92.

57 Armstrong WF, Pellikka PA, Ryan T, Crouse L, Zogbi WA. Stress echocardiography: recommendations for performance and interpretation of stress echocardiography. J Am Soc Echocardiogr. 1998;11:97-104.

58 Caldas M, Tsutsui JM, Kowatsch I, Andrade JL, Nicolau JC, Ramires JF, JR WM. Value of myocardial contrast echocardiography for predicting left ventricular remodeling and segmental functional recovery after anterior wall acute myocardial infarction. J Am Soc Echocardiogr. 2004;17:923-32. 
59 Grossman W. Brachial cut down approach. In: Baim D.S, Grossman W, editors. Cardiac catheterization, angiography, and intervention. Baltimore: William \& Wilkins; 1996. p.83-95.

60 Gregoratos G. Cardiac catheterization: basic techniques and complications. In: Peterson KL, Nicod P. editores. Cardiac catheterization: methods, diagnosis, and therapy. Philadelphia: W.B. Saunders Company; 1997. p.11-52.

61 Scanlon PJ, Faxon DP, Audet AM, Carabello B, Dehmer GJ, Eagle KA, Legako RD, Leon DF, Murray JA, Nissen SE, Pepine SE, Watson RM, Ritchie JL, Gibbons RJ, Cheitlin MD, Gardner TJ, Garson A Jr, Russel RO Jr, Ryan TJ, Smith SC Jr. ACC/AHA guidelines for coronary angiography. A report of the American College of Cardiology/American Heart Association Task Force on practice guidelines (Committee on Coronary Angiography). Developed in collaboration with the Society for Cardiac Angiography and Interventions. J Am Coll Cardiol. 1999;33:1756-824.

62 Haase J, Di Mario C, Slager CJ, Van Der Giessen WJ, Den Boer A, De Feyter PJ, Reiber JH, Verdouw PD, Serruys PW. In-vivo validation of on-line and off-line geometric coronary measurements using insertion of stenosis phantoms in porcine coronary arteries. Cathet Cardiovasc Diagn. 1992;27:16-27.

63 Drury AN, Szent-Gyorgyi A. The physiological activity of adenosine compounds with especial reference to their action on the mammalian heart. J Physiol. 1929;68:213-37

64 Klaubunde RE. Dipyridamole inhibition of adenosine metabolism in human blood. Eur J Pharmacol. 1983;93:21-6. 
65 Berne RM. The role of adenosine in the regulation of coronary blood flow. Circ Res. 1980;47:807-17.

66 Mairesse GH, Marwick TH, Vanoverschelde JLJ, Baudhuin T, Wijns W, Melin JA, Detry JM. How accurate is dobutamine stress electrocardiography for detection of coronary artery disease? Comparison with two-dimensional echocardiography and technetium99m methoxyl isobutyl isonitrile (Mibi) perfusion scintigraphy. J Am Coll Cardiol. 1994;24:920-7.

67 Marshall ES, Raichlen JS, Tighe DA, Paul JJ, Breuninger KM, Chung EK. ST-segment depression during adenosine infusion as a predictor of myocardial ischemia. Am Heart J. 1994;127:305-11.

68 Kim C, Kwok YS, Heagerty P, Redberg R. Pharmacologic stress testing for coronary disease diagnosis: A meta-analysis. Am Heart J. 2001;142:934-44.

69 Latiffe S, Matsugata H, Peters B, Togni M, Strachan M, Kwan LO, DeMaria AN. Comparative value of dobutamine and adenosine stress in the detection of coronary stenosis with myocardial contrast echocardiography. Circulation. 2001;103:2724-30.

70 Dawson D, Rinkevich D, Belcik T, Jayaweera AR, Rafter P, Kaul S, Wei K. Measurement of myocardial blood flow velocity reserve with myocardial contrast echocardiography in patients with suspected coronary artery disease: Comparison with quantitative gated technetium 99m sestamibi single photon emission computed tomography. J Am Soc Echocardiogr. 2003;16:1171-7. 
71 Ferrara N, Longobardi G, Nicolino A, Acanfora D, Odierna L, Furgi G, Rossi M, Leosco D, Rengo F. Effect of beta-adrenoceptor blockade on dipyridamol-induced myocardial asynergues in coronary artery disease. Am J Cardiol. 1992;70:724-27.

72 Fioretti PM, Poldermans D, Salustri A, Forster T, Bellotti P, Boersma E, McNeill AJ, el-Said ES, Roelandt JR. Atropine increases the accuracy of dobutamine stress echocardiography in patients taking beta-blockers. Eur Heart J. 1994;15:355-60. 